\title{
Patterned endogenous activity controls migration, morphogenesis and survival of adult-born neurons in the mouse olfactory bulb
}

Kaizhen $\mathrm{Li}^{1,7}$, Katherine Figarella ${ }^{1,8}$, Xin Su ${ }^{1,8}$, Yury Kovalchuk ${ }^{1}$, Jessika Gorzolka ${ }^{1}$, Jonas J. Neher ${ }^{2,3}$, Nima Mojtahedi ${ }^{1}$, Nicolas Casadei $^{4,5}$, Ulrike Hedrich-Klimosch ${ }^{6}$, Olga Garaschuk ${ }^{1, *}$

1, Department of Neurophysiology, Institute of Physiology, University of Tübingen, Tübingen, Germany

2, German Center for Neurodegenerative Diseases (DZNE), Tübingen, Germany

3, Department of Cellular Neurology, Hertie Institute for Clinical Brain Research, University of $\mathrm{T}$ bingen, $\mathrm{T}$ bingen, Germany

4, Institute of Medical Genetics and Applied Genomics, University of Tübingen, Tübingen, Germany

5, NGS Competence Center Tübingen, Tübingen, Germany

6, Department of Neurology and Epileptology, Hertie Institute for Clinical Brain

Research, University of T bingen, $T$ bingen, Germany

7, Current address: Department of Physiology, University of Bern, Bern, Switzerland

${ }^{8}$, These authors contributed equally

*Corresponding author: olga.garaschuk@uni-tuebingen.de 


\section{Abstract}

The integration of adult-born neurons in the existent neural circuitry is known to be activity-dependent. To decipher the underlying mechanisms, we genetically manipulated excitability of adult-born cells (via cell-specific overexpression of either Kv1.2 or Kir2.1 K+ channels). Longitudinal in vivo $\mathrm{Ca}^{2+}$ imaging and transcriptome analyses revealed that endogenous but not sensory-driven activity governs migration, morphogenesis, survival, and functional integration of adult-born juxtaglomerular neurons in the mouse olfactory bulb. The proper development of these cells required fluctuations of cytosolic $\mathrm{Ca}^{2+}$ levels, phosphorylation of CREB, and pCREB-mediated gene expression. Attenuating $\mathrm{Ca}^{2+}$ fluctuations via $\mathrm{K}^{+}$channel overexpression strongly downregulated genes involved in neuronal migration, differentiation, and morphogenesis and upregulated the apoptosisrelated genes, thus locking adult-born cells in the vulnerable and immature state. Together, the data identify signaling pathways connecting the endogenous intermittent neuronal activity/ $\mathrm{Ca}^{2+}$ fluctuations as well as proper $\mathrm{Kv} 1.2 / \mathrm{Kir} 2.1 \mathrm{~K}^{+}$channel function to migration, maturation, and survival of adult-born neurons.

\section{Introduction}

The rodent olfactory bulb $(\mathrm{OB})$ is a highly plastic brain region receiving new neurons throughout life. Cumulative evidence points to an important role of these cells for the fine tuning of odor perception/discrimination, facilitation of the task-dependent pattern separation as well as learning and memory (Alonso et al., 2012; Grelat et al., 2018; Li et al., 2018; Moreno et al., 2009; Shani-Narkiss et al., 2020; Sultan et al., 2010). Generated in the subventricular zone (SVZ) of the lateral ventricle (Lledo et al., 2006; Lois and 
Alvarez-Buylla, 1994), adult-born cells migrate along the rostral migratory stream (RMS) into the $\mathrm{OB}$ and differentiate into local GABAergic interneurons: granule cells (GCs) in the granule cell layer and juxtaglomerular cells (JGCs) in the glomerular layer (Lledo et al., 2008). Many molecules including GABA, glutamate, dopamine, serotonin, BDNF, and CREB influence the adult OB neurogenesis (Faigle and Song, 2013; García-González et al., 2017). Yet, the exact mechanisms underlying the migration, maturation, and incorporation of adult-born neurons into the existent OB circuitry remain unclear.

In analogy to perinatal brain development, it has been assumed that the above processes are governed by either endogenous or sensory-driven activity (Babij and De Marco Garcia, 2016; Bando et al., 2014; Bando et al., 2016; Cancedda et al., 2007; Hurni et al., 2017; Molnar et al., 2020). In fact, endogenous activity is present during all stages of the adult OB neurogenesis, i.e., in neural progenitor cells in the SVZ (Lacar et al., 2011), in neuroblasts in the RMS (García-González et al., 2017; Platel et al., 2007) and adult-born cells in the subependymal (Darcy and Isaacson, 2009) as well as glomerular (Maslyukov et al., 2018) layers of the OB. Still, the development of adult-born neurons in the OB was mostly studied from the perspective of sensory-driven activity. Indeed, manipulations reducing sensory-driven activity like (i) naris occlusion (Corotto et al., 1994; Mandairon et al., 2006; Pothayee et al., 2017), (ii) naris cauterization and benzodiazepine treatment (Yamaguchi and Mori, 2005), (iii) knocking-out olfactory receptors in olfactory sensory neurons (Petreanu and Alvarez-Buylla, 2002) or their axotomy (Mandairon et al., 2003) decreased survival and integration of adult-born neurons into the $\mathrm{OB}$ circuitry. Conversely, manipulations increasing sensory-driven activity like odor enrichment (Bovetti et al., 2009; Rochefort et al., 2002), odor discrimination training (Alonso et al., 
2006; Moreno et al., 2009) or olfactory learning (Sultan et al., 2011) increased the survival and integration of adult-born neurons. The role of cell-intrinsic endogenous activity was so far assessed only in adult-born GCs. For example, decreasing neuronal spiking via expression of ESKir2.1 (a nonrectifying variant of the Kir2.1 K+ channel) decreased, while increasing neuronal spiking via expression of $\mathrm{NaChBac}$ (the bacterial voltage-gated $\mathrm{Na}^{+}$ channel) facilitated the survival of adult-born OB GCs (Lin et al., 2010). The knocking down $\mathrm{Na}^{+}$channels Nav1.1-1.3 reduced the spine density of adult-born OB GCs (Dahlen et al., 2011).

In contrast to adult-born GCs, which migrate straight to their final destinations and integrate therein, adult-born JGCs enter the 3-4 weeks long pre-integration phase (Liang et al., 2016). During this phase, adult-born JGCs undergo a millimeter-long lateral migration (Liang et al., 2016), extensively grow and prune their dendritic trees (Kovalchuk et al., 2015; Su et al., 2020) and exhibit ongoing endogenous activity (Maslyukov et al., 2018). However, the role of this activity for migration, morphogenesis, and survival of adult-born JGCs remains unclear. To assess the contribution of endogenous activity to the maturation of adult-born JGCs during the pre-integration phase, we genetically suppressed their excitability and monitored their developmental history by means of longitudinal in vivo two-photon imaging. To understand the molecular pathways involved, we analyzed the transcriptome of adult-born cells right after their arrival to the OB. 


\section{Results}

\section{Alteration of endogenous but not sensory-driven activity impaired the lateral migration of adult-born cells}

To suppress the excitability of adult-born cells, we virally overexpressed either outwardly rectifying voltage-gated Kv1.2 channels or inwardly rectifying Kir2.1 channels (De Marco Garcia et al., 2011; Villa and Combi, 2016). Bicistronic lentiviruses enabling simultaneous expression of a genetically-encoded $\mathrm{Ca}^{2+}$ indicator Twitch-2B and either Kv1.2 or Kir2.1

(Figure $1 \mathrm{~A}$ and Figure $\mathrm{S} 1 \mathrm{~A}$ ) were injected into the RMS to transduce adult-born cells migrating towards the $\mathrm{OB}$ (Liang et al., 2016). In the control group, mCherry was expressed together with Twitch-2B. The efficiency of virus transduction was confirmed by the level of Twitch-2B fluorescence, the relative amount of the respective mRNA, and the heightened level of Kv1.2 immunofluorescence (Figure S1B-F). $\mathrm{Ca}^{2+}$ signaling and the developmental history of adult-born JGCs after their arrival in the glomerular layer of the bulb were monitored through a chronic cranial window from 8 days post-injection (dpi) till 45 dpi by means of in vivo two-photon imaging.

To analyze the migration of adult-born JGCs, we monitored the cell's position every 15 min during a 4-hour-long imaging session and compared migration distances of cells, moving during this time window (Figure 1B). Compared to Twitch-2B/mCherry-expressing control group, the expression of neither Kv1.2 nor Kir2.1 affected the apparent rate of adult-born cell's arrival in the glomerular layer of the bulb (Figure S2). However, it severely impaired cell migration at $8 \mathrm{dpi}$. Indeed, a significantly lower fraction of adult-born JGCs migrated during the 4-hour-long recording period in the Kv1.2 and Kir2.1 groups (Figure 1C). The median (per mouse) fraction of migrating cells was $33.3 \pm 21.7 \%$ in the control 
group but decreased significantly in the Kv1.2 and Kir2.1 groups $(12.1 \pm 6.6 \%$ and $0 \pm$ $5.9 \%$, respectively). Moreover, the median and maximum speed of migrating cells (Figure 1D, E) as well as the cumulative translocation in 4 hours (Figure 1F) decreased significantly in the Kv1.2 and Kir2.1 groups compared to the control group. Since adultborn JGCs have a saltatory migration pattern(Liang et al., 2016), some of them might pause during the 4-hour-long recording period. Therefore, we also evaluated the overall motility of adult-born JGC populations over a 3-day-long time period (8-11 dpi). The cells, which changed their positions between 8 and $11 \mathrm{dpi}$, were defined as migrating. In the control group, $82.1 \pm 8.8 \%$ of cells migrated between 8 and $11 \mathrm{dpi}$ (see also (Liang et al., 2016)). This fraction was significantly lower for the Kv1.2 and Kir2.1 groups (Figure 1G; $60 \pm 21.8 \%$ and $54 \pm 17 \%$ of cells, respectively)

The data suggested that observed impairment of migration in Kv1.2 and Kir2.1 groups was chronic, as it persisted at later developmental stage (14 dpi; Figure S3). By this time the lateral migration of control adult-born JGCs is known to slow down (Liang et al., 2016). Likely therefore there was no difference in the fraction of migrating cells as well as the median and maximum migrating speed between control and Kv1.2 groups (Figure S3AC). Yet, the significantly shorter net translocation distance in the Kv1.2 group (Figure S3D) suggested that cell motility was impaired. At 14 dpi Kir2.1 expressing cells were not migrating at all (Figure S3A). This finding is consistent with the somewhat stronger impact of Kir2.1 on cell migration compared to Kv1.2, visible throughout the data (Figure 1C-G). Next, we explored whether modulation of sensory input impacts the migration of adultborn JGCs. Because odors are inhaled through the nostrils into two segregated nasal passages (Kikuta et al., 2008), we occluded one nostril and thus also the ipsilateral 
hemibulb, leaving the other nostril open. Nostril occlusion (Figure 1H), which started at 5 dpi, completely blocked odor-evoked $\mathrm{Ca}^{2+}$ transients in adult-born JGCs residing in the ipsilateral hemibulb (measured at $20 \mathrm{dpi}$ ), while leaving the adult-born JGCs in the contralateral control hemibulb unaffected (compare Figure S4 to Figure 4). Surprisingly, odor deprivation was unable to affect any of the migration parameters mentioned above (Figure 1I-M). All migration parameters were similar between cells residing in the contralateral control and the ipsilateral odor-deprived hemibulbs. Moreover, odor deprivation did not affect the translocation distance in 12 hours at $6.5-14.5 \mathrm{dpi}$, repeatedly measured by us previously (see Figure S4 in (Liang et al., 2016)). Taken together, these data suggest that endogenous but not sensory-driven activity is critical for the lateral migration of adult-born JGCs during the pre-integration phase.

\section{Endogenous but not sensory-driven activity controls morphogenesis of adult-born JGCs}

Immature adult-born cells in the RMS maintain a spindle shape morphology to enable fast migration but adopt a rather complex dendritic structure shortly after reaching the glomerular layer (Carleton et al., 2003; Kovalchuk et al., 2015; Petreanu and AlvarezBuylla, 2002). Surprisingly, even at 20 dpi adult-born JGCs in Kv1.2 and Kir2.1 groups displayed remarkably retarded morphology with significantly shorter total dendritic branch length (TDBL) as well as fewer dendritic branches and intersections (Figure 2A-D). Control adult-born JGCs had a median (per cell) TDBL of $553 \pm 630 \mu \mathrm{m}$ and branch number of $38 \pm 50$. These values, however, dropped significantly to $75 \pm 197 \mu \mathrm{m} / 122 \pm$ $187 \mu \mathrm{m}(\mathrm{TDBL})$ and $3 \pm 6 / 3 \pm 16$ (branch number) in Kv1.2 and Kir2.1 groups, 
respectively (Figure 2B, C). This finding was not an artifact caused by an inferior resolution of thin dendritic processes in in vivo measurements, as similar differences were observed in the fixed tissue by means of immunocytochemistry (Figure S5). In 50- $\mu$ mthick slices, however, the overall length and complexity of the cells were somewhat reduced due to the slicing procedure. The observed impairment of morphogenesis was likely caused by Kv1.2/Kir2.1-mediated reduction of neuronal activity because expressing the non-conducting dominant-negative mutant of the Kir2.1 channel (Kir2.1mut) (PreisigMuller et al., 2002) within the adult-born cells did not inhibit the morphogenesis of cells under study (Figure S6). Moreover, we did not observe any changes in the morphology of adult-born JGCs, residing in the control and odor-deprived hemibulbs (Figure 2E-H). Together, these results show that endogenous but not sensory-driven activity is essential for the proper morphological development of adult-born JGCs.

\section{Alteration of the endogenous activity reduced the survival rate of adult-born JGCs}

Next, we analyzed the effect of altered endogenous activity on the survival of adult-born JGCs. Because the rapid migration of adult-born JGCs at the beginning of the preintegration phase (Liang et al., 2016) makes the identification of the individual cells difficult, we started to track cells at $14 \mathrm{dpi}$. We utilized a priori knowledge about the average speed of cell migration (Liang et al., 2016) to set a safety margin between the analyzed cells and the edge of the field of view (FOV), ensuring that cells, which disappeared from the FOV, did not simply move out. Cells, which stayed at the same position during the recording time period, were considered stable surviving cells (Figure 3A, C). We found that the expression of either Kv1.2 or Kir2.1 significantly reduced the survival rate of adult- 
born JGCs between 14 and 25 dpi (Figure 3B). Under these conditions, the mean (per mouse) survival rate was $66 \pm 5.6 \%$ in control, $40 \pm 6.4 \%$ in $\mathrm{Kv} 1.2$, and $32 \pm 5.8 \%$ in the Kir2.1 group. Between 25 and $45 \mathrm{dpi}$, the survival was still inhibited significantly in the Kir2.1 group ( $35.6 \pm 8.9 \%$ vs. $82 \pm 5.6 \%$ in control) but not in the Kv1.2 group (76.3 \pm $5.6 \%$ ) (Figure 3D), likely because the activity of cells was increasing in the course of development, enabling them to overcome the inhibitory effect of surplus Kv1.2 channels. Taken together, these data suggest that reduced endogenous activity inhibits the survival of adult-born JGCs during the pre-integration phase, with somewhat stronger effects observed in the Kir2.1 compared to the Kv1.2 group.

\section{Weaker integration of adult-born JGCs with altered endogenous activity into the existent neural circuitry}

Next, we explored whether adult-born JGCs belonging to Kv1.2 and Kir2.1 groups were able to integrate into the existent neural network. We used the fraction of odor-responsive adult-born JGCs as well as the amplitude and the area under the curve (AUC) of the odorevoked $\mathrm{Ca}^{2+}$ signals, measured at dpi 20 , as a functional readout of the strength of their network integration. We found that the overexpression of either Kv1.2 or Kir2.1 diminished the odor responsiveness of adult-born JGCs (Figure 4A). The mean (per mouse) fraction of odor responsive cell was $61.5 \pm 8.6 \%$ in the control group, decreasing slightly (to $51 \pm$ $6.1 \%$ ) in the Kv1.2 and significantly (to $24.8 \pm 6 \%$ ) in the Kir2.1 groups. The amplitudes and AUCs of odor-evoked $\mathrm{Ca}^{2+}$ transients in the $\mathrm{Kv1.2}$ and Kir2.1 groups were significantly smaller than in the control group (Figure 4B-D). The median (per cell) amplitude of odor-evoked $\mathrm{Ca}^{2+}$ transients reached $1.36 \pm 1.19 \Delta \mathrm{R} / \mathrm{R}$ in the control group, 
$0.83 \pm 0.69 \Delta R / R$ in the Kv1.2 group, and $0.85 \pm 0.46 \Delta R / R$ in the Kir2.1 group (Figure 4C). The median (per cell) AUC of odor-evoked $\mathrm{Ca}^{2+}$ transients was $5.7 \pm 6.3 \Delta R / R^{*}$ s in the control, $3.1 \pm 3.2 \Delta R / R^{*}$ s in the Kv1.2 and 2.0 $\pm 1.7 \Delta R / R^{*}$ s in the Kir2.1 group (Figure 4D).

Taken together, these data suggest that adult-born JGCs with altered endogenous activity have difficulties to integrate into the existent $\mathrm{OB}$ circuitry.

Spontaneous $\mathrm{Ca}^{2+}$ transients in adult-born JGCs were dampened by overexpression of Kv1.2 or Kir2.1 but maintained during odor deprivation

To extract features of the endogenous activity crucial for migration, morphogenesis, survival, and integration of adult-born JGCs, we conducted (at 12 dpi) comparative analyses of the pattern of endogenous activity recorded in control, Kv1.2, Kir2.1 groups as well as in two groups from odor-deprived mice (cells residing in odor-deprived ipsilateral and control contralateral hemibulbs). In adult-born JGCs, the overexpression of Kv1.2 or Kir2.1 did not affect the basal Twitch-2B ratios (reflecting basal levels of the intracellular free $\mathrm{Ca}^{2+}$ concentration $\left.\left(\left[\mathrm{Ca}^{2+}\right] \mathrm{i}\right)\right)$, maximum Twitch-2B ratios, and normalized AUCs (Figure S7A-C). However, it profoundly reduced the fraction of cells with spontaneous fluctuations in $\left[\mathrm{Ca}^{2+}\right]$ ( $(F i g u r e ~ 5 A)$. Using the Gaussian mixture model (McLachlan et al., 2019), 36 out of 60 cells with fluctuations in [Ca $\left.{ }^{2+}\right]$ (i.e., active cells) were identified in the control group, whereas in the Kv1.2 group only 23 out of 68 cells and in the Kir2.1 group only 18 out of 66 cells were active (Figure 5B). We also calculated the mean (per mouse) fraction of active cells, amounting to $57.5 \pm 7.8 \%$ in the control, $33.5 \pm 3.1 \%$ in the Kv1.2, and $23.5 \pm 6.7 \%$ in the Kir2.1 group (Figure $5 \mathrm{C}$ ). These results 
demonstrate that the overexpression of Kv1.2 or Kir2.1 significantly dampens spontaneous fluctuations in $\left[\mathrm{Ca}^{2+}\right]$ in adult-born JGCs.

In contrast, no significant changes in the pattern of endogenous activity were found in odor-deprived cells (Figure 5D-F). The mean fraction of active cells per mouse was 74.2 $\pm 6.7 \%$ in the contralateral control and $65.4 \pm 7.5 \%$ in the ipsilateral odor-deprived group (Figure 5F). Both values were similar to those measured in the control group. Besides, there was no significant difference in the basal and maximum Twitch-2B ratios as well as AUCs between the contralateral control and the ipsilateral odor-deprived groups (Figure S7D-F). However, we noticed that in both the contralateral control and the ipsilateral odordeprived groups the basal Twitch-2B ratios and AUCs were slightly but significantly smaller than the respective values measured in mice without nostril occlusion (i.e., control, Kv1.2, and Kir2.1 groups; Kruskal-Wallis test: for basal Twitch-2B ratios, $P=5.1 \times 10^{-5}$; for AUCs, $P=5.2 \times 10^{-5}$ ). As migration and morphology were not affected in odor-deprived mice, these data suggest that these parameters were not important for the proper development of adult-born JGCs.

Together, these data identify the patterned endogenous activity consisting of fluctuations in $\left[\mathrm{Ca}^{2+}\right]_{i}$ as a key parameter governing the migration, morphogenesis and survival of adult-born JGCs.

\section{The role of pCREB for regulation of early neuronal development}

Phosphorylation of the cAMP response element binding protein (CREB) at the Ser133 residue is known to play an important role in the differentiation and survival of adult-born cells in the OB (Giachino et al., 2005; Herold et al., 2011). Typically, pCREB is abundant 
in developing and low in mature neurons (Jagasia et al., 2009). We, therefore, measured the levels of pCREB in our 5 experimental groups (control, Kv1.2, Kir2.1, contralateral control, ipsilateral odor-deprived). Adult-born JGCs in the Kv1.2 and Kir2.1 groups showed a significant decrease in the level of pCREB both during the early (10 dpi, Figure $6 \mathrm{~A}, \mathrm{~B})$ and the late (28 dpi, Figure 6C) pre-integration phase. At $10 \mathrm{dpi}$, the mean (per mouse) relative pCREB level (i.e., normalized to the mean fluorescence intensity of pCREB of all surrounding mature NeuN-positive cells) of adult-born JGCs was $19.7 \pm 1.7$ in control but decreased sharply to $5.6 \pm 0.7$ in the Kv1.2 and $5.8 \pm 0.8$ in the Kir2.1 group. The pCREB levels in the odor-deprived mice were similar to that found in the control group, amounting to $16.8 \pm 2.8$ in the contralateral control and $17.9 \pm 2.5$ in the ipsilateral odor-deprived group and significantly different from that found in the Kv1.2/Kir2.1 groups (Figure 6B). As the pCREB level in adult-born cells gradually decreases during their maturation (Jagasia et al., 2009), at $28 \mathrm{dpi}$ the respective values were $4.6 \pm 0.5$ for the control, $1.5 \pm 0.2$ for the Kv1.2, and $1.4 \pm 0.2$ for the Kir2.1 group (Figure 6C).

These data show that in adult-born JGCs with dampened endogenous activity, the pCREB signaling pathway is strongly inhibited throughout the pre-integration phase.

\section{Transcriptomic analyses of pathways linked to pCREB signaling}

To investigate the molecular pathways that might lead to pCREB dysregulation, we isolated adult-born cells belonging to the control, Kv1.2, and Kir2.1 groups using fluorescence-activated cell sorting (FACS) and determined their transcriptomic profiles using next-generation sequencing (Figure 7). For a subset of genes (i.e., one representative member of pathways analyzed in Figure 7), the data obtained were further 
validated by quantitative real-time PCR (Figure S8). Because the FACS-sorted cells, isolated from the OB, also contained adult-born GCs, we ensured that adult-born GCs recapitulated the impairment in morphology and CREB phosphorylation, described above for adult-born JGCs (Figure S9).

As expected, the data revealed a significant upregulation of the Kcna2 and Kcnj2 mRNAs in the Kv1.2 and Kir2.1 groups, respectively (Figure S1E, F), as well as a stable expression pattern of housekeeping genes (Figure 7H, Figure S8G). Interestingly, the cells in the Kv1.2 and Kir2.1 groups showed a significantly lower expression of genes participating in the transport of the $\mathrm{Ca}^{2+} /$ Calmodulin complex $\left(\mathrm{Ca}^{2+} / \mathrm{CaM}\right)$ into the nucleus, such as several isoforms of the $\mathrm{Ca}^{2+} / \mathrm{CaM}-$ dependent protein kinase II (CaMKII) (Figure 7B; for details, see Table S1). Activation of this shuttle pathway is mediated by $\mathrm{Ca}^{2+}$ influx through either voltage-gated L-type $\mathrm{Ca}^{2+}$ channels (VGCC; Figure 7I) or NMDA receptors (Figure S10A). The final step in the cascade involves activation of the CaMKIV, which is responsible for pCREB phosphorylation. Transcripts, encoding the L-type $\mathrm{Ca}^{2+}$ channels, NMDA receptors, and CaMKIV, were also downregulated in the Kv1.2 and Kir2.1 groups (Figure 7B, I and Figure S10A). Moreover, additional molecules, required to fully activate the transcription complex of pCREB, like the CREB-regulated transcription coactivator 1 (CRTC1) and calcineurin (CaN), which dephosphorylates CRTC1 to allow its translocation into the nucleus and binding to the transcription unit, were also downregulated (Figure 7I). Next, we investigated further molecules, which act as coactivators or repressors within the transcription unit of pCREB, e.g., LIM domain only 4 (LMO4), DRE-Antagonist Modulator (DREAM), Calcium-Responsive Transactivator (CREST)(Cohen et al., 2018; Merz et al., 2011). The expression profile of these molecules 
was consistent with the decreased transcriptional activity of pCREB (Table S2). Of note, the other major pathway leading to CREB phosphorylation such as the MAPK/ERK pathway remained unchanged (Figure S10B).

In accordance with the above findings, we observed a decreased expression of pCREBdriven immediate early genes (e.g., early growth response 1 (Egr1), neuronal growth regulator 1 (Negr1), etc.; Figure $7 \mathrm{C}, \mathrm{I})$ and downregulation of pathways responsible for neuronal migration (GO:0001764), differentiation (GO:0045664) as well as dendritic morphogenesis (GO:0048813) in the Kv1.2 and Kir2.1 groups (Figure 7D-F, I; Figure S8; Table S1). These results are consistent with the in vivo functional properties of adult-born JGCs overexpressing Kv1.2 or Kir2.1 channels. Consistent with the reduced survival of adult-born JGCs in the Kv1.2 and Kir2.1 groups (Figure 3), the transcripts involved in the apoptotic process (GO:0006915) were upregulated, while the anti-apoptotic genes, like the apoptosis regulator Bcl2, were downregulated (Figure 7G, I; Figure S8; Table S1). Taken together, these data identify a defined signaling pathway, connecting the specific pattern of endogenous neuronal activity to downstream signaling cascades regulating migration, differentiation, morphogenesis, and survival of adult-born neurons.

\section{Discussion}

The current study examined the role of endogenous activity, present in the adult-born juxtaglomerular cells throughout the pre-integration phase, for the key aspects of their development including migration, differentiation, morphogenesis, and survival, and identified the possible molecular mechanisms involved. Thus, the proper development of adult-born JGCs critically depends on fluctuations in $\left[\mathrm{Ca}^{2+}\right]$ i, phosphorylation of CREB, 
and likely also the CRTC1 translocation to the nucleus (Figure 7I). Interestingly, the differences in the steady-state levels of $\left[\mathrm{Ca}^{2+}\right]$ i, reflected in the basal Twitch-2B ratios, turned out to be much less important. The candidate genes, identified by our transcriptomic data, relay this $\mathrm{Ca}^{2+} / \mathrm{pCREB} / \mathrm{CRTC} 1$ signal further to govern the integration of these newly-generated cells into the pre-existing neural circuitry.

The need for intermittent neuronal activity or ongoing fluctuations in $\left[\mathrm{Ca}^{2+}\right]$ i for the maturation process can be explained by the interplay of the CaMKII- and the CRTC1dependent pathways. Both pathways are triggered by the activation of L-type voltagegated $\mathrm{Ca}^{2+}$ channels (and NMDA receptors) and require the $\mathrm{Ca}^{2+} /$ calmodulin $(\mathrm{CaM})$ complex (Cohen et al., 2018; Ma et al., 2014; Saraf et al., 2018). While the CaMKIIdependent pathway leads to the yCaMKII-mediated shuttling of $\mathrm{Ca}^{2+} / \mathrm{CaM}$ to the nucleus and the subsequent phosphorylation of CREB (Cohen et al., 2018; Deisseroth et al., 2004; Ma et al., 2014), the calcineurin (CaN)-mediated dephosphorylation of CRTC1 (also known as the transducer of regulated CREB 1 (TORC1)) supports its translocation to the nucleus, where it is required for the pCREB-driven gene expression (Li et al., 2009; ParraDamas et al., 2017). One of such pCREB/CRTC1-dependent target genes is saltinducible kinase 1 (SIK1), which phosphorylates CRTC1, triggering its export from the nucleus and thus arresting pCREB/CRTC1-mediated transcription (Li et al., 2009). Via this mechanism long-lasting steady-state elevation of $\left[\mathrm{Ca}^{2+}\right]$ i weakens rather than potentiates the pCREB-mediated gene expression. Moreover, in the Kv1.2 and Kir2.1 groups analyzed in our study, we also observed the downregulation of transcripts, encoding the proteins involved in these important pathways (Figure 7), thus further impairing the signal transduction from the cell membrane to the nucleus. 
Cumulative evidence suggests that the aforementioned molecular pathways (Figure 7I) govern the development and maturation of different kinds of neurons during neonatal as well as adult neurogenesis. Indeed, (i) the pCREB-mediated signaling pathway is critically important for survival and morphological maturation of adult-born cells both in the hippocampus and the OB (Herold et al., 2011; Jagasia et al., 2009); (ii) $\mathrm{Ca}^{2+}$-dependent CRTC1 signaling is required for dendritic growth of neonatal cortical neurons (Li et al., 2009); and (iii) L-type channel-mediated spontaneous $\mathrm{Ca}^{2+}$ signaling is critical for migration and survival of neonatal OB GCs (Stéphane et al., 2020). Moreover, modification of cell-intrinsic neuronal activity and associated spontaneous $\mathrm{Ca}^{2+}$ transients by either overexpression/blockade of different voltage-gated $\mathrm{Na}^{+}$and $\mathrm{K}^{+}$channels or optogenetic stimulation impacts the (iv) migration and/or morphogenesis of neonatal cortical pyramidal cells and interneurons (Bando et al., 2014; Bando et al., 2016; Bitzenhofer et al., 2021; De Marco Garcia et al., 2011; Hurni et al., 2017); and (v) morphogenesis of adult-born hippocampal (Piatti et al., 2011) and OB (Dahlen et al., 2011) GCs as well as (vi) survival of olfactory bulb GCs (Lin et al., 2010). Interestingly, the molecular pathways described above are also very similar to the ones governing the activity-dependent synaptic plasticity as well as spatial memory acquisition and retrieval in the adult brain (Ch'ng et al., 2012; Cohen et al., 2018; Kovacs et al., 2007).

According to our current as well as previous (Liang et al., 2016) data, sensory-driven activity had surprisingly little impact on migration, differentiation, and morphogenesis of adult-born JGCs, despite their vivid odor responsiveness already at dpi 9 (Kovalchuk et al., 2015). Consistently, we did not observe any decrease in CREB phosphorylation in odor-deprived hemibulbs. While the comparable literature data on adult-born JGCs is 
largely lacking (but see (Mizrahi, 2007)), the data on OB GCs provides a somewhat inconsistent picture. On the one hand, the migration and morphology of adult-born GCs were normal in anosmic mice lacking any electrical activity in the olfactory epithelium (Petreanu and Alvarez-Buylla, 2002), as was the GCs morphology in young adult mice after 5 weeks of naris occlusion (Dahlen et al., 2011). On the other hand, 30-40 days of naris occlusion starting at postnatal days $4-5$ caused a significant reduction of TDBL of GCs (Saghatelyan et al., 2005). Moreover, naris occlusion also impeded the migration of neuroblasts along the RMS and the tenascin-R-dependent radial migration of neuroblasts from the RMS to the olfactory bulb (Pothayee et al., 2017; Saghatelyan et al., 2004). The literature data, however, are consistent regarding the negative impact of naris occlusion on the survival and synapse/spine density of adult-born GCs (Dahlen et al., 2011; Kelsch et al., 2009; Mandairon et al., 2006; Petreanu and Alvarez-Buylla, 2002; Platel et al., 2019; Yamaguchi and Mori, 2005).

To modify the endogenous neuronal activity and accompanying $\mathrm{Ca}^{2+}$ signaling, we overexpressed either $\mathrm{Kv} 1.2$ or Kir2.1 $\mathrm{K}^{+}$channels, thus mimicking their gain of function. Interestingly, gain-of-function mutations of both Kv1.2 and Kir2.1 channels are indeed found in clinical studies and are often accompanied by either developmental epileptic encephalopathies or somewhat "milder" symptoms like autism, ataxia, brain atrophy, and myoclonic seizures (Allen et al., 2020; Masnada et al., 2017; Syrbe et al., 2015; Villa and Combi, 2016). Strikingly, the gain-of-function mutations of Kv1.2 channels, which are supposed to promote neuronal repolarization and termination of neuronal firing, caused more severe symptoms in terms of epilepsy, ataxia, and intellectual disability than the loss-of-function mutations, which are supposed to promote neuronal hyperactivity (Allen 
et al., 2020; Syrbe et al., 2015). By showing that the "gain-of-function" of either Kv1.2 or Kir2.1 channels impairs the migration, differentiation, and morphogenesis of developing inhibitory neurons, our data provide a plausible explanation for these counterintuitive findings. Based on the discussed above shared molecular pathways, governing the development of adult-born and neonatal neurons, we envisage the retarded interneuron development as a key underlying mechanism of the aforementioned developmental pathologies. These pathologies are likely further exacerbated by increased apoptosis of the same neuronal population. According to the literature, apoptosis can be directly triggered by the enhanced transmembrane $\mathrm{K}^{+}$efflux (reviewed in (Shah and Aizenman, 2014)). The decreased expression of anti-apoptotic (Bc/2) and the increased expression of pro-apoptotic (Bid, Bax, Bad, caspases) genes, revealed by our study, is consistent with our longitudinal imaging data, documenting decreased survival of adult-born cells, and provides a second hypothesis for the gain-of-function-mediated epileptic encephalopathy in clinical settings. Besides, the mice from Kv1.2/Kir2.1 groups are expected to have some deficits in the fine tuning of odor perception/discrimination, facilitation of the task-dependent pattern separation as well as learning and memory, consistent with the aforementioned role of adult-born cells in the OB.

Taken together, our data show that despite developing in the rich sensory environment and being able to respond to sensory stimuli from early on (Kovalchuk et al., 2015; Livneh et al., 2014; Wallace et al., 2017), adult-born neurons strongly rely on cell-intrinsic activity for their migration and morphogenesis, being in this respect largely similar to neonatal neurons (Faigle and Song, 2013). Moreover, by providing several missing links our data revealed stringent signaling pathways connecting the intermittent neuronal activity or 
ongoing fluctuations in $\left[\mathrm{Ca}^{2+}\right]$ i on one side and the increased transmembrane $\mathrm{K}^{+}$efflux on the other side to neuronal migration, maturation, and survival.

\section{Acknowledgments}

We thank E. Zirdum, A. Weible and K. Schöntag for technical assistance, C. Lois for providing Mgi-Kir2.1wt and Mgi-Kir2.1mut plasmids, and O. Rieß, H. Lerche, Y. Liang, S. Ciocchi, and M. Sakaguchi for comments on the manuscript. This work was supported by the DFG grants GA 654/14-1 to O.G and GA 654/13-1/HE8155/1-1 (belonging to the Research Unit FOR-2715) to O.G. and U.H.-K. The NCCT is financed by the DFG grant INST 37/1049-1.

\section{Author Contributions}

O.G. conceived the study, K.L., K.F., X.S., Y.K., J.J.N., N.M., N.C., U.H.-K. performed experiments and/or data analyses. K.L., K.F., and O.G. wrote and all authors approved the manuscript.

\section{Declaration of Interests}

The authors declare no competing interests.

\section{Figure Legends}

Figure 1. Migration properties of adult-born JGCs from control, Kv1.2, Kir2.1, and odor-deprived groups.

(A) Schematics of lentiviral constructs. 
(B) Pseudocolor images showing migrating control (left) and Kv1.2-expressing (right) adult-born JGCs at different times (timestamps, relative time). Blood vessels are shown in gray, asterisks highlight the positions of migrating cells at 0 and $4 \mathrm{~h}$. Data shown in (BF) and (I-L) are obtained at $8 \mathrm{dpi}$.

(C) Box plot showing the median (per mouse) fractions of migrating JGCs during 4-hourlong recordings in control, Kv1.2, and Kir2.1 groups ( $\mathrm{n}=11,10$ and 6 mice, respectively). (D-F) Box plots showing (per cell) the median (D) or the maximum (E) migration speed and the translocation distance in 4 hours $(F) ; n=29 / 13,13 / 9,4 / 6$ cells/mice for control, Kv1.2 and Kir2.1 groups, respectively. Three mice had no migrating Kir2.1 cells.

(G) Box plot showing the median (per mouse) fractions of JGCs, migrating between 8 and $11 \mathrm{dpi}$; n=8, 10, 4 mice for control, Kv1.2, and Kir2.1 groups, respectively.

(H) Image illustrating the nostril occlusion.

(I-M) Box plots showing median (per mouse) fractions of JGCs migrating in 4 hours (I), the median (per cell) $(\mathrm{J})$ and maximum $(\mathrm{K})$ migration speed, the translocation distance in 4 hours (L), and the (per mouse) fraction of cells, migrating between 8 and $11 \mathrm{dpi}(\mathrm{M})$, in contralateral control and ipsilateral odor-deprived hemibulbs ( $n=16 / 5$ and 19/5 cells/mice for control and odor-deprived groups, respectively).

Data are shown as median \pm IQR (interquartile range). ${ }^{*} P<0.05,{ }^{* *} P<0.01,{ }^{* *} P<0.001$, ns=not significant. Here and below all exact $P$ values are listed in Table S4.

Figure 2. Morphology of adult-born JGCs from control, Kv1.2, Kir2.1, and odordeprived groups.

(A) Sample reconstructions of in vivo adult-born JGCs (20 dpi) belonging to control, Kv1.2, 
and Kir2.1 groups.

$(B, C)$ Box plots showing (per cell) the total dendritic branch length (TDBL, $(B)$ ) and the number of dendritic branches (C) of adult-born JGCs, imaged in vivo at $20 \mathrm{dpi}$; n=33/7, 36/6, and 46/6 cells/mice for control, Kv1.2, and Kir2.1 groups, respectively.

(D) Sholl analysis showing the number of intersections of centered Sholl spheres (10 $\mu \mathrm{m}$ step size, illustrated in the inset) with the dendritic trees of JGCs, belonging to control, Kv1.2 and Kir2.1 groups. n=33/7, 36/6, 46/6 cells/mice for control, Kv1.2 and Kir2.1 groups, respectively.

(E) Sample reconstructions of in vivo adult-born JGCs (20 dpi) from the contralateral control and ipsilateral odor-deprived hemibulbs.

$(F, G)$ Box plots illustrating (per cell) the TDBL $(F)$ and the number of dendritic branches (G) of control and odor-deprived adult-born JGCs.

(H) Sholl analysis of the dendritic trees of JGCs from control and odor-deprived hemibulbs; $n=7 / 4$ and 20/4 cells/mice for control and odor-deprived groups, respectively.

(B) (C) (F) and (G): Data are shown as median \pm IQR. (D) and (H): Data are shown as mean \pm SEM. ${ }^{* * *} P<0.001$, ns=not significant.

Figure 3. Kv1.2 or Kir2.1 overexpression reduced the survival of adult-born JGCs.

(A) Sample maximum intensity projection (MIP) images showing adult-born JGCs at 14 and 25 dpi in control (40-80 $\mu \mathrm{m}$ below the dura) and Kv1.2 (20-50 $\mu \mathrm{m}$ below the dura) groups. Note that in all images the safety margin is removed by cropping, showing just the central part of the image. Arrowheads point to cells, surviving till $25 \mathrm{dpi}$.

(B) Box plot showing the survival rates of adult-born JGCs between 14-25 dpi in control, 
Kv1.2 and Kir2.1 groups; n=40/5, 81/8 and 52/5 cells/mice for control, Kv1.2 and Kir2.1 groups, respectively.

(C) Sample MIP images showing adult-born JGCs at 25 and $45 \mathrm{dpi}$ in control (13-80 $\mu \mathrm{m}$

below the dura) and Kir2.1 (33-65 $\mu \mathrm{m}$ below the dura) groups. Arrowheads point to cells, surviving till $45 \mathrm{dpi}$.

(D) Box plot showing the survival rates of adult-born JGCs between 25-45 dpi in control, Kv1.2, and Kir2.1 groups; n=82/5, 23/5, and 49/4 cells/mice for control, Kv1.2 and Kir2.1 groups, respectively.

(B) and (D): Data are shown as median \pm IQR. ${ }^{*} P<0.05,{ }^{* *} P<0.01$, ns $=$ not significant.

Figure 4. Kv1.2 or Kir2.1 overexpression inhibited odor-evoked $\mathrm{Ca}^{2+}$ transients in adult-born JGCs.

(A) Box plot showing the fraction of odor-responsive adult-born JGCs in control, Kv1.2 and Kir2.1 groups (20 dpi); n=78/6, 59/7 and 63/6 cells/mice for control, Kv1.2 and Kir2.1 groups, respectively.

(B) Sample traces showing the odor-evoked $\mathrm{Ca}^{2+}$ transients of adult-born JGCs at $20 \mathrm{dpi}$. Colored bold traces are the means of all recordings (shown in gray).

(C) and (D) Box plots summarizing the median amplitude (C) and area under the curve (AUC, (D)) per cell of odor-evoked $\mathrm{Ca}^{2+}$ transients.

(B-D) $n=82 / 7,53 / 7$, and 17/5 cells/mice for control, Kv1.2, and Kir2.1 groups, respectively.

Data are shown as median \pm IQR (interquartile range). ${ }^{*} P<0.05,{ }^{* *} P<0.01,{ }^{* * *} P<0.001$, ns=not significant. 
Figure 5. Kv1.2 or Kir2.1 overexpression perturbed the pattern of spontaneous $\mathrm{Ca}^{2+}$ transients in adult-born JGCs while odor deprivation did not.

(A) Sample traces illustrating spontaneous $\mathrm{Ca}^{2+}$ transients obtained at 12 dpi from adultborn JGCs in control, Kv1.2, and Kir2.1 groups in awake mice.

(B) Stacked bars showing the fractions of cells with and without fluctuations in $\left[\mathrm{Ca}^{2+}\right]$. Here and in $(E)$ the numbers of cells in each category are given within the bars.

(C) Box plot illustrating the median (per mouse) fractions of adult-born JGCs with fluctuations in $\left[\mathrm{Ca}^{2+}\right]_{\mathrm{i}}$ (B, C) $\mathrm{n}=60 / 8,68 / 7$, and 66/5 cells/mice for control, $\mathrm{Kv} 1.2$, and Kir2.1 groups, respectively.

(D) Sample traces illustrating spontaneous $\mathrm{Ca}^{2+}$ transients of adult-born JGCs from contralateral control and ipsilateral odor-deprived hemibulbs.

(E) Stacked bars showing the fractions of cells with and without fluctuations in $\left[\mathrm{Ca}^{2+}\right]$ in control and odor-deprived groups.

(F) Box plot illustrating the median (per mouse) fractions of adult-born JGCs with fluctuations in $\left[\mathrm{Ca}^{2+}\right]$ in control and odor-deprived groups. (E, F) $n=34 / 4$ and $47 / 4$ cells/mice for contralateral control and ipsilateral odor-deprived groups, respectively.

(C) and (F): Data are shown as median \pm IQR (interquartile range). ${ }^{*} P<0.05,{ }^{* *} P<0.01$, ns=not significant.

Figure 6. Kv1.2 or Kir2.1 overexpression downregulated pCREB signaling pathway. (A) Sample MIP images (20 $\mu$ m depth) showing pCREB-, Twitch-2B- and NeuN-positive cells in the glomerular layer of the OB slices from control, Kv1.2, Kir2.1, Contra_Ctrl, and Ipsi_OD groups at $10 \mathrm{dpi}$. Twitch-2B labels the adult-born JGCs whereas NeuN labels the 
mature neurons. Arrowheads highlight the location of adult-born JGCs.

$(B, C)$ Box plots illustrating the median (per mouse) relative $p C R E B$ levels of adult-born JGCs in different experimental groups, as indicated, at $10 \mathrm{dpi}(\mathrm{B})$ and $28 \mathrm{dpi}(\mathrm{C})$. (B) $\mathrm{n}=152 / 6,230 / 6,177 / 5,129 / 5$, and 94/5 cells/mice for control, Kv1.2, Kir2.1, Contra_Ctrl, and Ipsi_OD groups, respectively. (C) n=110/5, 143/5, and 161/5 cells/mice for control, Kv1.2, and Kir2.1 groups, respectively.

Data are shown as median \pm IQR (interquartile range). ${ }^{* *} P<0.01,{ }^{* * *} P<0.001$, ns $=$ not significant.

Figure 7. Transcriptome analyses of adult-born cells in control, Kv1.2, and Kir2.1 groups.

(A) Schematic illustration of the workflow used for RNAseq.

$(\mathrm{B}-\mathrm{H})$ Box plots showing the expression levels of genes in the modules of $\mathrm{Ca}^{2+} / \mathrm{CaMKII}^{2}$ (B), pCREB-driven IEGs (C), neuronal migration GO:0001764 (D), neuronal differentiation GO:0045664 (E), dendritic morphogenesis GO:0048813 (F), apoptotic process GO:0006915 (G), and 9 housekeeping genes serving as internal controls $(\mathrm{H})$. All transcripts included in the box plots are listed in Table S1. $n=2$ biological replicates (12 mice in total, 2 mice per replicate per group).

(I) The schematic summary of the genes/pathways involved. See the discussion for further details. Asterisks indicate genes, expression of which was verified by qPCR.

Data are shown as median \pm IQR (interquartile range). ${ }^{* *} P<0.01,{ }^{* * *} P<0.001$, ns $=$ not significant. 
Figure S1, related to Figure 1. Bicistronic lentiviral vectors induced simultaneous expression of Kv1.2/Kir2.1 and Twitch-2B.

(A) Sample images showing the transient expression of the lentiviral vectors in HEK-293T cells.

(B) Sample MIP immunofluorescence images (20 $\mu \mathrm{m}$ depth) showing the expression of Kv1.2 in adult-born JGCs at 10 dpi in control (upper panel) and Kv1.2 (lower panel) groups. Arrowheads highlight the location of adult-born JGCs.

(C) Cumulative distributions of the relative Kv1.2 expression levels in control and Kv1.2expressing adult-born JGCs.

(D) Box plot showing the median fractions (per mouse) of adult-born JGCs with a ringshape Kv1.2 expression pattern, likely reflecting enhanced somatic targeting of the protein. (C, D) n=96/6 and 155/6 cells/mice for control and Kv1.2 groups, respectively. $(E, F)$ Bar graphs showing the mean relative expression levels of mRNA encoding for the potassium voltage-gated channel subfamily A member 2 (Kcna2, encoding Kv1.2. (E)) and the potassium inwardly-rectifying channel subfamily $\mathrm{J}$ member 2 (Kcnj2, encoding Kir2.1. (F)) as determined by qPCR analyses of FACS-sorted adult-born cells (see Methods).

Data are shown as median \pm IQR. ${ }^{*} P<0.05,{ }^{* * *} P<0.001$, ns=not significant.

Figure S2, related to Figure1. Kv1.2 or Kir2.1 overexpression did not influence the arrival of adult-born JGCs in the glomerular layer.

Box plots showing the median (per 3D stack volume) density of adult-born JGCs in the OB glomerular layer (i.e., number of adult-born JGCs divided by the respective 3D stack 
volume) at $8 \mathrm{dpi}(\mathrm{A})$ and $14 \mathrm{dpi}(\mathrm{B})$ in control, Kv1.2 and Kir2.1 groups. (A) n = 57/5, 131/9, and 65/6 cells/mice for control, Kv1.2, and Kir2.1 groups, respectively. (B) n=71/5, 89/7, and 60/4 mice/mice for control, Kv1.2, and Kir2.1 groups, respectively.

Data are shown as median \pm IQR. ns=not significant.

Figure S3, related to Figure1. Kv1.2 or Kir2.1 overexpression impaired the migration of adult-born JGCs at $14 \mathrm{dpi}$.

(A) Box plot showing the median (per mouse) fractions of adult-born JGCs migrating during 4-hour-long recordings in control, Kv1.2, and Kir2.1 groups. Here and below $\mathrm{n}=30 / 10,5 / 7$, and $0 / 4$ migrating cells/mice for control, Kv1.2 and Kir2.1 groups, respectively. In total, we analyzed $216 / 10,86 / 7$, and 60/4 cells/mice for control, Kv1.2, and Kir2.1 groups, respectively.

(B-D) Box plots showing (per cell) the median migration speed (B), maximum migration speed (C), and the translocation distance in 4 hours (D) of adult-born JGCs in control and Kv1.2 groups.

Data are shown as median $\pm I Q R .{ }^{*} P<0.05$, ns=not significant.

Figure S4, related to Figure1. Nostril occlusion blocked odor-evoked responsiveness of adult-born JGCs.

(A) Sample odor-evoked $\mathrm{Ca}^{2+}$ transients of adult-born JGCs residing in the contralateral control and ipsilateral odor-deprived hemibulbs.

(B-D) Box plots illustrating the fractions of odor responding cells per mouse (B) and (per cell) the amplitude (C) and AUC (D) of odor-evoked $\mathrm{Ca}^{2+}$ transients. $n=13 / 4$ and 29/4 
cells/mice for contralateral control and ipsilateral odor-deprived hemibulbs.

Data are shown as median \pm IQR. ${ }^{* *} P<0.01$.

Figure S5, related to Figure 2. Immunocytochemical analyses confirming the retarded morphology of Kv1.2- and Kir2.1-expressing adult-born JGCs.

(A) Sample images of adult-born JGCs (20 dpi) belonging to control, Kv1.2 and Kir2.1 groups, reconstructed from in vitro images taken in $50 \mu \mathrm{m}$ thick fixed slices, immunofluorescently labeled against Twitch-2B.

(B) Box plots showing (per cell) the TDBL of adult-born JGCs.

(C) Box plots showing (per cell) the number of dendritic branches of adult-born JGCs. (B) and (C): n=26/5, 25/5, and 25/5 cells/mice for control, Kv1.2, and Kir2.1, respectively.

(D) Sholl analysis illustrating the complexity of adult-born JGC's dendritic morphology in fixed brain slices at 20 dpi. $n=25 / 5$ cells/mice per group.

(B) and (C): Data are shown as median \pm IQR. (D) Data are shown as mean \pm SEM. ${ }^{*} P<0.05,{ }^{* *} P<0.01,{ }^{* *} P<0.001$, ns $=$ not significant.

Figure S6, related to Figure 2. Expression of Kir2.1 channel with a dominantnegative loss-of-function mutation (Kir2.1mut) did not impair the morphogenesis of adult-born JGCs.

(A) Sample reconstructions of in vivo adult-born JGCs (20 dpi) expressing Kir2.1mut.

(B) Box plots showing (per cell) the TDBL of adult-born JGCs imaged in vivo at 20 dpi in control, Kir2.1, and Kir2.1mut groups.

(C) Box plots showing (per cell) the number of dendritic branches of adult-born JGCs 
imaged in vivo at $20 \mathrm{dpi}$ in control, Kir2.1, and Kir2.1mut groups. Control and Kir2.1 datasets are the same as in Figure 2.

(D) Sholl analysis of Kir2.1- and Kir2.1mut-expressing adult-born JGCs.

(E) Sholl analysis of control and Kir2.1mut-expressing adult-born JGCs.

(D) and (E): $n=33 / 7,46 / 6$, and 35/3 cells/mice for control, Kir2.1, and Kir2.1mut groups.

$(B)$ and $(C)$ : Data are shown as median \pm IQR. $(D)$ and $(E)$ : Data are shown as mean \pm SEM. ${ }^{* * *} P<0.001, \mathrm{~ns}=$ not significant.

Figure S7, related to Figure5. Neither Kv1.2 or Kir2.1 overexpression nor odor deprivation affected basal and maximum Twitch-2B ratios and AUCs of adult-born JGCs.

Box plots showing the median (per cell) basal and maximum Twitch-2B ratios and AUCs of spontaneous $\mathrm{Ca}^{2+}$ transients in adult-born JGCs in control, Kv1.2, and Kir2.1 groups $(A-C)$ as well as contralateral control and ipsilateral odor-deprived groups (D-F). $n=60 / 8$, 68/7, 66/5, 34/4, and 47/4 cells/mice for control, Kv1.2, Kir2.1, contralateral control, and ipsilateral odor-deprived groups, respectively.

Data are shown as median \pm IQR. ns=not significant.

Figure S8, related to Figure 7. Relative expression levels of transcripts involved in pathways related to neuronal development, differentiation, and cell death.

Bar graphs showing mean relative expression levels of mRNA encoding for the calcium/calmodulin-dependent protein kinase II gamma (Camk2g; A), doublecortin (Dcx; B), microtubule-associated protein tau (Mapt; C), neural cell adhesion molecule 1 (Ncam1; 
D), synaptophysin (Syp; E), BH3 interacting domain death agonist (Bid; F) and ribosomal protein L5 (Rp/5; G), as determined by qPCR analyses of FACS-sorted adult-born cells (see Methods).

Data are shown as mean \pm SEM. $\mathrm{n}=3$ biological replicates. ${ }^{*} P<0.05,{ }^{* *} P<0.01$, ${ }^{* * *} P<0.001$, ns=not significant.

Figure S9, related to Figures 2, 6 and 7. Morphology and relative pCREB levels of adult-born granule cells from control, Kv1.2, and Kir2.1 groups.

(A) Sample images of adult-born GCs (20 dpi) belonging to control, Kv1.2 and Kir2.1 groups, reconstructed from in vitro images taken in $50 \mu \mathrm{m}$ thick fixed slices, immunofluorescently labeled against Twitch-2B.

(B) Box plots showing (per cell) the TDBL (B) and the number of dendritic branches (C) of adult-born GCs.

(D) Sholl analysis illustrating the complexity of adult-born GCs' dendritic morphology in fixed brain slices at $20 \mathrm{dpi}$.

(E) Sample MIP images (15 $\mu \mathrm{m}$ depth) showing pCREB-, Twitch-2B- and NeuN-positive cells in the granule cell layer of the OB slices from control, Kv1.2 and Kir2.1 groups at 10 dpi. Twitch-2B labels the adult-born GCs whereas NeuN labels the mature neurons. Arrowheads highlight the location of adult-born JGCs.

(F) Box plots illustrating the median (per mouse) relative pCREB levels of adult-born GCs in control, Kv1.2, and Kir2.1 groups at 10 dpi. $n=119 / 5,207 / 4$, and 222/5 cells/mice for control, Kv1.2 and Kir2.1, respectively.

(B-D): $n=177 / 7,149 / 5$, and 133/6 cells/mice for control, Kv1.2 and Kir2.1 respectively. 
(B) (C) and (F): Data are shown as median \pm IQR. (D): Data are shown as mean \pm SEM. ${ }^{*} P<0.05,{ }^{* *} P<0.001$, ns $=$ not significant.

Figure S10, related to Figure 7. Relative expression levels of transcripts encoding for $\mathrm{N}$-methyl-D-aspartate (NMDA) receptors and members of mitogen-activated protein kinase (MAPK) signaling cascade.

Box plots showing mean values of z-scores for four isoforms of the NMDA receptor (A) and 18 members of the MAPK/ERK signaling cascade (B). All transcripts included in the box plots are listed in Table S1. $\mathrm{n}=2$ biological replicates (12 mice in total, 2 mice per replicate per group).

Data are shown as median \pm IQR. ${ }^{* *} P<0.01,{ }^{* * *} P<0.001$, ns $=$ not significant. 
Table S1. Transcripts included in the box plots shown in Figures 7 and S10.

\begin{tabular}{|l|l|}
\hline Figure & Genes \\
\hline 7B & Camk2g, Camk2b, Camk2a, Calm3, Cacna1c, Cacna1d \\
\hline 7C & Vgefa, JunB, Nr4a1, Egr1, Fra2, Negr1, Ank3, Ank2 \\
\hline 7D & $\begin{array}{l}\text { Camk2a, Camk2b, Cck, Dclk1, Dcx, Nr2f1, Fyn,Fzd3, Gja1,Mdk, Mapt, } \\
\text { Ntrk2, Ptprz1, Reln, Olfm1, Kirrel3, Fbxo31, Gpm6a, Mrtfb, Adgrl3, } \\
\text { Cdk15, Flrt2 }\end{array}$ \\
\hline 7E & $\begin{array}{l}\text { Bdnf, Camk2b,Cdh2, Cntn1,Dcx,Nr2f1,Fyn, Grin1,Id4,Itsn1,Mdk, Meis1, } \\
\text { Map1b, Map2, Mapt, Ncoa1, Nedd4, Nefl, Nf1, Ntrk2, Pcp4, Ptn, Ptprs, } \\
\text { Ptprz1, Reln, Snap25, Snap91, Plk2, Sox9, Syt1, Dpys/3, Vim, Ywhag, } \\
\text { Magi2, Olfm1, Rapgef4, Syne1, Fuom, Grip1, Plppr5, Fbxo31, Kank1, } \\
\text { Baiap2, Eif4g1, Gpr37l1, Cpeb3, Adgrb3, Cdkl3, Arhgap44, Acs/6, } \\
\text { Arhgap33, Amigo1, Ndrg4, Ntm, Fez1, Shank1, Nlgn3, Robo2, Nrcam, } \\
\text { II1rapl1, Cdkl5, Kalrn, Tnik, Acp4 }\end{array}$ \\
\hline 7F & $\begin{array}{l}\text { Camk2a, Camk2b, Dclk1, Dcx, Epha5, Fyn, Grin1, Nedd4, Ctnnd2, Ptn, } \\
\text { Ptprz1, Reln, Syne1, Fbxo31, Baiap2, Adgrb3, Cdkl3, Arhgap44, } \\
\text { Arhgap33, Shank1, Nlgn3, Il1rapl1, Cdk15, Kalrn, Tnik }\end{array}$ \\
\hline 7G & $\begin{array}{l}\text { Bcl10, Bcl7a, Bad, Casp8, Casp6, Casp1, Casp4, Casp12, Casp7, } \\
\text { Casp2, Bcl2a1a, Bax, Bid }\end{array}$ \\
\hline 7H & Psmc5, Gapdh, Mkrn1, Tuba1b, Dars, Rpl27, Ldha, Rpl5, Actb \\
\hline S10A & Nmda2b, Nmda2a, Nmda1,Nmda3a \\
\hline S10B & $\begin{array}{l}\text { Mapk1, Mapk2, Mapk3, Mapk6, Mapk7, Mapk8, Mapk9, Mapk10, } \\
\text { Mapk14, Lamtor1, Lamtor2, Lamtor3, Lamtor4, Lamtor5, Mapkapk3, } \\
\text { Mapkap1, Mapk1ip1, Jkamp }\end{array}$ \\
\hline
\end{tabular}

Table S2, related to Figure 7. Differential expression of factors interacting with CREB

\begin{tabular}{|l|c|c|c|c|}
\hline \multirow{2}{*}{ Genes } & \multicolumn{2}{|c|}{ Control vs Kv1.2 } & \multicolumn{2}{c|}{ Control vs Kir2.1 } \\
\cline { 2 - 5 } & logFC & $P$ value & logFC & $P$ value \\
\hline Crtc2 & 4.59 & 0.1818 & 6.34 & 0.1002 \\
\hline Crtc3 & 0.21 & 0.9484 & 0.61 & 0.8533 \\
\hline Lmo4 & -1.65 & 0.2554 & -1.04 & 0.4539 \\
\hline Dream (Kcnip3) & -0.84 & 0.5959 & -8.61 & 0.0046 \\
\hline Crest (Ss18/1) & -6.04 & 0.1098 & 0.56 & 0.8377 \\
\hline Smarca4 & -1.55 & 0.5495 & -0.91 & 0.7210 \\
\hline Hdac1 & -1.84 & 0.3210 & 0.29 & 0.8663 \\
\hline
\end{tabular}


Table S3, related to Figure S8. Primers used for qPCR

\begin{tabular}{|l|l|l|l|}
\hline Gene & Accession N & Primers & $\begin{array}{l}\text { Size } \\
\text { (bp) }\end{array}$ \\
\hline Gapdh & NM_001289726.1 & $\begin{array}{l}\text { F: TGCACCACCAACTGCTTAG } \\
\text { R: GGATGCAGGGATGATGTTC }\end{array}$ & 177 \\
\hline Rp/5 & NM_016980.2 & $\begin{array}{l}\text { F: TGGCAGACTACATGCGCTAC } \\
\text { R: ATACATCTCCTCCATCATGTCTG }\end{array}$ & 109 \\
\hline Kcna2 & NM_008417.5 & $\begin{array}{l}\text { F: TGGTACCCATCTGCAAGGGC } \\
\text { R: CCTTTGGAAGGAAGGAGGCAA }\end{array}$ & 99 \\
\hline Kcnj2 & NM_008425.4 & $\begin{array}{l}\text { F: GGCAAGCAGTGTCTTGGGAAT } \\
\text { R: AGAGAACTTGTCCTGTTGCTGG }\end{array}$ & 138 \\
\hline Dcx & NM_001110222.1 & $\begin{array}{l}\text { F: GAGTGGGGCTTTCGAGTGAT } \\
\text { R: AAAGAAAGCCGTGTGCCTTG }\end{array}$ & 78 \\
\hline Camk2g & NM_178597.5 & $\begin{array}{l}\text { F: AGTCAGATGGCGGTGTCAAG } \\
\text { R: GCTGGGCTTACGAGACTGTT }\end{array}$ & 91 \\
\hline Mapt & NM_001038609.2 & $\begin{array}{l}\text { F: CGCCCCTAGTGGATGAGAGA } \\
\text { R: TCCTTCTGGGATCTCCGTGT }\end{array}$ & 71 \\
\hline Ncam1 & NM_001081445.1 & $\begin{array}{l}\text { F: CAAGTACAGAGCGCTCGCC } \\
\text { R: AGGGACTTGAGCATGACGTG }\end{array}$ & 81 \\
\hline Syp & NM_009305.2 & $\begin{array}{l}\text { F: CTGCGTTAAAGGGGGCACTA } \\
\text { R: GGAAGTCCATCATTGGCCCT }\end{array}$ & 175 \\
\hline
\end{tabular}

mRNA sequence accession numbers were obtained from the Mouse Genome Database accessed at www.ncbi.nlm.nih.gov/genome. 
Table S4. Exact results of all statistical tests

\begin{tabular}{|c|c|c|}
\hline Figure & Statistical test & Post hoc comparisons \\
\hline $1 \mathrm{C}$ & Kruskal-Wallis test: $P=2 \times 10^{-4}$ & $\begin{array}{l}\text { Dunn's multiple comparison test: control } \\
\text { vs. Kv1.2: } P=0.04 \text {, control vs. Kir2.1: } \\
P=2 \times 10^{-4}, \mathrm{Kv} 1.2 \text { vs. Kir2.1: } P=0.22 \text {. }\end{array}$ \\
\hline 1D & Kruskal-Wallis test: $P=6 \times 10^{-5}$ & $\begin{array}{l}\text { Dunn's multiple comparison test: control } \\
\text { vs. Kv1.2: } P=2 \times 10^{-4} \text {, control vs. Kir2.1: } \\
P=1.6 \times 10^{-3}, \mathrm{Kv} 1.2 \text { vs. Kir2.1: } P=0.36 \text {. }\end{array}$ \\
\hline $1 \mathrm{E}$ & Kruskal-Wallis test: $P=2 \times 10^{-4}$ & $\begin{array}{l}\text { Dunn's multiple comparison test: control } \\
\text { vs. Kv1.2: } P=3 \times 10^{-4} \text {, control vs. Kir2.1: } \\
P=6.3 \times 10^{-3}, \mathrm{Kv} 1.2 \text { vs. Kir2.1: } P=0.67 \text {. }\end{array}$ \\
\hline $1 \mathrm{~F}$ & Kruskal-Wallis test: $P=3 \times 10^{-4}$ & $\begin{array}{l}\text { Dunn's multiple comparison test: control } \\
\text { vs. Kv1.2: } P=8.9 \times 10^{-3} \text {, control vs. Kir2.1: } \\
P=3 \times 10^{-3}, \mathrm{Kv1} .2 \text { vs. Kir2.1: } P=0.55 \text {. }\end{array}$ \\
\hline $1 G$ & $\begin{array}{l}\text { One-way ANOVA: } \\
\mathrm{F}_{2,19}=7.982, P=3 \times 10^{-3}\end{array}$ & $\begin{array}{l}\text { Tukey's multiple comparison test: control } \\
\text { vs. Kv1.2: } P=0.01 \text {, control vs. Kir2.1: } \\
P=6.6 \times 10^{-3}, \text { Kv1.2 vs. Kir2.1: } P=0.59 \text {. }\end{array}$ \\
\hline $1 \mathrm{I}-\mathrm{M}$ & $\begin{array}{l}\text { Two-sided unpaired } t \text { test, } \\
P>0.05 \text { for all comparisons. }\end{array}$ & \\
\hline 2B & Kruskal-Wallis test: $P=2 \times 10^{-9}$ & $\begin{array}{l}\text { Dunn's multiple comparison test: control } \\
\text { vs. Kv1.2: } P=3 \times 10^{-9} \text {; control vs. Kir2.1: } \\
P=8 \times 10^{-6} ; \mathrm{Kv1} .2 \text { vs. Kir2.1: } P=0.21\end{array}$ \\
\hline $2 \mathrm{C}$ & Kruskal-Wallis test: $P=5 \times 10^{-10}$ & $\begin{array}{l}\text { Dunn's multiple comparison test: control } \\
\text { vs. Kv1.2: } P=2 \times 10^{-9} \text {; control vs. Kir2.1: } \\
P=5 \times 10^{-7} ; \mathrm{Kv1} 1.2 \text { vs. Kir2.1: } P=0.58\end{array}$ \\
\hline 2D & $\begin{array}{l}\text { Generalized linear mixed } \\
\text { model fit by maximum } \\
\text { likelihood (Laplace } \\
\text { Approximation) }\end{array}$ & $\begin{array}{l}\text { control vs. Kv1.2: } P<0.001 \text {, control vs. } \\
\text { Kir2.1: } P<0.001, \mathrm{Kv1} .2 \text { vs. Kir2.1: } \\
P<0.001\end{array}$ \\
\hline $2 F, G$ & $\begin{array}{l}\text { Two-sided unpaired } t \text { test, } \\
P>0.05 \text { for both comparisons. }\end{array}$ & \\
\hline $2 \mathrm{H}$ & $\begin{array}{l}\text { Generalized linear mixed } \\
\text { model fit by maximum } \\
\text { likelihood (Laplace } \\
\text { Approximation) }\end{array}$ & $P=0.98$ \\
\hline 3B & $\begin{array}{l}\text { One-way ANOVA: } \\
F_{2,15}=6.747, P=8.1 \times 10^{-3}\end{array}$ & $\begin{array}{l}\text { Tukey's multiple comparison test: control } \\
\text { vs. Kv1.2: } P=0.02 \text {; control vs. Kir2.1: } \\
P=9.6 \times 10^{-3} \text {; Kv1.2 vs. Kir2.1: } P=0.69 \text {. }\end{array}$ \\
\hline
\end{tabular}




\begin{tabular}{|c|c|c|}
\hline $3 \mathrm{D}$ & $\begin{array}{l}\text { One-way ANOVA: } \\
F_{2,11}=13.84, P=1 \times 10^{-3}\end{array}$ & $\begin{array}{l}\text { Tukey's multiple comparison test: control } \\
\text { vs. Kv1.2: } P=0.81 \text {; control vs. Kir2.1: } \\
P=1.2 \times 10^{-3} ; \mathrm{Kv} 1.2 \text { vs. Kir2.1: } P=3.3 \times 10^{-3} \text {. }\end{array}$ \\
\hline $4 \mathrm{~A}$ & $\begin{array}{l}\text { One-way ANOVA: } \\
\mathrm{F}_{2,16}=7.061, P=0.0063\end{array}$ & $\begin{array}{l}\text { Tukey's multiple comparison test: control } \\
\text { vs. Kv1.2: } P=0.54 ; \text { control vs. Kir2.1: } \\
P=5.9 \times 10^{-3} ; \text { Kv1.2 vs. Kir2.1: } P=0.04 \text {. }\end{array}$ \\
\hline $4 \mathrm{C}$ & Kruskal-Wallis test: $P=2 \times 10^{-6}$ & $\begin{array}{l}\text { Dunn's multiple comparison test: control } \\
\text { vs. Kv1.2: } P=4 \times 10^{-5} \text {; control vs. Kir2.1: } \\
P=6 \times 10^{-4} ; \mathrm{Kv1} .2 \text { vs. Kir2.1: } P>0.99 \text {. }\end{array}$ \\
\hline 4D & Kruskal-Wallis test: $P=7 \times 10^{-9}$ & $\begin{array}{l}\text { Dunn's multiple comparison test: control } \\
\text { vs. Kv1.2: } P=3 \times 10^{-6} ; \text { control vs. Kir2.1: } \\
P=4 \times 10^{-6} ; \mathrm{Kv} 1.2 \text { vs. Kir2.1: } P=0.39 \text {. }\end{array}$ \\
\hline $5 \mathrm{~B}$ & Chi-square test, $P=3 \times 10^{-6}$ & \\
\hline $5 C$ & $\begin{array}{l}\text { One-way ANOVA: } \\
F_{2,15}=5.468, P=0.016\end{array}$ & $\begin{array}{l}\text { Tukey's multiple comparison test: control } \\
\text { vs. Kv1.2: } P=0.03 \text {; control vs. Kir2.1: } \\
P=6.2 \times 10^{-3} ; \mathrm{Kv} 1.2 \text { vs. Kir2.1: } P=0.57 \text {. }\end{array}$ \\
\hline $5 \mathrm{E}$ & Chi-square test, $P=0.28$ & \\
\hline $5 \mathrm{~F}$ & $\begin{array}{l}\text { Two-sided unpaired } t \text { test, } \\
P=0.75\end{array}$ & \\
\hline $6 \mathrm{~B}$ & $\begin{array}{l}\text { One-way ANOVA: } \\
F_{4,22}=14.66, P=6 \times 10^{-6}\end{array}$ & $\begin{array}{l}\text { Tukey's multiple comparison test: control } \\
\text { vs. Kv1.2: } P=7 \times 10^{-5} \text {; control vs. Kir2.1: } \\
P=2 \times 10^{-4} \text {; control vs. Contra_Ctrl: } \\
P=0.79 \text {; control vs. Ipsi_OD: } P=0.95 ; \\
\text { Kv1.2 vs. Kir2.1: } P=0.99 ; \text { Kv1 } 1.2 \text { vs. } \\
\text { Contra_Ctrl: } P=2.1 \times 10^{-3} ; \text { Kv1.2 vs. } \\
\text { Ipsi_OD: } P=7 \times 10^{-4} ; \text { Kir2.1 vs. } \\
\text { Contra_Ctrl: } P=3.8 \times 10^{-3} ; \text { Kir2.1 vs. } \\
\text { Ipsi_OD: } P=1.4 \times 10^{-3} ; \text { Contra_Ctrl vs. } \\
\text { Ipsi_OD: } P=0.99 \text {. }\end{array}$ \\
\hline $6 \mathrm{C}$ & $\begin{array}{l}\text { One-way ANOVA: } \\
F_{2,12}=27.88, P=3 \times 10^{-5}\end{array}$ & $\begin{array}{l}\text { Tukey's multiple comparison test: control } \\
\text { vs. Kv1.2: } P=1 \times 10^{-5} \text {; control vs. Kir2.1: } \\
P=7 \times 10^{-5} ; \mathrm{Kv} 1.2 \text { vs. Kir2.1: } P=0.95 \text {. }\end{array}$ \\
\hline $7 \mathrm{~A}$ & $\begin{array}{l}\text { One-way ANOVA: } \\
F_{2,10}=14.12, P=2.4 \times 10^{-3}\end{array}$ & $\begin{array}{l}\text { Tukey's multiple comparison test: control } \\
\text { vs. Kv1.2: } P=2.9 \times 10^{-3} ; \text { control vs. Kir2.1: } \\
P=2.2 \times 10^{-3} ; \mathrm{Kv} 1.2 \text { vs. Kir2.1: } P=0.99 \text {. }\end{array}$ \\
\hline $7 \mathrm{~B}$ & $\begin{array}{l}\text { One-way ANOVA: } \\
\mathrm{F}_{2,14}=18.02, P=1.3 \times 10^{-4}\end{array}$ & $\begin{array}{l}\text { Tukey's multiple comparison test: control } \\
\text { vs. Kv1.2: } P=4.3 \times 10^{-3} \text {; control vs. Kir2.1: } \\
P=1.1 \times 10^{-4} ; \mathrm{Kv} 1.2 \text { vs. Kir2.1: } P=0.15 \text {. }\end{array}$ \\
\hline
\end{tabular}




\begin{tabular}{|c|c|c|}
\hline $7 \mathrm{C}$ & $\begin{array}{l}\text { One-way ANOVA: } \\
F_{2,42}=121.7, P=1 \times 10^{-15} \text {, }\end{array}$ & $\begin{array}{l}\text { Tukey's multiple comparison test: control } \\
\text { vs. Kv1.2: } P=1 \times 10^{-12} \text {; control vs. Kir2.1: } \\
P=1 \times 10^{-12} ; \mathrm{Kv} 1.2 \text { vs. Kir2.1: } P=0.56 \text {. }\end{array}$ \\
\hline $7 \mathrm{D}$ & Friedman test, $P=1 \times 10^{-15}$ & $\begin{array}{l}\text { Dunn's multiple comparison test: control } \\
\text { vs. Kv1.2: } P=1 \times 10^{-15} \text {; control vs. Kir2.1: } \\
P=1 \times 10^{-15} \text {; Kv1.2 vs. Kir2.1: } P=0.75 \text {. }\end{array}$ \\
\hline $7 \mathrm{E}$ & $\begin{array}{l}\text { One-way ANOVA: } F_{2,48}=99.8 \text {, } \\
P=1 \times 10^{-15}\end{array}$ & $\begin{array}{l}\text { Tukey's multiple comparison test: control } \\
\text { vs. Kv1.2: } P=1 \times 10^{-15} \text {; control vs. Kir2.1: } \\
P=2 \times 10^{-15} \text {; Kv1 } 2 \text { vs. Kir2.1: } P=0.84 \text {. }\end{array}$ \\
\hline $7 \mathrm{~F}$ & $\begin{array}{l}\text { One-way ANOVA: } \\
F_{2,26}=22.02, P=2.5 \times 10^{-6}\end{array}$ & $\begin{array}{l}\text { Tukey's multiple comparison test: control } \\
\text { vs. Kv1.2: } P=1.3 \times 10^{-5} ; \text { control vs. Kir2.1: } \\
P=1.4 \times 10^{-5} ; \text { Kv1 } 2 \text { vs. Kir2.1: } P=0.99 \text {. }\end{array}$ \\
\hline $7 G$ & $\begin{array}{l}\text { One-way ANOVA: } F_{2,16}=1.27 \text {, } \\
P=0.31\end{array}$ & \\
\hline S1C & $\begin{array}{l}\text { Kolmogorov-Smirnov test, } \\
P=1 \times 10^{-8}, D=0.399 .\end{array}$ & \\
\hline S1D & $\begin{array}{l}\text { Unpaired } t \text { test with Welch's } \\
\text { correction, } t_{5}=17.13, P=1 \times 10^{-} \\
5 \text {. }\end{array}$ & \\
\hline S1E & $\begin{array}{l}\text { One-way ANOVA: } F_{2,6}=696.8 \text {, } \\
P=7.9 \times 10^{-8}\end{array}$ & $\begin{array}{l}\text { Tukey's multiple comparison test: control } \\
\text { vs. Kv1.2: } P=2.4 \times 10^{-7} \text {; control vs. Kir2.1: } \\
P=0.98 ; \mathrm{Kv1} 1.2 \text { vs. Kir2.1: } P=2.5 \times 10^{-7} \text {. }\end{array}$ \\
\hline S1F & $\begin{array}{l}\text { One-way ANOVA: } F_{2,6}=8.16 \text {, } \\
P=0.02\end{array}$ & $\begin{array}{l}\text { Tukey's multiple comparison test: control } \\
\text { vs. Kv1.2: } P=0.97 ; \text { control vs. Kir2.1: } \\
P=0.03 ; \text { Kv1.2 vs. Kir2.1: } P=0.03 \text {. }\end{array}$ \\
\hline S2A & $\begin{array}{l}\text { One-way ANOVA: } F_{2,17}=0.05 \text {, } \\
P=0.95\end{array}$ & \\
\hline S2B & $\begin{array}{l}\text { One-way ANOVA: } F_{2,13}=2.18 \text {, } \\
P=0.15\end{array}$ & \\
\hline S3A & $\begin{array}{l}\text { One-way ANOVA: } F_{2,18}=4.01 \\
P=0.04\end{array}$ & $\begin{array}{l}\text { unpaired t test with Welch's correction for } \\
\text { multiple comparisons: control vs. Kv1.2: } \\
P=0.17 \text {; control vs. Kir2.1: } P=1.9 \times 10^{-3} \text {; } \\
\text { Kv1.2 vs. Kir2.1: } P=0.04 \text {. }\end{array}$ \\
\hline S3B & $\begin{array}{l}\text { Two-sided Mann-Whitney } \\
\text { test, } P=0.68\end{array}$ & \\
\hline S3C & $\begin{array}{l}\text { Two-sided Mann-Whitney } \\
\text { test, } P=0.82\end{array}$ & \\
\hline
\end{tabular}




\begin{tabular}{|c|c|c|}
\hline S3D & $\begin{array}{l}\text { Two-sided Mann-Whitney } \\
\text { test, } P=0.02\end{array}$ & \\
\hline S4B & $\begin{array}{l}\text { Unpaired } t \text { test with Welch's } \\
\text { correction, } \mathrm{t}_{3}=6.31, P=8 \times 10^{-3}\end{array}$ & \\
\hline S5B & Kruskal-Wallis test: $P=5 \times 10^{-9}$ & $\begin{array}{l}\text { Dunn's multiple comparison test: control } \\
\text { vs. Kv1.2: } P=5 \times 10^{-9} \text {; control vs. Kir2.1: } \\
P=4 \times 10^{-6} \text {; Kv1.2 vs. Kir2.1: } P=0.72\end{array}$ \\
\hline S5C & Kruskal-Wallis test: $P=6 \times 10^{-10}$ & $\begin{array}{l}\text { Dunn's multiple comparison test: control } \\
\text { vs. Kv1.2: } P=1 \times 10^{-9} \text {; control vs. Kir2.1: } \\
P=2 \times 10^{-5} ; \mathrm{Kv} 1.2 \text { vs. Kir2.1: } P=0.27\end{array}$ \\
\hline S5D & $\begin{array}{l}\text { Generalized linear mixed } \\
\text { model fit by maximum } \\
\text { likelihood (Laplace } \\
\text { Approximation) }\end{array}$ & $\begin{array}{l}\text { control vs. Kv1.2: } P=0.004 \text {, control vs. } \\
\text { Kir2.1: } P=0.011, \mathrm{Kv1} .2 \text { vs. Kir2.1: } \\
P=0.016\end{array}$ \\
\hline S6B & Kruskal-Wallis test: $P=1 \times 10^{-9}$ & $\begin{array}{l}\text { Dunn's multiple comparison test: control } \\
\text { vs. Kir2.1: } P=1 \times 10^{-5} \text {; control vs. } \\
\text { Kir2.1mut: } P=0.7 ; \text { Kir2.1 vs. Kir2.1mut: } \\
P=6 \times 10^{-9}\end{array}$ \\
\hline S6C & Kruskal-Wallis test: $P=7 \times 10^{-11}$ & $\begin{array}{l}\text { Dunn's multiple comparison test: control } \\
\text { vs. Kir2.1: } P=3 \times 10^{-7} \text {; control vs. } \\
\text { Kir2.1mut: } P=0.99 \text {; Kir2.1 vs. Kir2.1mut: } \\
P=3 \times 10^{-9}\end{array}$ \\
\hline S6D & $\begin{array}{l}\text { Generalized linear mixed } \\
\text { model fit by maximum } \\
\text { likelihood (Laplace } \\
\text { Approximation) }\end{array}$ & $P<0.001$ \\
\hline S6E & $\begin{array}{l}\text { Generalized linear mixed } \\
\text { model fit by maximum } \\
\text { likelihood (Laplace } \\
\text { Approximation) }\end{array}$ & $P=0.28$ \\
\hline $7 A-C$ & $\begin{array}{l}\text { Kruskal-Wallis test, } P>0.05 \\
\text { for all tests }\end{array}$ & \\
\hline S7D-F & $\begin{array}{l}\text { Mann-Whitney test, } P>0.05 \\
\text { for all tests }\end{array}$ & \\
\hline S8A & $\begin{array}{l}\text { One-way ANOVA: } F_{2,6}=25.21 \text {, } \\
P=0.0012\end{array}$ & $\begin{array}{l}\text { Fisher's multiple comparison test: contro } \\
\text { vs. Kv1.2: } P=8.2 \times 10^{-4} \text {; control vs. Kir2.1: } \\
P=8.8 \times 10^{-4} ; \mathrm{K} 1.2 \text { vs. Kir2.1: } P=0.94 \text {. }\end{array}$ \\
\hline
\end{tabular}




\begin{tabular}{|c|c|c|}
\hline S8B & $\begin{array}{l}\text { One-way ANOVA: } F_{2,6}=10.77 \text {, } \\
P=0.01\end{array}$ & $\begin{array}{l}\text { Fisher's multiple comparison test: control } \\
\text { vs. Kv1.2: } P=8.3 \times 10^{-3} \text {; control vs. Kir2.1: } \\
P=6 \times 10^{-3} ; \mathrm{Kv} 1.2 \text { vs. Kir2.1: } P=0.78 \text {. }\end{array}$ \\
\hline S8C & $\begin{array}{l}\text { One-way ANOVA: } F_{2,6}=27.17 \\
P=9.8 \times 10^{-4}\end{array}$ & $\begin{array}{l}\text { Fisher's multiple comparison test: control } \\
\text { vs. Kv1.2: } P=6.5 \times 10^{-4} \text {; control vs. Kir2.1: } \\
P=7.4 \times 10^{-4} \text {; Kv1.2 vs. Kir2.1: } P=0.88 \text {. }\end{array}$ \\
\hline S8D & $\begin{array}{l}\text { One-way ANOVA: } F_{2,6}=43.04 \text {, } \\
P=2.7 \times 10^{-4}\end{array}$ & $\begin{array}{l}\text { Fisher's multiple comparison test: control } \\
\text { vs. Kv1.2: } P=1.9 \times 10^{-4} \text {; control vs. Kir2.1: } \\
P=2.1 \times 10^{-4} \text {; Kv1.2 vs. Kir2.1: } P=0.91 \text {. }\end{array}$ \\
\hline S8E & $\begin{array}{l}\text { One-way ANOVA: } F_{2,6}=46.98 \text {, } \\
P=2.2 \times 10^{-4}\end{array}$ & $\begin{array}{l}\text { Fisher's multiple comparison test: control } \\
\text { vs. Kv1.2: } P=1.6 \times 10^{-4} \text {; control vs. Kir2.1: } \\
P=1.5 \times 10^{-4} \text {; Kv1.2 vs. Kir2.1: } P=0.89 \text {. }\end{array}$ \\
\hline S8F & $\begin{array}{l}\text { One-way ANOVA: } F_{2,6}=9.19 \text {, } \\
P=0.015\end{array}$ & $\begin{array}{l}\text { Fisher's multiple comparison test: control } \\
\text { vs. Kv1.2: } P=6 \times 10^{-3} \text {; control vs. Kir2.1: } \\
P=0.03 \text {; Kv1.2 vs. Kir2.1: } P=0.24 \text {. }\end{array}$ \\
\hline S8G & $\begin{array}{l}\text { One-way ANOVA: } F_{2,6}=0.15 \text {, } \\
P=0.86\end{array}$ & \\
\hline S9B & Kruskal-Wallis test: $P=1 \times 10^{-14}$ & $\begin{array}{l}\text { Dunn's multiple comparison test: control } \\
\text { vs. Kv1.2: } P=1 \times 10^{-14} \text {; control vs. Kir2.1: } \\
P=1 \times 10^{-14} \text {; Kv1.2 vs. Kir2.1: } P=0.99\end{array}$ \\
\hline S9C & Kruskal-Wallis test: $P=1 \times 10^{-14}$ & $\begin{array}{l}\text { Dunn's multiple comparison test: control } \\
\text { vs. Kv1.2: } P=1 \times 10^{-14} \text {; control vs. Kir2.1: } \\
P=1 \times 10^{-14} \text {; Kv1.2 vs. Kir2.1: } P=0.99\end{array}$ \\
\hline S9D & $\begin{array}{l}\text { Generalized linear mixed } \\
\text { model fit by maximum } \\
\text { likelihood (Laplace } \\
\text { Approximation) }\end{array}$ & $\begin{array}{l}\text { control vs. Kv1.2: } P<0.001 \text {, control vs. } \\
\text { Kir2.1: } P<0.001, \mathrm{Kv1} .2 \text { vs. Kir2.1: } \\
P<0.001\end{array}$ \\
\hline S9F & $\begin{array}{l}\text { One-way ANOVA: } \\
\mathrm{F}_{2,11}=6.524, P=0.013\end{array}$ & $\begin{array}{l}\text { Tukey's multiple comparison test: control } \\
\text { vs. Kv1.2: } P=0.02 \text {; control vs. Kir2.1: } \\
P=0.049 ; \text { Kv1.2 vs. Kir2.1: } P=0.69 \text {. }\end{array}$ \\
\hline S10A & $\begin{array}{l}\text { One-way ANOVA: } F_{2,6}=31.74 \text {, } \\
P=6 \times 10^{-4}\end{array}$ & $\begin{array}{l}\text { Tukey's multiple comparison test: control } \\
\text { vs. Kv1.2: } P=8 \times 10^{-4} \text {; control vs. Kir2.1: } \\
P=1.6 \times 10^{-3} ; \mathrm{Kv1} .2 \text { vs. Kir2.1: } P=0.67 \text {. }\end{array}$ \\
\hline S10B & $\begin{array}{l}\text { One-way ANOVA: } F_{2,34}=0.18 \text {, } \\
P=0.83\end{array}$ & \\
\hline
\end{tabular}




\section{Methods}

\section{Animals}

All experimental procedures were performed in accordance with Institutional Animal Welfare Guidelines and were approved by the state government of Baden-Württemberg, Germany. Three- to four-month-old C57BL/6 mice of either sex were used in this study. Animals were kept in pathogen-free conditions at $22^{\circ} \mathrm{C}, 60 \%$ air humidity, 12 -hours lightdark-cycle with ad libitum access to food and water. Females stayed in groups of 3-5 mice, males were kept individually.

\section{Implantation of a cranial window}

A chronic cranial window was implanted over the mouse $\mathrm{OB}$ as described previously ${ }^{34,35}$. Mice were anesthetized by an intraperitoneal (i.p.) injection of ketamine/xylazine (80/4 $\mu \mathrm{g} / \mathrm{g}$ of body weight $(\mathrm{BW}))$. Anesthetic depth was monitored by toe pinches throughout the surgery and additional ketamine/xylazine $(40 / 2 \mu \mathrm{g} / \mathrm{g}$ of BW) was injected when necessary. Dexamethasone ( $2 \mu \mathrm{g} / \mathrm{g}$ of BW) was administered intramuscularly before the surgery. Local anesthetic lidocaine (2\%) was applied subcutaneously over the OB 5-10 minutes before removing the scalp. The ointment was used to prevent dehydration of the mouse's eyes. A circular cranial opening ( $3 \mathrm{~mm}$ in diameter) was made by repeated drilling over the two OB hemispheres. Small pieces of bone were removed with a sharp blade and tweezers. Extreme care was taken, not to damage any blood vessels on the surface of the $\mathrm{OB}$. The opening was rinsed with a standard extracellular solution (composition in mM: $125 \mathrm{NaCl}, 4.5 \mathrm{KCl}, 26 \mathrm{NaHCO}_{3}, 1.25 \mathrm{NaH}_{2} \mathrm{PO}_{4}, 2 \mathrm{CaCl}_{2}, 1 \mathrm{MgCl}_{2}$, 
and 20 glucose; pH 7.4, bubbled continuously with $95 \% \mathrm{O}_{2}$ and $5 \% \mathrm{CO}_{2}$ ) and covered with a glass coverslip ( $\varnothing 3 \mathrm{~mm}$, Warner Instruments, Hamden, CT, USA). The gap between the edge of the coverslip and the skull was filled with cyanoacrylate glue and then strengthened by dental cement. During the surgery and until full recovery from anesthesia the mouse was kept on a heated plate. Postoperative care included an analgesic dose of carprofen (5 $\mathrm{\mu g} / \mathrm{g}$ of BW) for 3 days subcutaneously and the antibiotic Enrofloxacin $(1: 100 \mathrm{v} / \mathrm{v})$ in drinking water for consecutive 10 days. Mice were allowed to recover for at least 3-4 weeks and were subsequently examined for window clarity. Mice were singly housed after cranial window implantation on a $12 \mathrm{~h}$ light/dark cycle with food and water available ad libitum.

\section{Construction of viral vectors and production of viruses}

All lentiviral vectors were based on the FUGW backbone ${ }^{68}$. The eGFP in the original FUGW plasmid was replaced by a $\mathrm{Ca}^{2+}$ indicator Twitch-2B at $\mathrm{BamHI}$ and EcoRI restriction sites to generate FUW-Twitch-2B ${ }^{69}$. Kv1.2wt-T2A and Kir2.1wt-T2A fragments were magnified by PCR (Phusion High-Fidelity PCR Kit, NEB) from pcDNA3-Kv1.2wt (human cDNA template) and Mgi-Kir2.1wt (mouse cDNA template, from Carlos Lois laboratory, Caltech) plasmids and were inserted into FUW-Twitch-2B between Xbal and BamHI restriction enzyme sites. To construct Lenti-Twitch-2B-T2A-H2B-mCherry, H2BmCherry was inserted after Twitch-2B and T2A to enable nuclear-located expression of mCherry. The sequence of T2A used in this study is 5'tgggccaggattctcctcgacgtcaccgcatgttagcagacttcctctgccctctccactgcctaccgg-3' . 
The second generation of virus packaging system was used in this study. Briefly, HEK$293 T$ cells were transiently transfected with plasmids encoding target genes (LentiTwitch-2B-T2A-H2B-mCherry, Lenti-Kv1.2-T2A-Twitch-2B, or Lenti-Kir2.1-T2A-Twitch2B), plus viral packaging helper plasmids pMD2.G (plasmid \#12259, Addgene) and psPAX2 (plasmid \#12260, Addgene) as described previously ${ }^{34}$. The Lipofectamine 3000 reagent (Invitrogen) was used for transfection. To block the $\mathrm{K}^{+}$channel overexpressioninduced reduction of the lentivirus-producing capacity of HEK-293T cells ${ }^{70}, \mathrm{~K}^{+}$channel blocker $\mathrm{Ba}^{2+}(0.3 \mathrm{mM})$ was added to the cell culture medium. 48-72 hours after transfection, cell culture supernatant containing viral particles was collected and concentrated by centrifugation at $135,000 \mathrm{~g}$ at $4^{\circ} \mathrm{C}$ for 2 hours. Concentrated supernatants were resuspended with PBS and titrated in HEK-293T cells. Titers of about $8 \times 10^{9}$ virus particles per $\mathrm{ml}$ concentrated supernatant were used for the following experiments. Retroviral vector Mgi-Kir2.1mut encoding 3 dominant negative site mutations (G144A, Y145A, G146A; Carlos Lois laboratory, Caltech), was packaged in 1F8 cells derived from 293GPG cell line. The vector was derived from a Moloney leukemia virus with an internal promoter from the Rous sarcoma virus. 48 hours after transfection, cell culture supernatant containing the retroviral particles was harvested and concentrated by centrifugation at $135,000 \mathrm{~g}$ at $4^{\circ} \mathrm{C}$ for 6 hours. After concentration, the pellet was resuspended with an as little volume of ice-chilled PBS as possible. Titers above $10^{8}$ particles per $\mathrm{ml}$ supernatant were used for in vivo injections. 


\section{Virus injection into the RMS}

Animals with implanted cranial windows were anesthetized with ketamine/xylazine (80/4 $\mu \mathrm{g} / \mathrm{g}$ of BW) and fixed in a stereotaxic frame. The ointment was used to prevent dehydration of the mouse's eyes and $2 \%$ lidocaine was applied subcutaneously on top of the injection sites. Viruses were stereotactically injected into the RMS at the following coordinates: anterior-posterior $+3.0 \mathrm{~mm}$, medial-lateral \pm 0.83 , and dorsal-ventral -2.95 $\pm 0.05 \mathrm{~mm}$ from the pial surface. Approximately, $0.8-1 \mu \mathrm{l}$ of the virus-containing solution was injected into the RMS of each hemisphere. Thereafter, a metal bar, required for head fixation during the subsequent imaging sessions, was fixed to the caudal part of the skull with dental cement. The other exposed parts of the skull were also covered with dental cement. The mice were returned to the home cage and carprofen ( $5 \mu \mathrm{g} / \mathrm{g}$ of BW) was injected subcutaneously for 3 subsequent days.

\section{In vivo two-photon imaging}

Mice with implanted cranial windows were anesthetized with either isoflurane or an MMF (medetomidine $0.5 \mu \mathrm{g} / \mathrm{g}$ BW, midazolam $5.0 \mu \mathrm{g} / \mathrm{g} \mathrm{BW}$, fentanyl $0.05 \mu \mathrm{g} / \mathrm{g} \mathrm{BW}$ ) anesthesia and placed on a heating plate. Breathing rate and body temperature were monitored continuously using the animal monitoring system (AD Instruments, Sydney, Australia). The head of the mouse was fixed with the metal bar to the $X-Y$ table, ensuring consistent positioning through imaging sessions. In vivo two-photon imaging was performed using an Olympus FV1000 system (Olympus, Tokyo, Japan) with a MaiTai Deep See Laser (Spectra-Physics, Mountain View, CA, USA) and a Zeiss 20x water-immersion objective 
lens (NA 1.0, Carl Zeiss, Jena, Germany). Unless otherwise indicated, cells were imaged using the $890 \mathrm{~nm}$ excitation wavelength.

\section{Imaging migration of adult-born JGCs}

Mice were anesthetized with isoflurane ( $2 \%$ for induction, $0.8-1.0 \%$ for maintenance) and transferred into the imaging setup. The body temperature was kept at $\sim 37^{\circ} \mathrm{C}$. Breathing rate was monitored during the whole imaging session and maintained at $110-140$ breaths per minute by slightly adjusting the isoflurane concentration in $\mathrm{O}_{2}$. To measure the migration speed, the positions of adult-born neurons were monitored every 15 minutes for 4 hours at 8 and 14 dpi according to the previously established protocol ${ }^{34}$. To create landmarks for single-cell tracking, we labeled blood vessels via i.p. injection of sulforhodamine B (0.1 ml/20g BW, $1 \mathrm{mM}$ in PBS, Sigma-Aldrich, St. Louis, USA). In addition, the same FOVs were re-imaged with the same imaging settings at 11,25 , and 45 dpi.

Recording spontaneous and odor-evoked $\mathrm{Ca}^{2+}$ transients of adult-born JGCs

The spontaneous $\mathrm{Ca}^{2+}$ transients were recorded in awake mice. Prior to imaging sessions, the mice were trained for head fixation for 10-12 days, as described in ref. 71. Spontaneous $\mathrm{Ca}^{2+}$ transients of adult-born JGCs were recorded at $12 \mathrm{dpi}$ continuously for 2 minutes with a frame rate of $7-10 \mathrm{~Hz}$. Twitch-2B was excited at $890 \mathrm{~nm}$ and the emitted light was split into 2 channels by a $515 \mathrm{~nm}$ dichroic mirror. The emission light of 
mCerulean3 was filtered with a $475 / 64 \mathrm{~nm}$ band-pass filter and the emission light of cpVenusCD was filtered with a $500 \mathrm{~nm}$ long-pass filter.

The odor-evoked responsiveness of adult-born JGCs was measured at $20 \mathrm{dpi}$. Mice were anesthetized using MMF anesthesia, the temperature was kept at $\sim 37^{\circ} \mathrm{C}$ and the breathing rate was $\sim 140$ breaths per minute during the whole imaging session. Odors were applied through a custom-built flow-dilution olfactometer, positioned in front of the mouse's snout as described previously ${ }^{72}$. Odor mixture containing 2-hexanone, isoamyl acetate, and ethyl tiglate (purchased from Sigma-Aldrich, $0.6 \%$ of saturated vapor each) were applied as a 4-second-long pulse with an inter-pulse interval of at least 2 minutes. The odor delivery was not timed relative to respiration. Each cell was stimulated at least twice, as described in ref. 72 .

\section{Odor deprivation (OD) and two-photon imaging of odor-deprived mice}

Unilateral naris closure was performed at $5 \mathrm{dpi}$. Nose plugs were constructed of $2 \mathrm{~mm}$ polyethylene tube $(0.58 \mathrm{~mm}$ inner diameter, $0.96 \mathrm{~mm}$ outer diameter, Portex, UK) and suture thread (size 3-0, Ethicon, Germany) as described previously ${ }^{34}$. Mice were anesthetized using MMF anesthesia and the plug was accurately inserted into the nostril. Thereafter, mice received an antidote containing flumazenil $(0.5 \mathrm{mg} / \mathrm{kg} \mathrm{BW}$, Fresenius, Germany) and atipamezole (2.5 mg/kg BW, Alfavet, Germany) and returned to their home cages. After naris occlusion, physiological conditions of experimental animals (e.g., breathing, body weight, and stability of nose plug) were monitored carefully every day. Two-photon imaging of odor-deprived mice was conducted under MMF anesthesia, as described above. 


\section{Immunocytochemistry}

Mice were transcardially perfused with $4 \%$ paraformaldehyde (PFA) in PBS. The brains were removed and fixed in $4 \%$ PFA for 24 hours at $4^{\circ} \mathrm{C}$, and then cryoprotected in $25 \%$ sucrose in PBS overnight at $4^{\circ} \mathrm{C}$. Next, the brains were embedded in Tissue Tek (Sakura, Zoeterwoude, Netherlands) and frozen at $-80^{\circ} \mathrm{C}$. The immunostaining was performed on free-floating sagittal cryoslices (thickness $30-50 \mu \mathrm{m}$ ) at room temperature. The sections were incubated in a blocking buffer containing 5\% normal donkey serum (Jackson Immuno Research, Dianova) and 0.1\% Triton-X 100 (Sigma, USA) in PBS for 1 hour to prevent nonspecific background staining. After blocking, the sections were incubated with the primary antibodies diluted in the blocking buffer. Following primary antibodies were used: goat polyclonal antibody against GFP (Rockland 600-101-215, 1:1,000), mouse monoclonal antibody against Kv1.2 (NeuroMab K14/16, 1:200), rabbit monoclonal antibody against pCREB (Cell Signaling 9198S, 1:400), mouse monoclonal antibody against NeuN (Millipore MAB377, 1:1,000). After overnight incubation with primary antibodies at $4{ }^{\circ} \mathrm{C}$, the sections were rinsed in PBS three times for 10 minutes each and incubated with secondary antibodies (2\% BSA and 1\% Triton-X 100 in PBS) for 2 hours in the dark at room temperature. The secondary antibodies were as follows: donkey-antimouse or anti-rabbit IgG-conjugated Alexa Fluor 488 (A21202 or A21206, 1:1,000), donkey-anti-goat IgG-conjugated Alexa Fluor 594 (A11058, 1:1,000), donkey-anti-mouse IgG conjugated Alexa Fluor 680 (A10038, 1:1,000), all purchased from Invitrogen (Grand Island, NY). Afterward, the sections were washed three times in PBS for 10 minutes, transferred to Superfrost Plus charged glass slides (Langenbrink, Emmendingen, 
Germany), and mounted in Vectashield (Vector Laboratories, USA) or ProLong Gold (Invitrogen) mounting medium. Immunostained slices were imaged using an Olympus Fluoview 300 laser scanning microscope (Olympus, Tokyo, Japan) coupled with a MaiTai mode-locked laser (Spectra Physics, Mountain View, CA, USA). Alexa Fluor 488 and 594 were excited at $800 \mathrm{~nm}$ and the emitted light was split by a $570 \mathrm{~nm}$ dichroic mirror and filtered with a 536/40 $\mathrm{nm}$ band-pass filter as well as a $570 \mathrm{~nm}$ long-pass filter. Alexa Fluor 680 was also excited at $800 \mathrm{~nm}$ and the signal was collected in the long-pass channel of a $670 \mathrm{~nm}$ dichroic mirror.

\section{RNA sequencing}

Male 3-month-old mice were bilaterally injected into the RMS with either Lenti-Twitch-2BT2A-H2B-mCherry, Lenti-Kv1.2-T2A-Twitch-2B, or Lenti-Kir2.1-T2A-Twitch-2B viruses and sacrificed at $9 \mathrm{dpi}$. Mice were deeply anesthetized by ketamine/xylazine $(100 / 10 \mu \mathrm{g} / \mathrm{g}$ of BW) and transcardially perfused with $20 \mathrm{~mL}$ ice-cold PBS to empty blood vessels from the blood. Then mice were decapitated and the olfactory bulbs were quickly dissected and transferred into an ice-cold $35 \mathrm{~mm}$ dish containing $0.5 \mathrm{~mL}$ dissection medium (Hank's balanced salt solution containing $15 \mathrm{mM}$ HEPES, $25 \mathrm{mM}$ glucose, $0.4 \mathrm{mg} / \mathrm{mL}$ DNase I, and $80 \mathrm{U} / \mathrm{mL}$ RNAse inhibitor). Olfactory bulbs from two animals were pooled to assure isolation of at least 3000 adult-born cells. Minced tissue was very gently homogenized in an ice-cold dissection medium and passed through a $70 \mu \mathrm{m}$ cell strainer. The filtrate was spin for $10 \mathrm{~min}$ at $250 \mathrm{~g}$ in a refrigerated centrifuge at $4^{\circ} \mathrm{C}$. Pellet was resuspended in $37 \%$ Percoll and centrifuged for $30 \mathrm{~min}$ at $800 \mathrm{~g}$ and $4^{\circ} \mathrm{C}$. First, the upper myelin layer and then supernatant were removed, the pellet was resuspended in sorting buffer (dissection 
medium without DNase I) and centrifuged once again for $10 \mathrm{~min}$ at $800 \mathrm{~g}$ and $4^{\circ} \mathrm{C}$. Finally, isolated cells were resuspended in sorting buffer and kept on ice until sorting. Adult-born cells expressing Twitch-2B were separated by fluorescence-activated cell sorting on a Sony SH800Z sorter (Sony Biotechnology Inc, Surrey, UK) immediately after staining samples with propidium iodide (PI). Single cells were selected based on FSC-W/FSC-H gating, dead cells were excluded based on the PI-signals and transduced cells were identified by their Twitch-2B signal (using a 450/50 bandpass filter). Single Twitch-2Bexpressing cells were sorted directly into Eppendorf tubes containing $10 \mu \mathrm{L}$ sorting buffer, immediately frozen in liquid nitrogen, and kept at $-80^{\circ} \mathrm{C}$ until libraries for RNA-sequencing analysis were prepared.

The synthesis of the cDNA was performed using the SMART-Seq v4 Ultra Low Input RNA Kit (Takara Bio). 3,000 to 4,500 frozen sorted cells were lysed using a concentration of 100 cells per $\mu$ l of lysis buffer. Lysis was performed by resuspending the cells by pipetting and incubation for 5 minutes at room temperature. First-strand cDNA synthesis was performed using $5 \mu \mathrm{l}$ of cDNA for $90 \mathrm{~min}$ at $42^{\circ} \mathrm{C}$. Amplification of the full-length doublestrand cDNA was monitored by qPCR and was stopped at 17 PCR cycles during the linear amplification phase. The resulting cDNA presented a fragment size distribution of 1,500 up to $5,000 \mathrm{bp}$ on the Bioanalyzer High Sensitivity DNA Kit (Agilent) and a concentration above $300 \mathrm{pg} / \mu \mathrm{l}$ measured with Qubit dsDNA HS fluorometric quantification (ThermoFisher Scientific). Next-generation sequencing (NGS) libraries were prepared using 150 pg of cDNA input in the Nextera XT DNA Library Preparation Kit (Illumina), followed by 12 cycles of PCR. Final libraries had a mean fragment size of 370 bp on the Bioanalyzer, a concentration $>5 \mathrm{ng} / \mu \mathrm{L}$, and molarity of $>30 \mathrm{nmol} / \mathrm{L}$ measured with Qubit. 
Libraries were sequenced as single reads ( 75 bp read length) on a NextSeq500 (Illumina) with a depth of $>20$ million reads. Library preparation and sequencing procedures were performed by the same individual and a design aimed to minimize technical batch effects was chosen.

\section{Quantitative real-time PCR}

Reverse transcribed RNA from sorted cells was generated by SMART-Seq v4 Ultra Low Input RNA Kit (Takara Bio). Real-time PCR was performed using a Fast SYBR green PCR Master Mix (Applied Biosystems) and the QuantStudio ${ }^{\text {TM }} 5$ equipment (Applied Biosystems, Germany). Specific primers (Supplementary Table 3) were designed using the NCBI tool primer BLAST selecting those sequences that span an exon-exon junction to avoid amplification of any contaminating genomic DNA. Three biological samples were determined in triplicate. Single product amplification was confirmed running the melting curves. Input quantities were normalized to those for glyceraldehyde 3-phosphate dehydrogenase (Gapdh) and the relative mRNA expression was estimated by the efficiency corrected method ${ }^{73}$.

\section{Analyses}

\section{Calculation of the migration speed of adult-born JGCs}

The migration speed of adult-born JGCs was analyzed as described previously ${ }^{34}$. The 3D image stacks acquired during the consecutive imaging sessions (containing both adultborn JGCs and blood vessels) were aligned offline using the blood vessel pattern as an anatomical landmark. Each cell received an identification number and its position (the 
center of the cell's soma) was identified in each of 17 stacks (0-4 hours, 15 min interstack interval), enabling the reconstruction of the cell's trajectory. Next, the $X-Y$ coordinates of each cell's position were readout using the Fluoview 3.0 Viewer (Olympus). For Z-axis coordinates, the depth of the cells was the relative depth from the dura. With 3D coordinates for each position point, migration distance (D) between the two points in space was calculated according to the following formula:

$$
D=\sqrt{(X 1-X 0)^{2}+(Y 1-Y 0)^{2}+(Z 1-Z 0)^{2}}
$$

where $(X 1, Y 1, Z 1)$ and $(X 0, Y 0, Z 0)$ were coordinates of the cell's position in the current and the immediately preceding stacks, respectively. Migration speed was defined as the translocation of the cell's soma between the two consecutive time points divided by the respective time interval ( $\mu \mathrm{m}$ per 15 minutes). Because the step size of the acquired stacks was $2 \mu \mathrm{m}$, a cell was considered moving if the translocation of the cell's soma between the two consecutive time points was more than $4 \mu \mathrm{m}$.

\section{Analyses of spontaneous $\mathrm{Ca}^{2+}$ transients}

Data analysis was performed offline with ImageJ and custom-made routine in Matlab (R2016b, The MathWorks, United States). Circular regions of interest (ROls) were manually drawn within the soma of each cell. Fluorescence trace for each cell was obtained by averaging all pixels within the ROI. The background signal was obtained from the ROI of the comparable size devoid of fluorescent processes and located near the cell of interest. The image stack was separated into 2 substacks for mCerulean3 and cpVenus $^{\mathrm{CD}}$ channels, respectively. The fluorescence traces were calculated separately for 
both substacks and filtered using a lowpass Butterworth infinite impulse response filter with a cut-off frequency of $0.6 \mathrm{~Hz}$. The Twitch-2B ratio signal was calculated using the formula:

$$
\text { Ratio }=\frac{F\left(\text { cpVenus }^{\mathrm{CD}}\right) \text { Soma }-\mathrm{F}\left(\text { cpVenus }^{\mathrm{CD}}\right) \text { Background }}{\mathrm{F} \text { (mCerulean3)Soma }-\mathrm{F}(\text { mCerulean3)Background }}
$$

Thereafter, the traces were imported into Matlab to analyze the following parameters: basal and maximum Twitch-2B ratio and the area under the curve normalized to the total recording time $\left(\mathrm{AUC} / \mathrm{sec}^{21}\right)$. The basal ratio was the mean of the lowest $10 \%$ data points in the histogram of each individual trace. The value for the maximum ratio was calculated as follows: the filtered traces were processed by a sliding average algorithm with a window size of 1.5 seconds to determine the maximum ratio (maximum average value). Parameters of $\mathrm{Ca}^{2+}$ fluctuations were also analyzed in Matlab. The difference between oscillation patterns has been used to compare experimental and control groups. The fluctuations in $\mathrm{Ca}^{2+}$ signals were detected using the mid-reference level crossing approach (function midcross in Matlab) and the numbers of crossing points, passing through the mid-reference level, per trace were counted. The Gaussian mixture model ${ }^{42}$ was used to explore and detect the naturally existing clusters among the counted numbers of crossing points. The correct number of clusters has been estimated using Bayesian information criterion ${ }^{74}$. Assigned cluster labels (i.e., with and without fluctuations in $\mathrm{Ca}^{2+}$ signals) have been used to calculate the fraction of each cluster in a given experimental group. Subsequently, these fractions were compared statistically using ANOVA. 
Analyses of odor-evoked responsiveness of adult-born JGCs

The odor-evoked $\mathrm{Ca}^{2+}$ transients of individual neurons were detected with a customwritten Igor Pro routine (WaveMetrics Inc., OR 97035 USA). First, background fluorescence, measured in the neuropil surrounding the adult-born JGCs, was subtracted as described above and the Twitch-2B ratio signals were calculated and expressed as relative Twitch-2B ratio changes $(\Delta R / R)$. For automatic detection of responding cells, all $\Delta R / R$ traces were smoothed with a binomial filter (time window $0.3 \mathrm{~s}$ ). Each smoothed trace was subtracted from the original $\Delta R / R$ trace, resulting in the "baseline noise" trace. $\Delta R / R$ transients were automatically detected with a template-matching algorithm, taking into account their sharp rise. $A \Delta R / R$ change was recognized as an odor-evoked $\mathrm{Ca}^{2+}$ transient if its amplitude was three times larger than the standard deviation of the corresponding baseline noise.

\section{Sholl analyses}

The dendritic morphology of adult-born JGCs was analyzed both in vivo and in situ. The three-dimensional stacks were imported into Neuromantic software (https://www.reading.ac.uk/neuromantic/body index.php) for 3D reconstruction. Neuronal morphology was manually traced to obtain accurate reconstructions. Digitally reconstructed neurons were imported into Image $\mathrm{J}$ and analyzed with the Simple Neurite Tracer plugin. The following morphological parameters were read out: the number of dendritic branches and the total dendritic branch length (TDBL). Sholl analysis was performed by counting the number of intersections between dendrites and centered on the soma concentric spheres with $10 \mu \mathrm{m}$ radius increments ${ }^{75}$. 
Analyses of the survival rate

All FOVs including cells and blood vessels were imaged at 14, 25, and 45 dpi under the same settings. The size of each image stack was $635 \mu \mathrm{m} \times 635 \mu \mathrm{m} \times 200 \mu \mathrm{m}(\mathrm{XYZ})$. To minimize the effects of cell migration, a safe margin amounting to $100 \mu \mathrm{m} \times 100 \mu \mathrm{m}(\mathrm{XY})$ from the image border was introduced, and cells residing within the margin area were excluded from the analysis. By using blood vessels as a landmark, a cell was considered surviving if its soma was found at the same position in both image stacks (14 and 25 dpi, or 25 and $45 \mathrm{dpi}$ ). An offset of $\leq 4 \mu \mathrm{m}$ was tolerated due to the resolution of the microscope.

Analyses of the pCREB expression level and quantification of the Kv1.2 expression

All brain slices were stained and imaged under the same conditions (i.e., antibody concentration, incubation time, laser power, photomultiplier voltage, etc.). Backgroundsubtracted images were generated by estimating background noise from 5 negative control slices, which were stained with secondary antibodies only, and subtracting the median noise value from the original images. Each slice was simultaneously stained with anti-pCREB, anti-GFP (recognizes Twitch-2B), and anti-NeuN antibodies, with secondary antibodies conjugated with Alexa Fluro-488, 594, and 680, respectively. All images were processed using the following protocol in ImageJ: (i) generate 3 substacks for pCREB, GFP, and NeuN staining by splitting the original 3D stack; (ii) draw the ROls for the adultborn JGCs on the central slice (Z-axis) of the GFP (Twitch-2B) stack; (iii) find the corresponding frame (same depth) in the NeuN stack; (iv) subtract the median background noise value from the NeuN stack; (v) adjust the threshold of the image to 
highlight all NeuN positive regions and draw ROls for NeuN-positive cells in the whole field of view; (vi) measure the fluorescence intensity of NeuN-positive mature neurons and GFP-positive adult-born JGCs in the stack of pCREB; (vii) calculate the relative pCREB expression level as the intensity of pCREB fluorescence of each GFP-positive adult-born JGC divided by the median intensity of all NeuN positive mature neurons located in the same field of view.

For quantification of the Kv1.2 expression, the background-subtracted images were generated as described above and a custom-written Matlab code was used to calculate separately the intensity of immunofluorescence in the cell somata and the surrounding neuropil. The relative Kv1.2 expression level was calculated as the ratio of the somatic fluorescence divided by the fluorescence of the surrounding neuropil.

\section{Transcriptomic analyses}

Read quality of RNA-seq data in fastq files was assessed with ReadQC (ngs-bits version 2019_09). Raw reads were filtered to remove sequencing adapters and for quality trimming using SeqPurge (ngs-bits version 2019_09). Filtered reads were aligned against the reference mouse genome of the Ensembl Mus Musculus GRCm38 using STAR (v2.7.0f), allowing gapped alignments to account for splicing. Low mapping quality reads or those mispairing or multi-mapping were removed using Samtools (v1.9) and visually inspected in the Integrative Genome Viewer (v2.4.19). A matrix of raw counts was built using subread (v1.6.4). Low expressed transcripts were filtered out to minimize the falsepositive rate. For each dataset, all transcripts with less than 1 count per million in at least two samples were excluded, leaving 11,611 genes for further differential expression 
analysis. Differentially expressed genes (DEGs) were identified using edgeR (v.3.24.3) with R (v3.5.2) (https://www.R-project.org/) following the standard workflow. With this method, the size of the library is corrected and differential expression is tested by using negative binomial generalized linear models ${ }^{76}$. Genes with an absolute $>2$-times-fold change between the control and Kv1.2/Kir2.1 groups were considered as DEGs and imported into the online portal Metascape (https://metascape.org/gp/index.html\#/main/step1) to run GO biological processes, cell components, molecular functions, and KEGG pathway enrichment analyses ${ }^{77}$. In this study, the focus was on signaling pathways downstream of $p C R E B$ as well as on the routes leading to CREB phosphorylation.

\section{Statistics}

Statistical analyses were performed using the GraphPad Prism 9 software (GraphPad Software Inc, San Diego, California USA). Shapiro-Wilk test was used to check the normality of data distribution within the data sets. $P<0.05$ was considered statistically significant. In the case of normally distributed data, the parametric (i.e., Student's t-test or ANOVA followed by Tukey's multiple comparison test) otherwise nonparametric (i.e., Mann-Whitney U test or Kruskal-Wallis test followed by Dunn's multiple comparisons test) tests were used. For Sholl analysis, we used the generalized mixed-effects model with Poisson family (R programming language (Team, 2013) with Ime4 package (Bates et al., 2015)). P-values were obtained using ImerTest package, which estimates p-values based on Satterthwaite approximation (Kuznetsova et al., 2017). Post-hoc comparisons were done using Ismeans package (Lenth, 2016). Box plots were used to present 5 parameters 
bioRxiv preprint doi: https://doi.org/10.1101/2021.04.21.440775; this version posted April 22, 2021. The copyright holder for this preprint (which was not certified by peer review) is the author/funder. All rights reserved. No reuse allowed without permission.

of the dataset: 10 th, 25 th percentile, median, 75 th, and 90 th percentile. Unless otherwise indicated, the error bars represent median \pm IQR (interquartile range). 


\section{References}

Allen, N.M., Weckhuysen, S., Gorman, K., King, M.D., and Lerche, H. (2020). Genetic potassium channel-associated epilepsies: Clinical review of the Kv family. Eur J Paediatr Neurol 24, 105-116.

Alonso, M., Lepousez, G., Sebastien, W., Bardy, C., Gabellec, M.M., Torquet, N., and Lledo, P.M. (2012). Activation of adult-born neurons facilitates learning and memory. Nat Neurosci 15, 897-904.

Alonso, M., Viollet, C., Gabellec, M.M., Meas-Yedid, V., Olivo-Marin, J.C., and Lledo, P.M. (2006). Olfactory discrimination learning increases the survival of adult-born neurons in the olfactory bulb. J Neurosci $26,10508-10513$.

Babij, R., and De Marco Garcia, N. (2016). Neuronal activity controls the development of interneurons in the somatosensory cortex. Front Biol (Beijing) 11, 459-470.

Bando, Y., Hirano, T., and Tagawa, Y. (2014). Dysfunction of KCNK potassium channels impairs neuronal migration in the developing mouse cerebral cortex. Cereb Cortex 24, 1017-1029. Bando, Y., Irie, K., Shimomura, T., Umeshima, H., Kushida, Y., Kengaku, M., Fujiyoshi, Y., Hirano, T., and Tagawa, Y. (2016). Control of Spontaneous $\mathrm{Ca}^{2+}$ Transients Is Critical for Neuronal Maturation in the Developing Neocortex. Cereb Cortex 26, 106-117.

Bates, D., Machler, M., Bolker, B.M., and Walker, S.C. (2015). Fitting Linear Mixed-Effects Models Using Ime4. J Stat Softw 67, 1-48.

Bitzenhofer, S.H., Popplau, J.A., Chini, M., Marquardt, A., and Hanganu-Opatz, I.L. (2021). A transient developmental increase in prefrontal activity alters network maturation and causes cognitive dysfunction in adult mice. Neuron 109, 1350-1364.

Bovetti, S., Veyrac, A., Peretto, P., Fasolo, A., and De Marchis, S. (2009). Olfactory enrichment 
influences adult neurogenesis modulating GAD67 and plasticity-related molecules expression in newborn cells of the olfactory bulb. PLoS One 4, e6359.

Cancedda, L., Fiumelli, H., Chen, K., and Poo, M.M. (2007). Excitatory GABA action is essential for morphological maturation of cortical neurons in vivo. J Neurosci 27, 5224-5235.

Carleton, A., Petreanu, L.T., Lansford, R., Alvarez-Buylla, A., and Lledo, P.M. (2003). Becoming a new neuron in the adult olfactory bulb. Nat Neurosci 6, 507-518.

Ch'ng, T.H., Uzgil, B., Lin, P., Avliyakulov, N.K., O'Dell, T.J., and Martin, K.C. (2012). Activitydependent transport of the transcriptional coactivator CRTC1 from synapse to nucleus. Cell 150, 207-221.

Cohen, S.M., Suutari, B., He, X., Wang, Y., Sanchez, S., Tirko, N.N., Mandelberg, N.J., Mullins, C., Zhou, G., Wang, S., et al. (2018). Calmodulin shuttling mediates cytonuclear signaling to trigger experience-dependent transcription and memory. Nat Commun 9, 2451.

Corotto, F.S., Henegars, J.R., and Maruniak, J.A. (1994). Odor deprivation leads to reduced neurogenesis and reduced neuronal survival in the olfactory bulb of the adult mouse. Neuroscience 61, 739-744.

Dahlen, J.E., Jimenez, D.A., Gerkin, R.C., and Urban, N.N. (2011). Morphological analysis of activity-reduced adult-born neurons in the mouse olfactory bulb. Front Neurosci 5, 66.

Darcy, D.P., and Isaacson, J.S. (2009). L-type calcium channels govern calcium signaling in migrating newborn neurons in the postnatal olfactory bulb. J Neurosci 29, 2510-2518.

De Marco Garcia, N.V., Karayannis, T., and Fishell, G. (2011). Neuronal activity is required for the development of specific cortical interneuron subtypes. Nature 472, 351-355.

Deisseroth, K., Singla, S., Toda, H., Monje, M., Palmer, T.D., and Malenka, R.C. (2004). Excitation-Neurogenesis Coupling in Adult Neural Stem Progenitor Cells. Neuron 42, 535- 
552.

Faigle, R., and Song, H. (2013). Signaling mechanisms regulating adult neural stem cells and neurogenesis. Biochim Biophys Acta 1830, 2435-2448.

Fomin-Thunemann, N., Kovalchuk, Y., Fink, S., Alsema, A., Mojtahedi, N., Zirdum, E., and Garaschuk, O. (2020). Unique Functional Properties of Mature Adult-Born Neurons in the Mouse Olfactory Bulb. Stem cell reports 15, 1333-1346.

García-González, D., Khodosevich, K., Watanabe, Y., Rollenhagen, A., L bke, J.H.R., and Monyer, H. (2017). Serotonergic Projections Govern Postnatal Neuroblast Migration. Neuron 94, 534-549.e539.

Giachino, C., De Marchis, S., Giampietro, C., Parlato, R., Perroteau, I., Schutz, G., Fasolo, A., and Peretto, P. (2005). cAMP response element-binding protein regulates differentiation and survival of newborn neurons in the olfactory bulb. J Neurosci 25, 10105-10118.

Grelat, A., Benoit, L., Wagner, S., Moigneu, C., Lledo, P.M., and Alonso, M. (2018). Adult-born neurons boost odor-reward association. Proceedings of the National Academy of Sciences of the United States of America 115, 2514-2519.

Herold, S., Jagasia, R., Merz, K., Wassmer, K., and Lie, D.C. (2011). CREB signalling regulates early survival, neuronal gene expression and morphological development in adult subventricular zone neurogenesis. Mol Cell Neurosci 46, 79-88.

Homma, R., Kovalchuk, Y., Konnerth, A., Cohen, L.B., and Garaschuk, O. (2013). In vivo functional properties of juxtaglomerular neurons in the mouse olfactory bulb. Front Neural Circuits 7, 23.

Hurni, N., Kolodziejczak, M., Tomasello, U., Badia, J., Jacobshagen, M., Prados, J., and Dayer, A. (2017). Transient Cell-intrinsic Activity Regulates the Migration and Laminar 
Positioning of Cortical Projection Neurons. Cereb Cortex 27, 3052-3063.

Jagasia, R., Steib, K., Englberger, E., Herold, S., Faus-Kessler, T., Saxe, M., Gage, F.H., Song,

H., and Lie, D.C. (2009). GABA-CAMP response element-binding protein signaling regulates maturation and survival of newly generated neurons in the adult hippocampus. J Neurosci 29, 7966-7977.

Kelsch, W., Lin, C.W., Mosley, C.P., and Lois, C. (2009). A critical period for activity-dependent synaptic development during olfactory bulb adult neurogenesis. J Neurosci 29, 1185211858.

Kikuta, S., Kashiwadani, H., and Mori, K. (2008). Compensatory rapid switching of binasal inputs in the olfactory cortex. J Neurosci $28,11989-11997$.

Kovacs, K.A., Steullet, P., Steinmann, M., Do, K.Q., Magistretti, P.J., Halfon, O., and Cardinaux, J.R. (2007). TORC1 is a calcium- and cAMP-sensitive coincidence detector involved in hippocampal long-term synaptic plasticity. Proceedings of the National Academy of Sciences of the United States of America 104, 4700-4705.

Kovalchuk, Y., Homma, R., Liang, Y., Maslyukov, A., Hermes, M., Thestrup, T., Griesbeck, O., Ninkovic, J., Cohen, L.B., and Garaschuk, O. (2015). In vivo odourant response properties of migrating adult-born neurons in the mouse olfactory bulb. Nat Commun 6 , 6349.

Kuznetsova, A., Brockhoff, P.B., and Christensen, R.H.B. (2017). ImerTest Package: Tests in Linear Mixed Effects Models. J Stat Softw 82, 1-26.

Lacar, B., Young, S.Z., Platel, J.C., and Bordey, A. (2011). Gap junction-mediated calcium waves define communication networks among murine postnatal neural progenitor cells. Eur J Neurosci 34, 1895-1905. 
Lenth, R.V. (2016). Least-Squares Means: The R Package Ismeans. J Stat Softw 69, 1-33.

Li, S., Zhang, C., Takemori, H., Zhou, Y., and Xiong, Z.Q. (2009). TORC1 regulates activitydependent CREB-target gene transcription and dendritic growth of developing cortical neurons. J Neurosci 29, 2334-2343.

Li, W.L., Chu, M.W., Wu, A., Suzuki, Y., Imayoshi, I., and Komiyama, T. (2018). Adult-born neurons facilitate olfactory bulb pattern separation during task engagement. Elife.

Liang, Y., Li, K., Riecken, K., Maslyukov, A., Gomez-Nicola, D., Kovalchuk, Y., Fehse, B., and Garaschuk, O. (2016). Long-term in vivo single-cell tracking reveals the switch of migration patterns in adult-born juxtaglomerular cells of the mouse olfactory bulb. Cell Res 26, 805-821.

Lin, C.W., Sim, S., Ainsworth, A., Okada, M., Kelsch, W., and Lois, C. (2010). Genetically increased cell-intrinsic excitability enhances neuronal integration into adult brain circuits. Neuron 65, 32-39.

Livneh, Y., Adam, Y., and Mizrahi, A. (2014). Odor Processing by Adult-Born Neurons. Neuron $81,1097-1110$

Lledo, P.M., Alonso, M., and Grubb, M.S. (2006). Adult neurogenesis and functional plasticity in neuronal circuits. Nat Rev Neurosci 7, 179-193.

Lledo, P.M., Merkle, F.T., and Alvarez-Buylla, A. (2008). Origin and function of olfactory bulb interneuron diversity. Trends Neurosci 31, 392-400.

Lois, C., and Alvarez-Buylla, A. (1994). Long-Distance Neuronal Migration in the Adult Mammalian Brain. Science 264, 1145-1148.

Lois, C., Hong, E., Pease, S., Brown, E., and Baltimore, D. (2002). Germline transmission and tissue-specific expression of transgenes delivered by lentiviral vectors. Science 295,868 - 
872.

Love, M.I., Huber, W., and Anders, S. (2014). Moderated estimation of fold change and dispersion for RNA-seq data with DESeq2. Genome Biol 15, 550.

Ma, H., Groth, Rachel D., Cohen, Samuel M., Emery, John F., Li, B., Hoedt, E., Zhang, G., Neubert, Thomas A., and Tsien, Richard W. (2014). YCaMKII Shuttles $\mathrm{Ca}^{2+} / \mathrm{CaM}$ to the Nucleus to Trigger CREB Phosphorylation and Gene Expression. Cell 159, 281-294.

Mandairon, N., Jourdan, F., and Didier, A. (2003). Deprivation of sensory inputs to the olfactory bulb up-regulates cell death and proliferation in the subventricular zone of adult mice. Neuroscience 119, 507-516.

Mandairon, N., Sacquet, J., Jourdan, F., and Didier, A. (2006). Long-term fate and distribution of newborn cells in the adult mouse olfactory bulb: Influences of olfactory deprivation. Neuroscience $141,443-451$.

Maslyukov, A., Li, K., Su, X., Kovalchuk, Y., and Garaschuk, O. (2018). Spontaneous calcium transients in the immature adult-born neurons of the olfactory bulb. Cell Calcium 74, 4352.

Masnada, S., Hedrich, U.B.S., Gardella, E., Schubert, J., Kaiwar, C., Klee, E.W., Lanpher, B.C., Gavrilova, R.H., Synofzik, M., Bast, T., et al. (2017). Clinical spectrum and genotypephenotype associations of KCNA2-related encephalopathies. Brain: a journal of neurology 140, 2337-2354.

McLachlan, G., and Peel, D. (2000). Finite mixture models.

Merz, K., Herold, S., and Lie, D.C. (2011). CREB in adult neurogenesis--master and partner in the development of adult-born neurons? Eur J Neurosci 33, 1078-1086.

Mizrahi, A. (2007). Dendritic development and plasticity of adult-born neurons in the mouse 
olfactory bulb. Nat Neurosci $10,444-452$.

Molnar, Z., Luhmann, H.J., and Kanold, P.O. (2020). Transient cortical circuits match spontaneous and sensory-driven activity during development. Science 370.

Moreno, M.M., Linster, C., Escanilla, O., Sacquet, J., Didier, A., and Mandairon, N. (2009). Olfactory perceptual learning requires adult neurogenesis. Proceedings of the National Academy of Sciences of the United States of America 106, 17980-17985.

Okada, M., Andharia, N., and Matsuda, H. (2015). Increase in the titer of lentiviral vectors expressing potassium channels by current blockade during viral vector production. BMC Neurosci 16, 30.

Parra-Damas, A., Rubio-Ferrarons, L., Shen, J., and Saura, C.A. (2017). CRTC1 mediates preferential transcription at neuronal activity-regulated CRE/TATA promoters. Scientific reports 7, 18004.

Petreanu, L., and Alvarez-Buylla, A. (2002). Maturation and death of adult-born olfactory bulb granule neurons role of olfaction. J Neurosci 22, 6106-6113.

Pfaffl, M.W. (2001). A new mathematical model for relative quantification in real-time RT-PCR. Nucleic Acids Research 29, e45.

Piatti, V.C., Davies-Sala, M.G., Esposito, M.S., Mongiat, L.A., Trinchero, M.F., and Schinder, A.F. (2011). The timing for neuronal maturation in the adult hippocampus is modulated by local network activity. J Neurosci 31, 7715-7728.

Platel, J.-C., Lacar, B., and Bordey, A. (2007). GABA and glutamate signaling: homeostatic control of adult forebrain neurogenesis. Journal of Molecular Histology 38, 303-311.

Platel, J.C., Angelova, A., Bugeon, S., Wallace, J., Ganay, T., Chudotvorova, I., Deloulme, J.C., Beclin, C., Tiveron, M.C., Core, N., et al. (2019). Neuronal integration in the adult mouse 
olfactory bulb is a non-selective addition process. Elife 8.

Pothayee, N., Cummings, D.M., Schoenfeld, T.J., Dodd, S., Cameron, H.A., Belluscio, L., and Koretsky, A.P. (2017). Magnetic resonance imaging of odorant activity-dependent migration of neural precursor cells and olfactory bulb growth. Neuroimage 158, 232-241.

Preisig-Muller, R., Schlichthorl, G., Goerge, T., Heinen, S., Bruggemann, A., Rajan, S., Derst, C., Veh, R.W., and Daut, J. (2002). Heteromerization of Kir2.x potassium channels contributes to the phenotype of Andersen's syndrome. Proceedings of the National Academy of Sciences of the United States of America 99, 7774-7779.

Rochefort, C., Gheusi, G., Vincent, J.D., and Lledo, P.M. (2002). Enriched odor exposure increases the number of newborn neurons in the adult olfactory bulb and improves odor memory. J Neurosci 22, 2679-2689.

Saghatelyan, A., de Chevigny, A., Schachner, M., and Lledo, P.M. (2004). Tenascin-R mediates activity-dependent recruitment of neuroblasts in the adult mouse forebrain. Nat Neurosci 7, 347-356.

Saghatelyan, A., Roux, P., Migliore, M., Rochefort, C., Desmaisons, D., Charneau, P., Shepherd, G.M., and Lledo, P.-M. (2005). Activity-Dependent Adjustments of the Inhibitory Network in the Olfactory Bulb following Early Postnatal Deprivation. Neuron 46, 103-116.

Saraf, J., Bhattacharya, P., Kalia, K., Borah, A., Sarmah, D., Kaur, H., Dave, K.R., and Yavagal, D.R. (2018). A Friend or Foe: Calcineurin across the Gamut of Neurological Disorders. ACS Central Science 4, 805-819.

Shah, N.H., and Aizenman, E. (2014). Voltage-Gated Potassium Channels at the Crossroads of Neuronal Function, Ischemic Tolerance, and Neurodegeneration. Translational Stroke 
Research 5, 38-58.

Shani-Narkiss, H., Vinograd, A., Landau, I.D., Tasaka, G., Yayon, N., Terletsky, S., Groysman, M., Maor, I., Sompolinsky, H., and Mizrahi, A. (2020). Young adult-born neurons improve odor coding by mitral cells. Nat Commun 11, 5867.

Sholl, D.A. (1953). Dendritic orgnization in the neurons of the visual and motor cortices of the cat. J Anatomy 87, 387-406.

Stéphane, B., Clara, H., Alexandre, R., Harold, C., and Jean-Claude, P. (2020). Intrinsic neuronal activity during migration controls the recruitment of specific interneuron subtypes in the postnatal mouse olfactory bulb. bioRxiv.

Su, X., Kovalchuk, Y., Mojtahedi, N., and Garaschuk, O. (2020). Enhanced ongoing endogenous activity predicts elimination of adultborn neurons in the mouse olfactory bulb. bioRxiv.

Sultan, S., Lefort, J.M., Sacquet, J., Mandairon, N., and Didier, A. (2011). Acquisition of an olfactory associative task triggers a regionalized down-regulation of adult born neuron cell death. Front Neurosci 5, 52.

Sultan, S., Mandairon, N., Kermen, F., Garcia, S., Sacquet, J., and Didier, A. (2010). Learningdependent neurogenesis in the olfactory bulb determines long-term olfactory memory. FASEB J 24, 2355-2363.

Syrbe, S., Hedrich, U.B.S., Riesch, E., Djémié, T., M ller, S., Møller, R.S., Maher, B., Hernandez-Hernandez, L., Synofzik, M., Caglayan, H.S., et al. (2015). De novo loss- or gain-of-function mutations in KCNA2 cause epileptic encephalopathy. Nature Genetics 47, 393-399.

Team, R.C. (2013). R: A language and environment for statistical computing. . Foundation for 
Statistical Computing, Vienna, Austria

Thestrup, T., Litzlbauer, J., Bartholomaus, I., Mues, M., Russo, L., Dana, H., Kovalchuk, Y., Liang, Y., Kalamakis, G., Laukat, Y., et al. (2014). Optimized ratiometric calcium sensors for functional in vivo imaging of neurons and T lymphocytes. Nat Methods 11, 175-182.

Villa, C., and Combi, R. (2016). Potassium Channels and Human Epileptic Phenotypes: An Updated Overview. Frontiers in Cellular Neuroscience 10.

Wallace, J.L., Wienisch, M., and Murthy, V.N. (2017). Development and Refinement of Functional Properties of Adult-Born Neurons. Neuron 96, 883-897.

Wit, E., Heuvel, E.v.d., and Romeijn, J.-W. (2012). 'All models are wrong...': an introduction to model uncertainty. Statistica Neerlandica 66, 217-236.

Yamaguchi, M., and Mori, K. (2005). Critical period for sensory experience-dependent survival of newly generated granule cells in the adult mouse olfactory bulb. Proceedings of the National Academy of Sciences of the United States of America 102, 9697-9702.

Zhou, Y., Zhou, B., Pache, L., Chang, M., Khodabakhshi, A.H., Tanaseichuk, O., Benner, C., and Chanda, S.K. (2019). Metascape provides a biologist-oriented resource for the analysis of systems-level datasets. Nat Commun 10, 1523. 
Fig. 1

bioRxiv preprint doi: https://doi.org/10.1101/2021.04.21.440775; this version posted April 22, 2021. The copyright holder for this preprint (which was not certified by peer review) is the author/funder. All rights reserved. No reuse allowed without permission.

A

Ubia Twitch-2B T2A H2B-mCherry WPREUbia Kv1.2 T2A Twitch-2B WPREUbiq Kir2.1 T2A Twitch-2B WPRE-

C

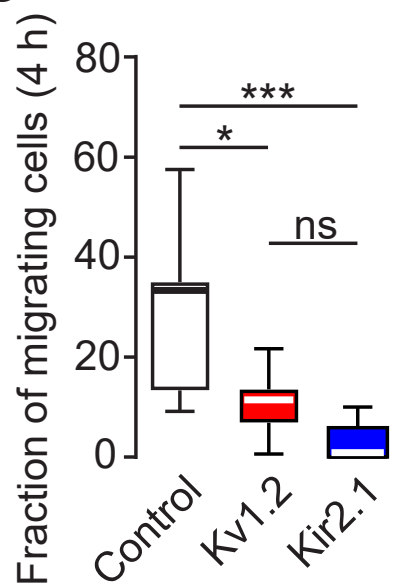

$\mathrm{E}$

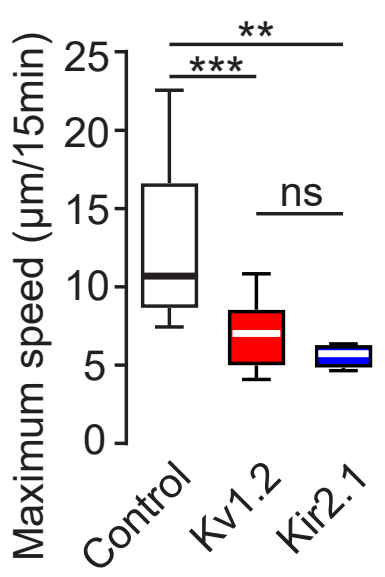

I

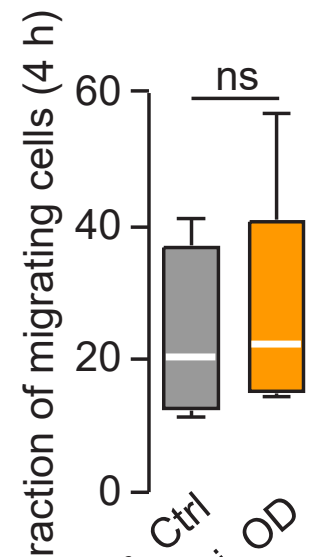

ㄴ.

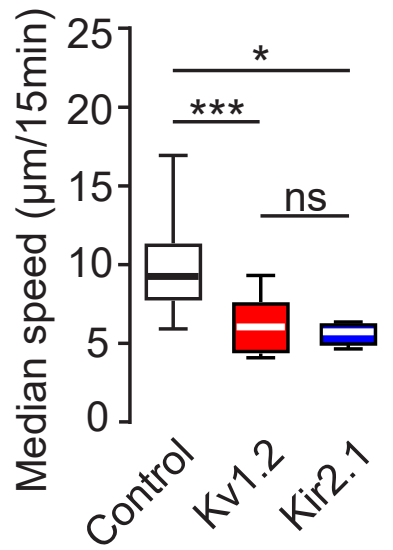

F

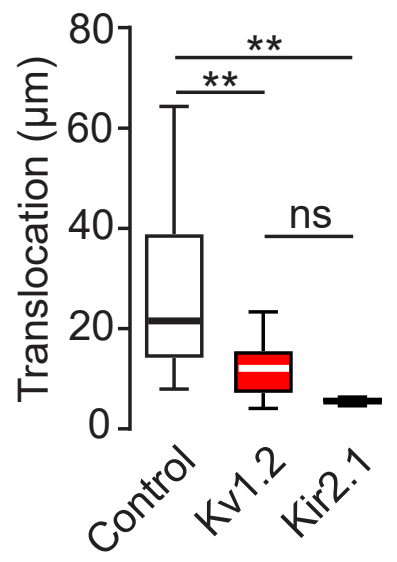

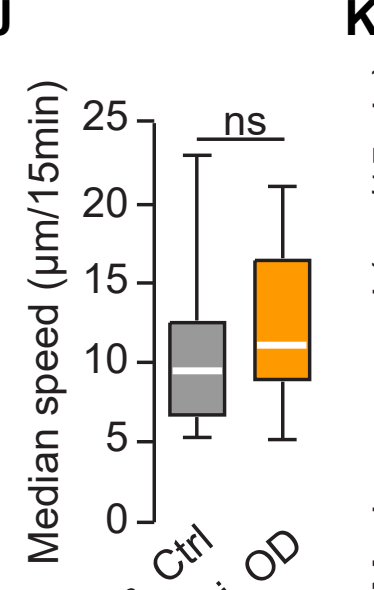

B
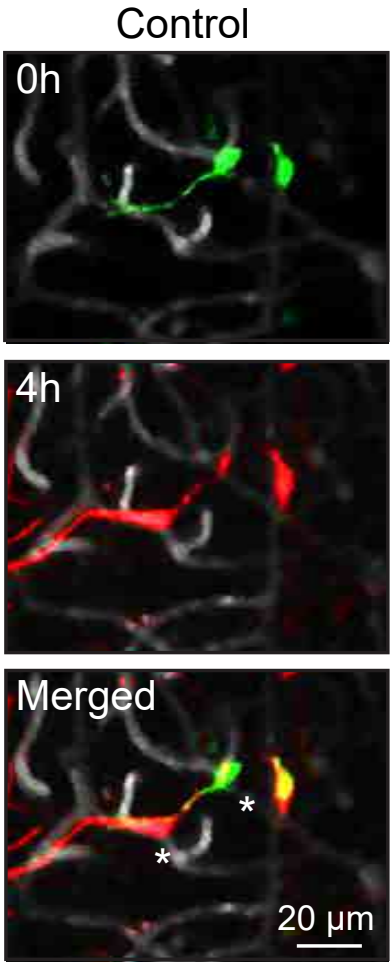

G

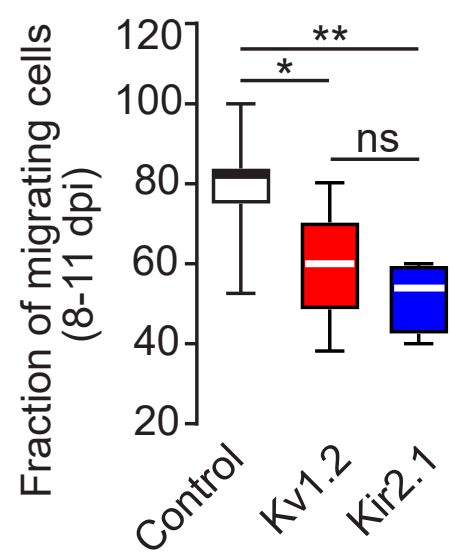

L

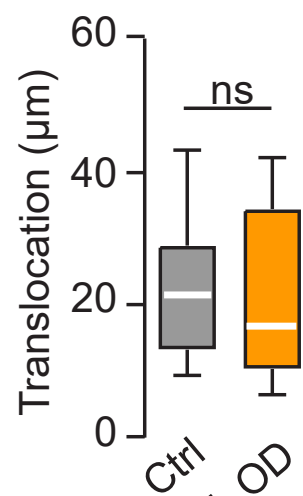

Kv1.2
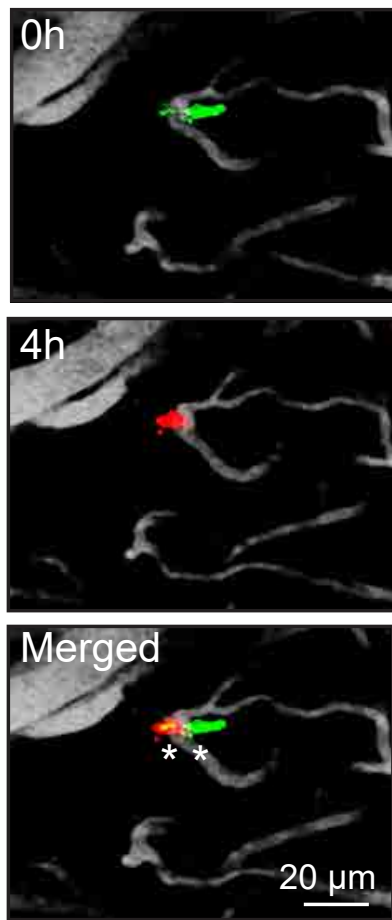

H

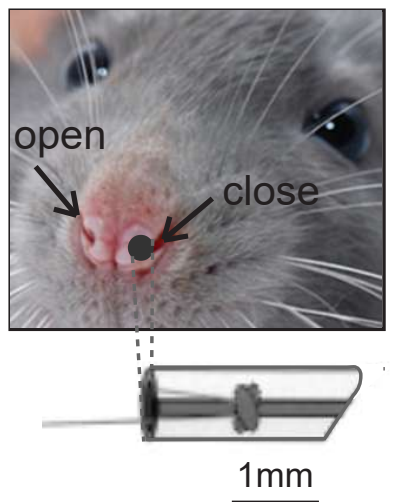

M

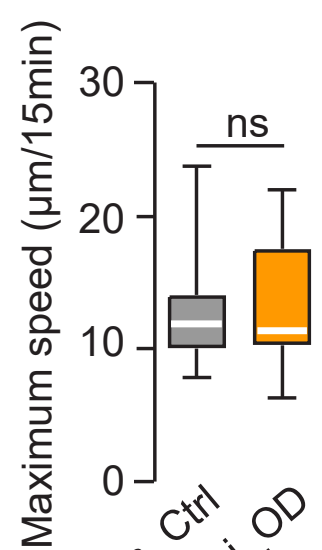

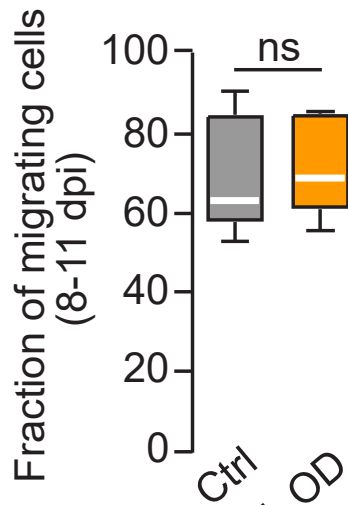

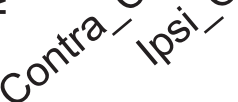
$0_{0, r^{2}} / p^{s^{\prime}}$ $00^{n x^{2}} / 1 p^{s^{\prime}}$ 
Fig. 2

A
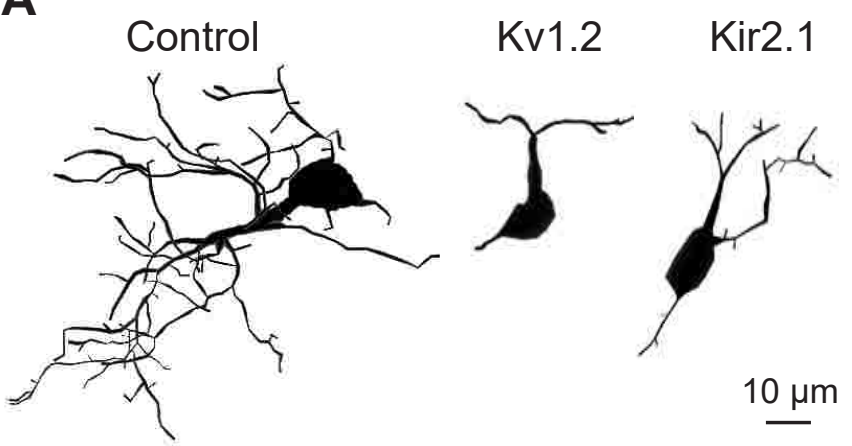

$\underline{10 \mu \mathrm{m}}$

D

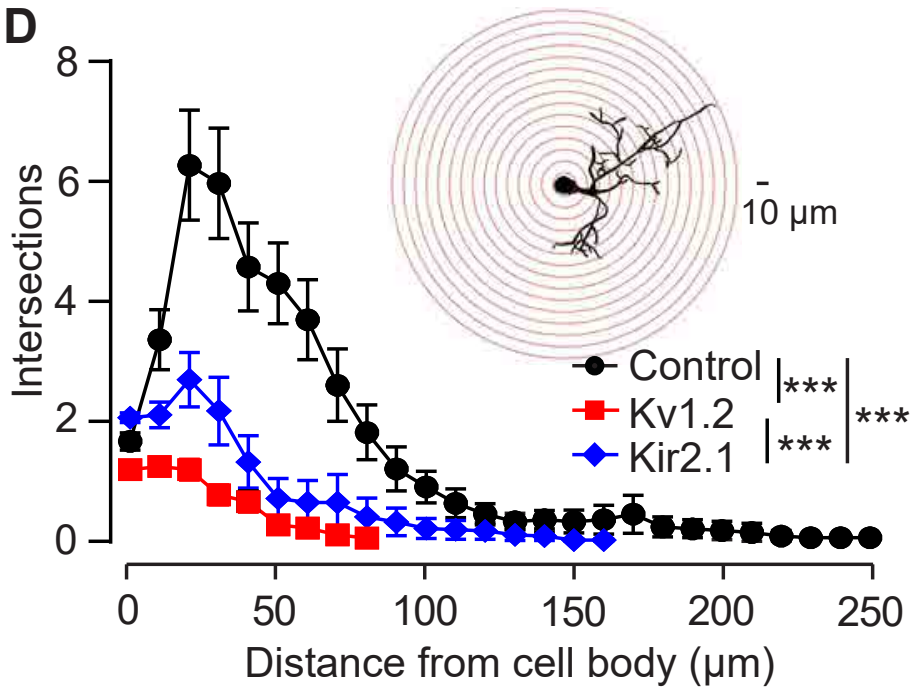

F

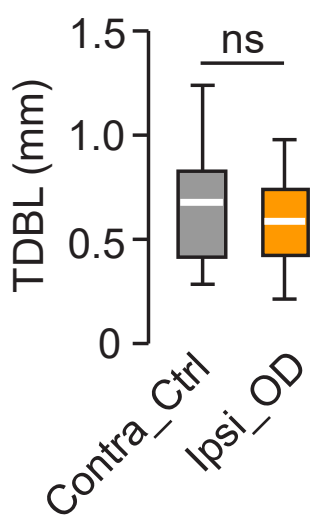

B
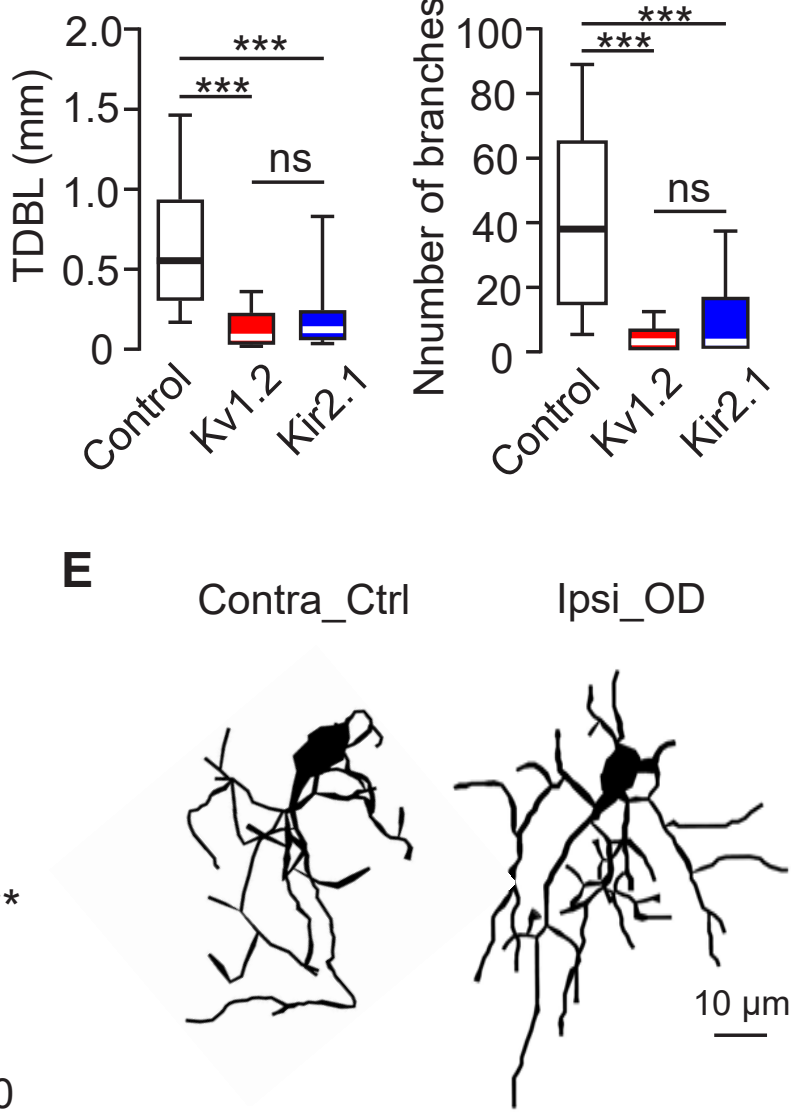

C

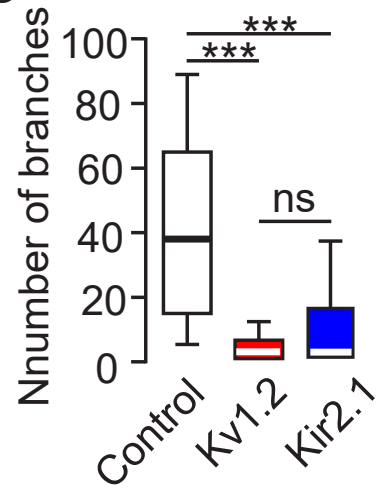

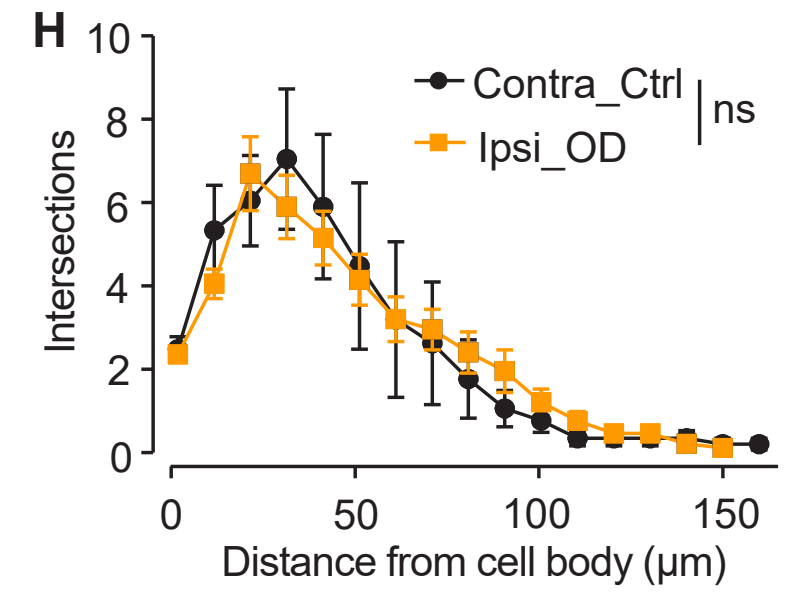


Fig. 3

A
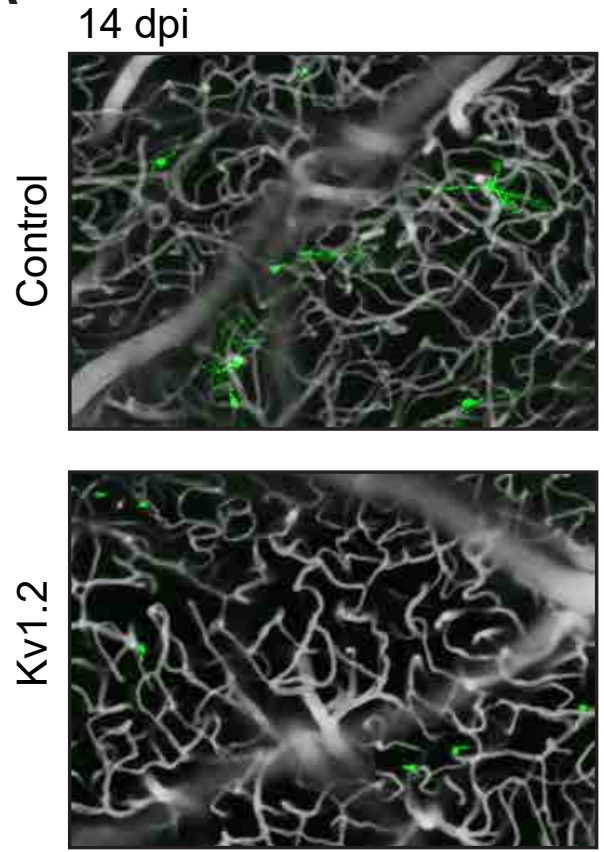

C

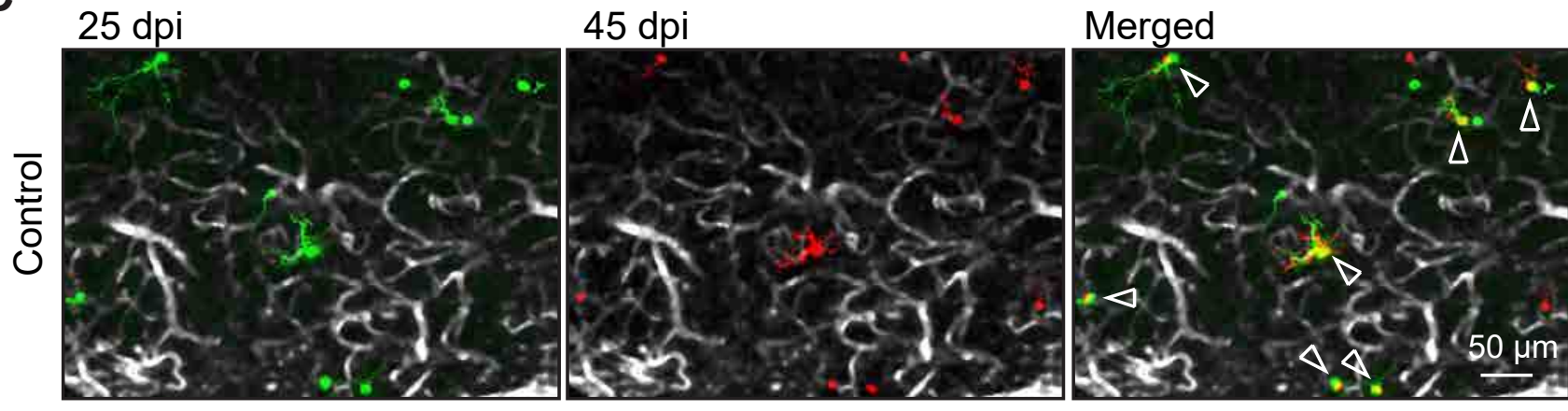

$25 \mathrm{dpi}$
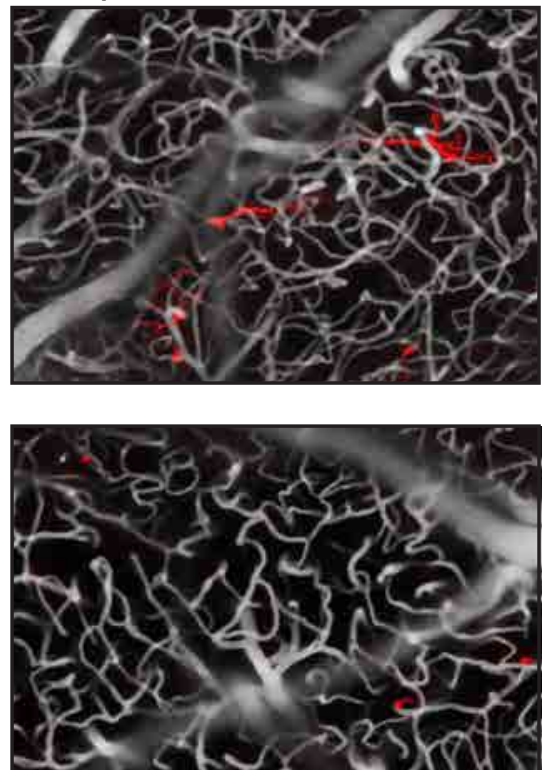

(2)
Merged
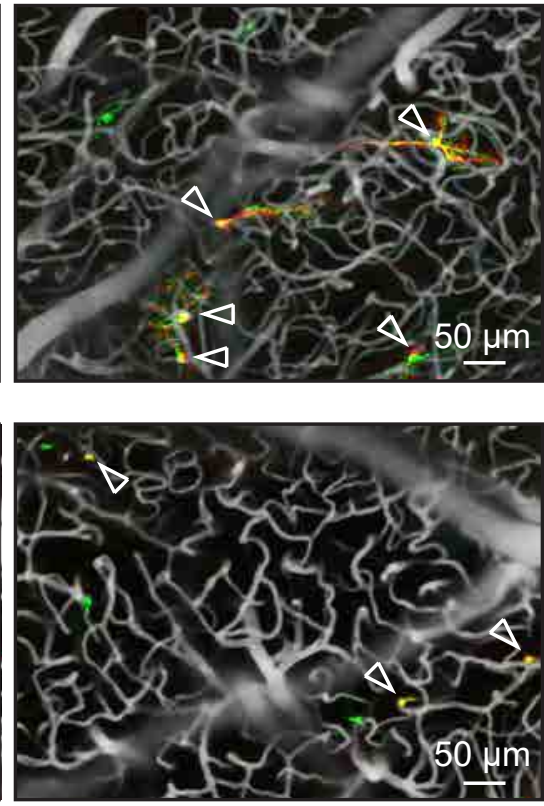

Merged

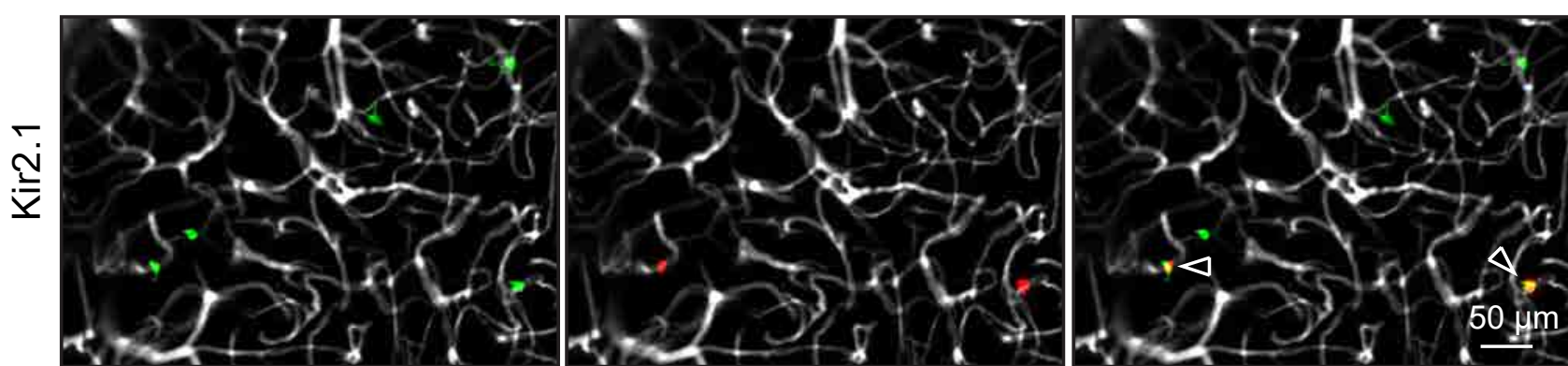

B

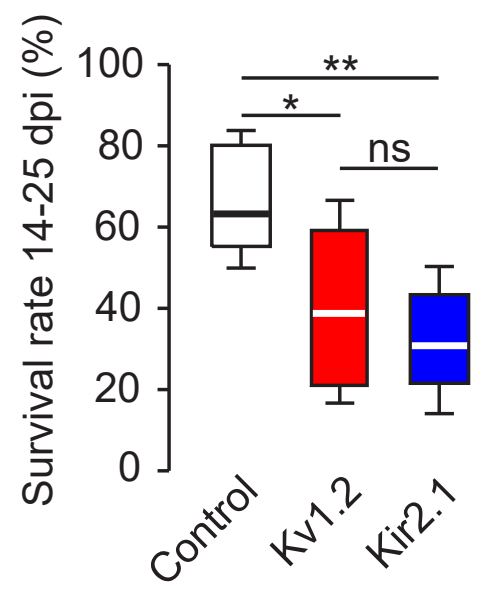

D

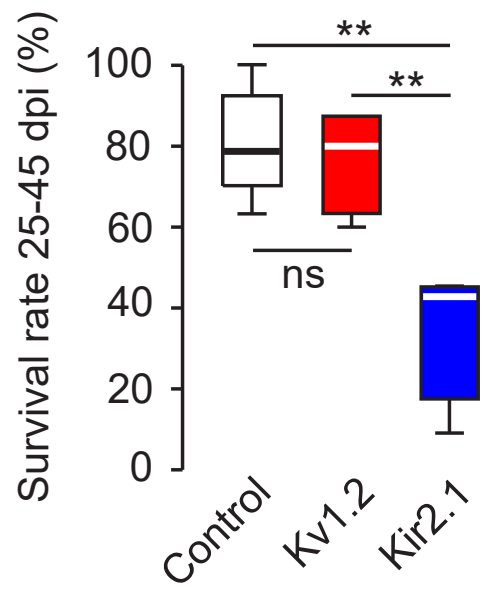


Fig. 4

bioRxiv preprint doi: https://doi.org/10.1101/2021.04.21.440775; this version posted April 22, 2021. The copyright holder for this preprint (which was not certified by peer review) is the author/funder. All rights reserved. No reuse allowed without permission.

A

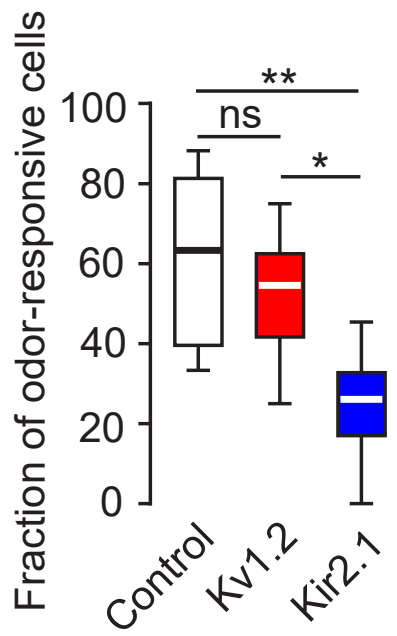

B

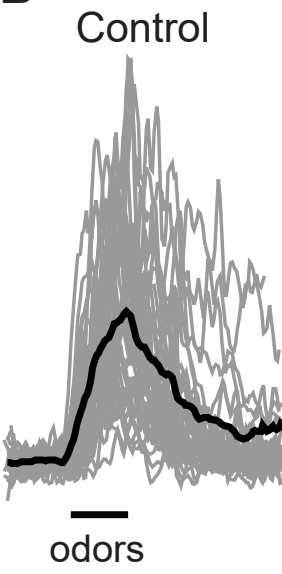

Kv1.2

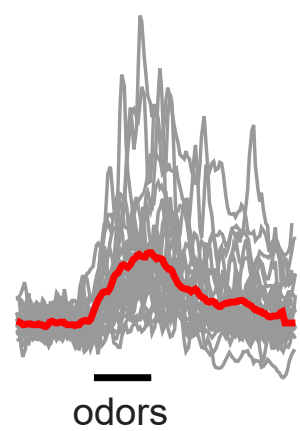

Kir2.1

| $0.5 \Delta R / R$

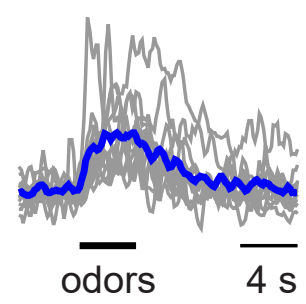

C

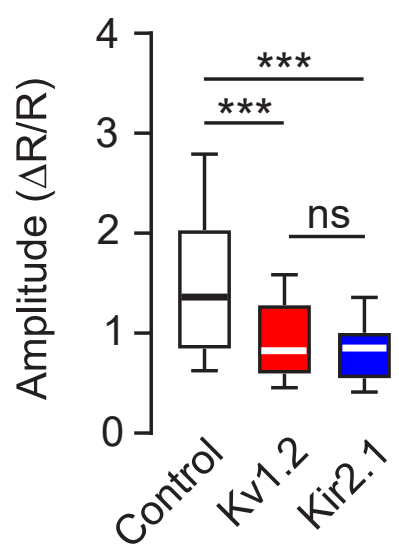

D

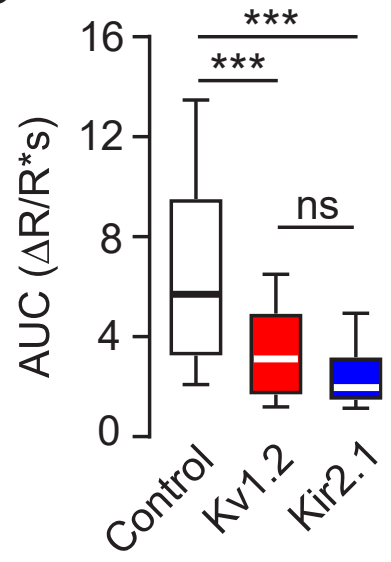


Fig. 5

bioRxiv preprint doi: https://doi.org/10.1101/2021.04.21.440775; this version posted April 22, 2021. The copyright holder for this preprint (which was not certified by peer review) is the author/funder. All rights reserved. No reuse allowed without permission.

A Control

$\mathrm{Kv1.2}$

Kir2.1

$11 \Delta \mathrm{R} / \mathrm{R}$

"ind

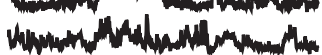
(1)

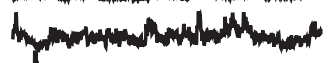

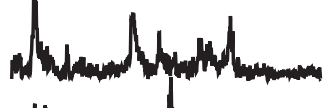

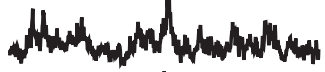

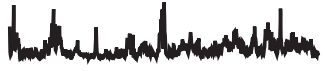

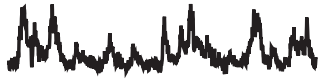

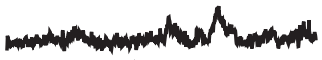

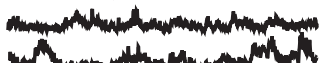
(n)

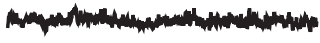

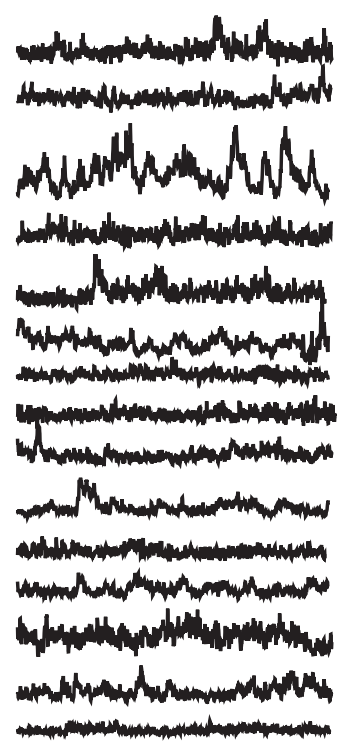

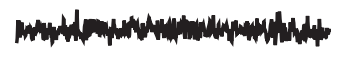
(1)

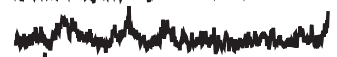

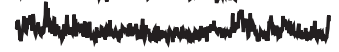

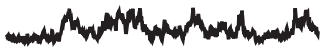
(N) (1)

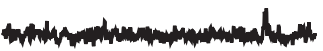

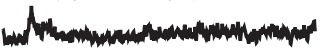
Him

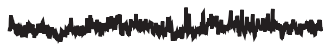

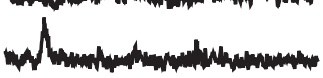
(1) manmmanm (1) $\overline{20 s}$
D Contra_Ctrl

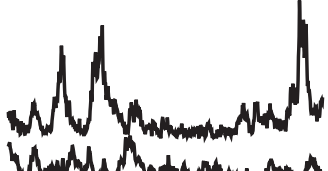

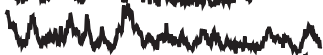
mom mimmannm

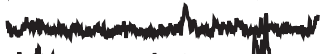

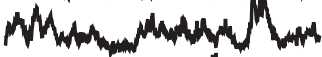

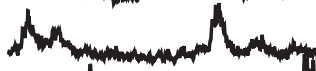

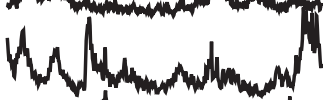

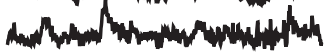
(n)

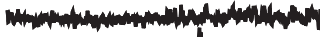

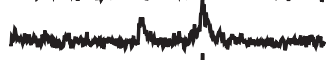

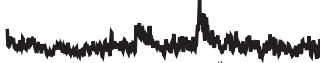

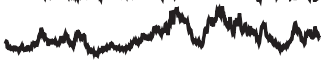

Ipsi_OD

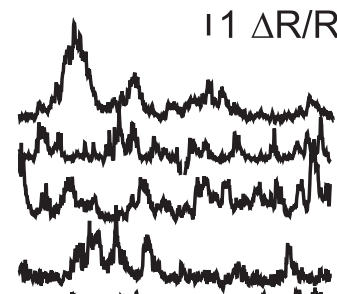
(n)

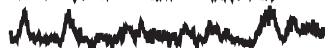

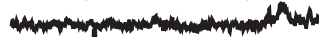
Mnd Mndhum

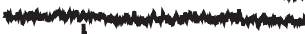

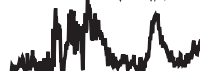

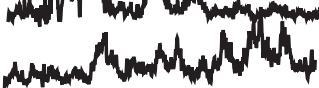
(1) $\frac{20}{20 s}$

B

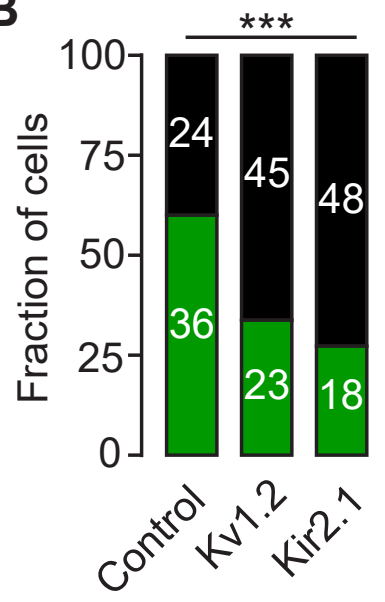

C

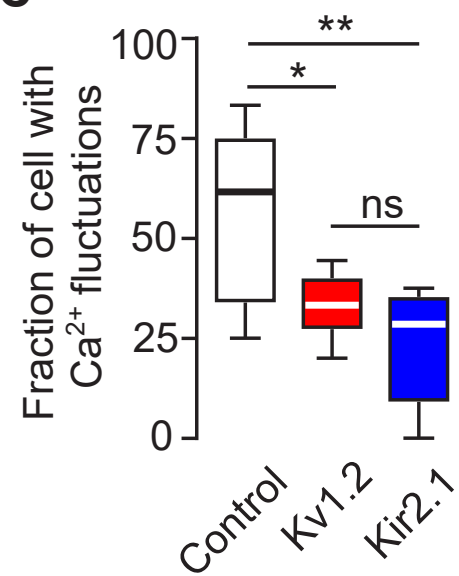

E

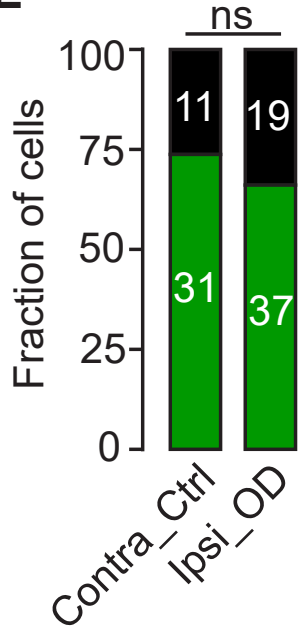

F

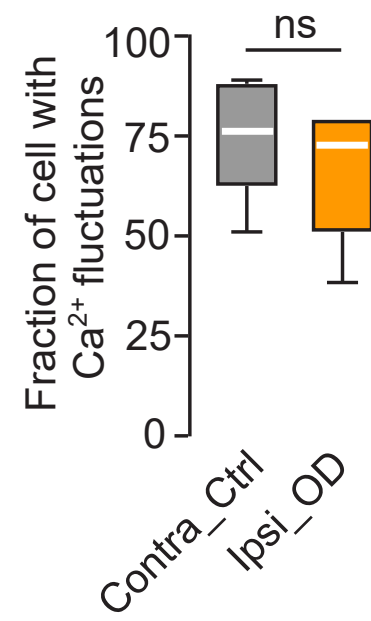

\footnotetext{
$\mathrm{Ca}^{2+}$ fluctuations, $-\mathrm{no} \mathrm{Ca}^{2+}$ fluctuations
} 
Fig. 6

A
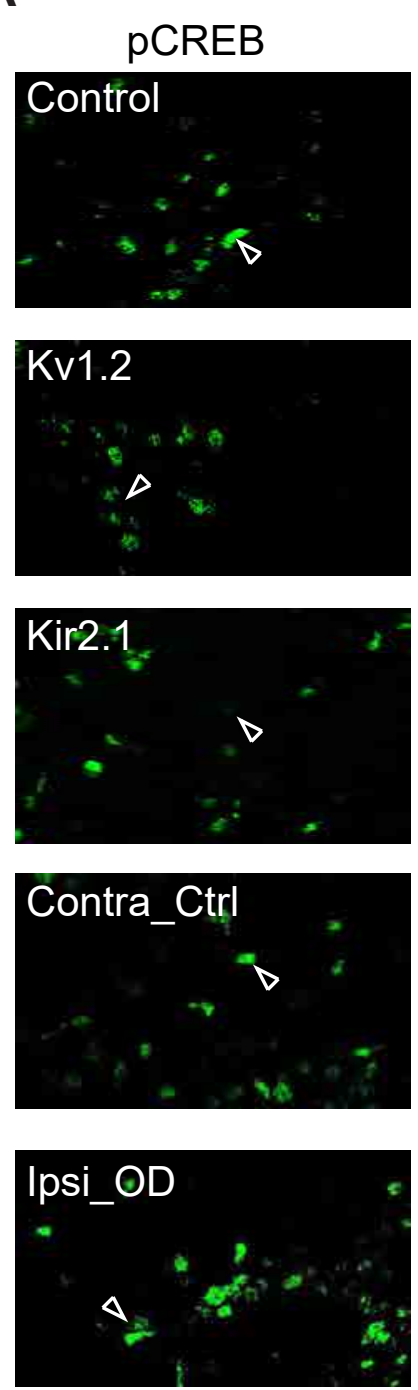
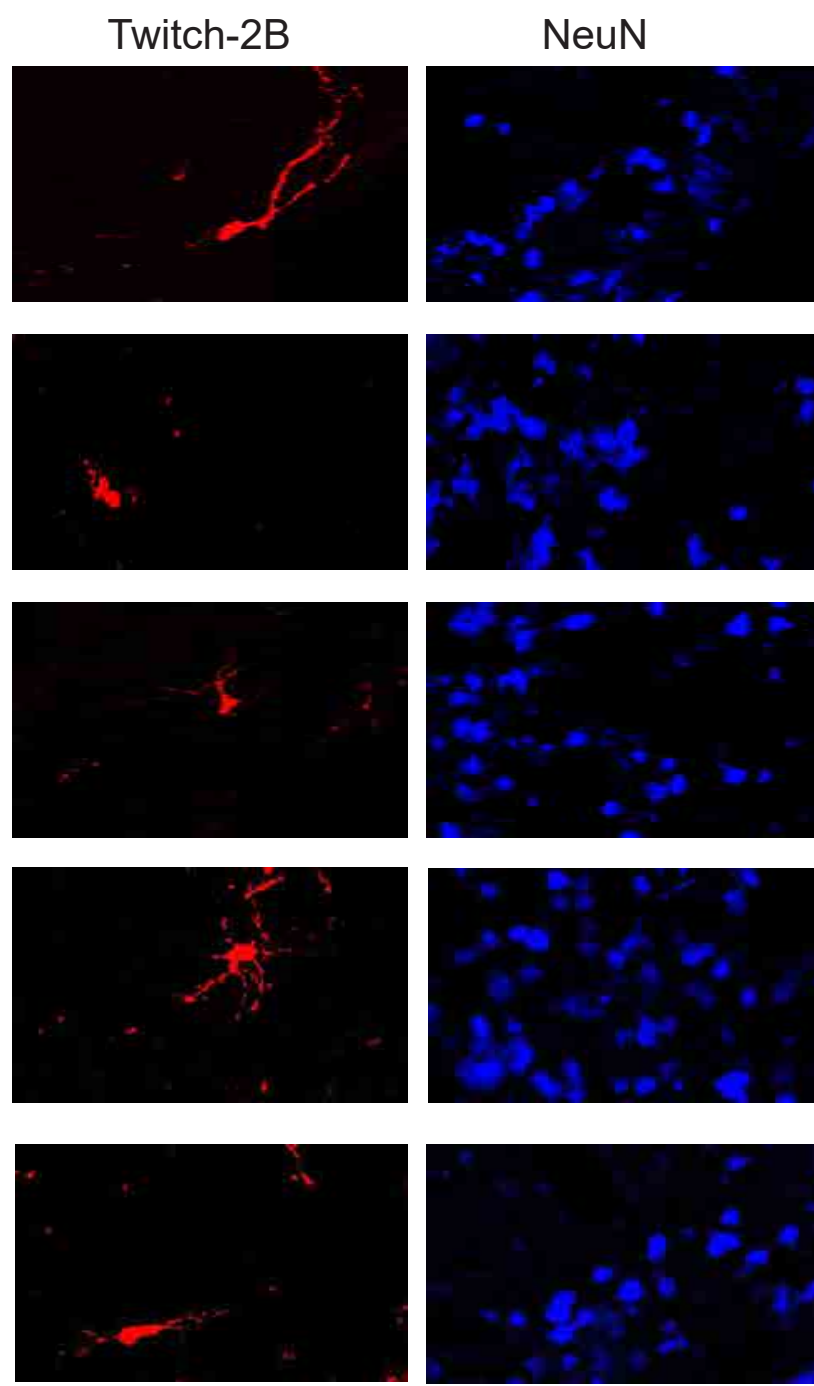
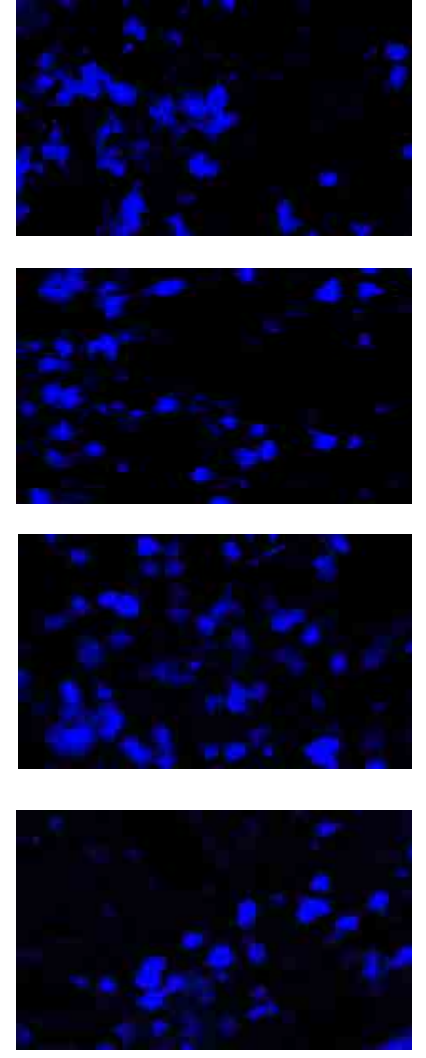

Merged
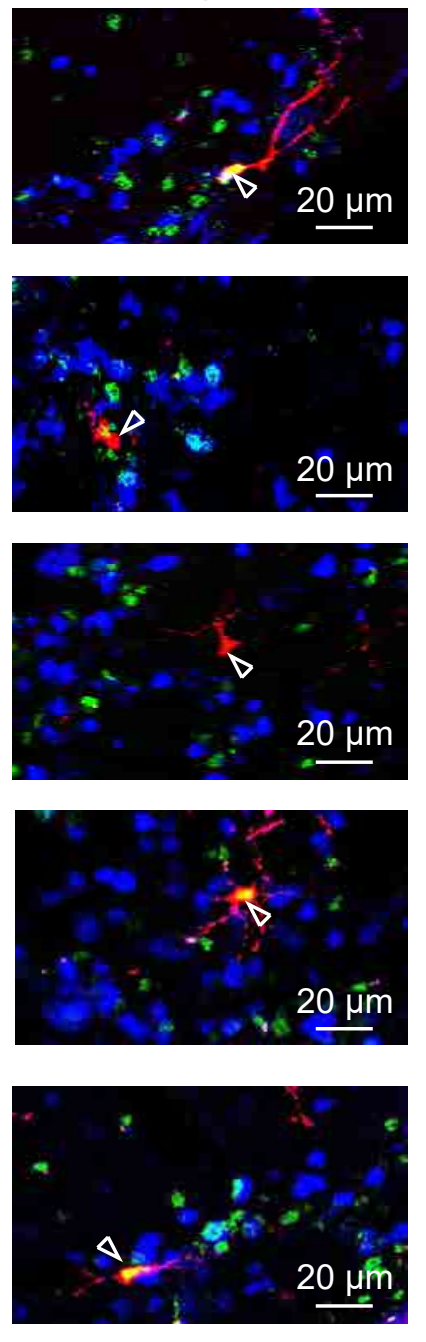

B

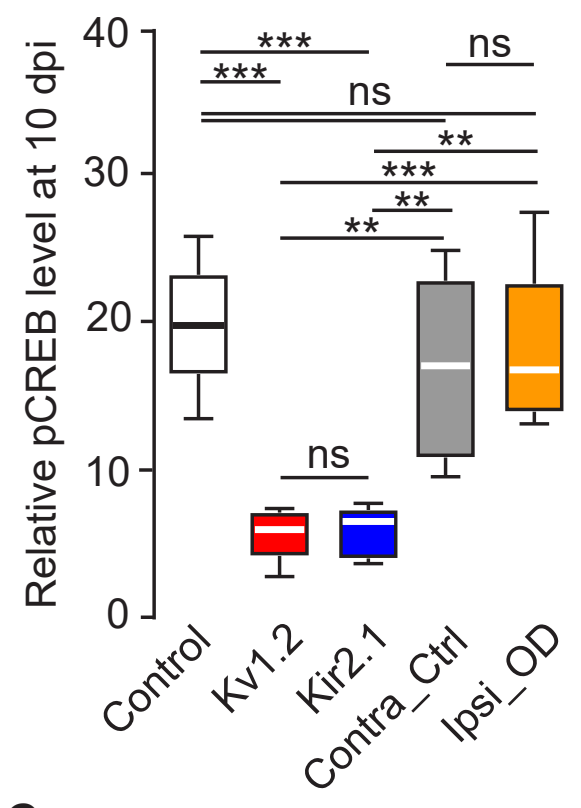

C

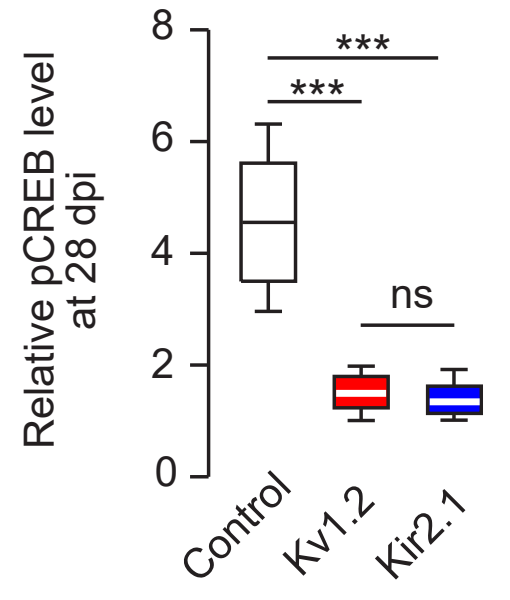


Fig. hiofziv preprint doi: https://doi.org/10.1101/2021.04.21.440775; this version posted April 22, 2021. The copyright holder for this preprint (which was not certified by peer review) is the author/funder. All rights reserved. No reuse allowed without permission.

A Virus injection $\longrightarrow$ FACS $\longrightarrow \begin{aligned} & \text { RNA seq } \\ & \text { Data analysis }\end{aligned}$

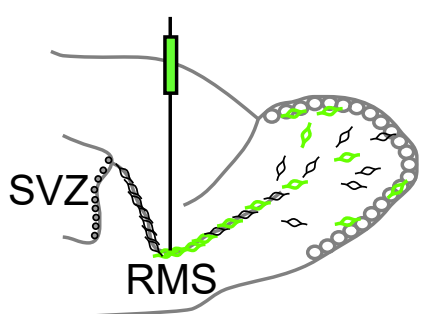

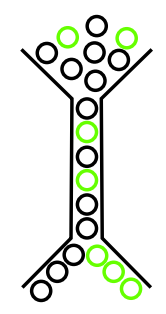

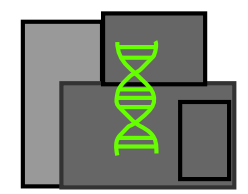

B

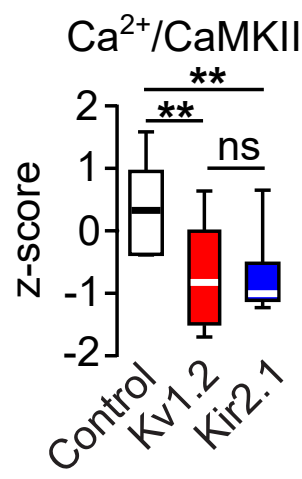

C pCREB-driven IEGs

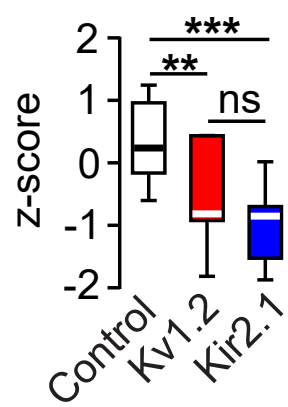

D Neuronal migration

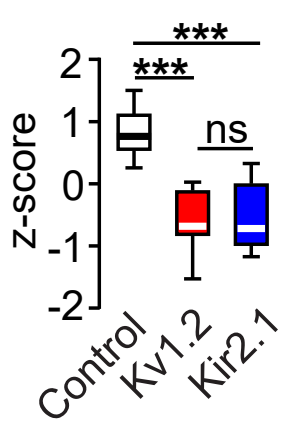

E

Neuronal differentiation

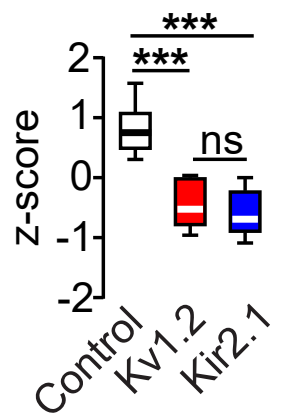

G F
Dendritic
morphogenesis

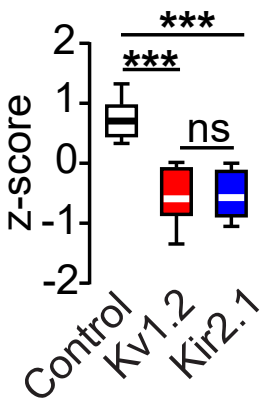

Apoptosis

H

Internal controls

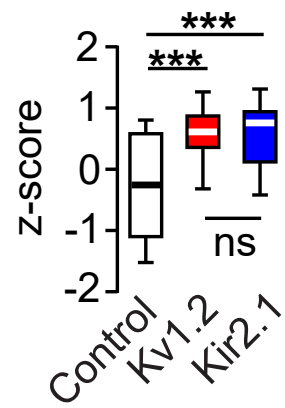

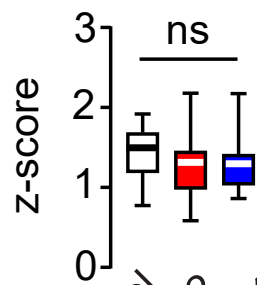

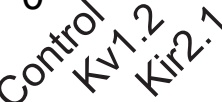

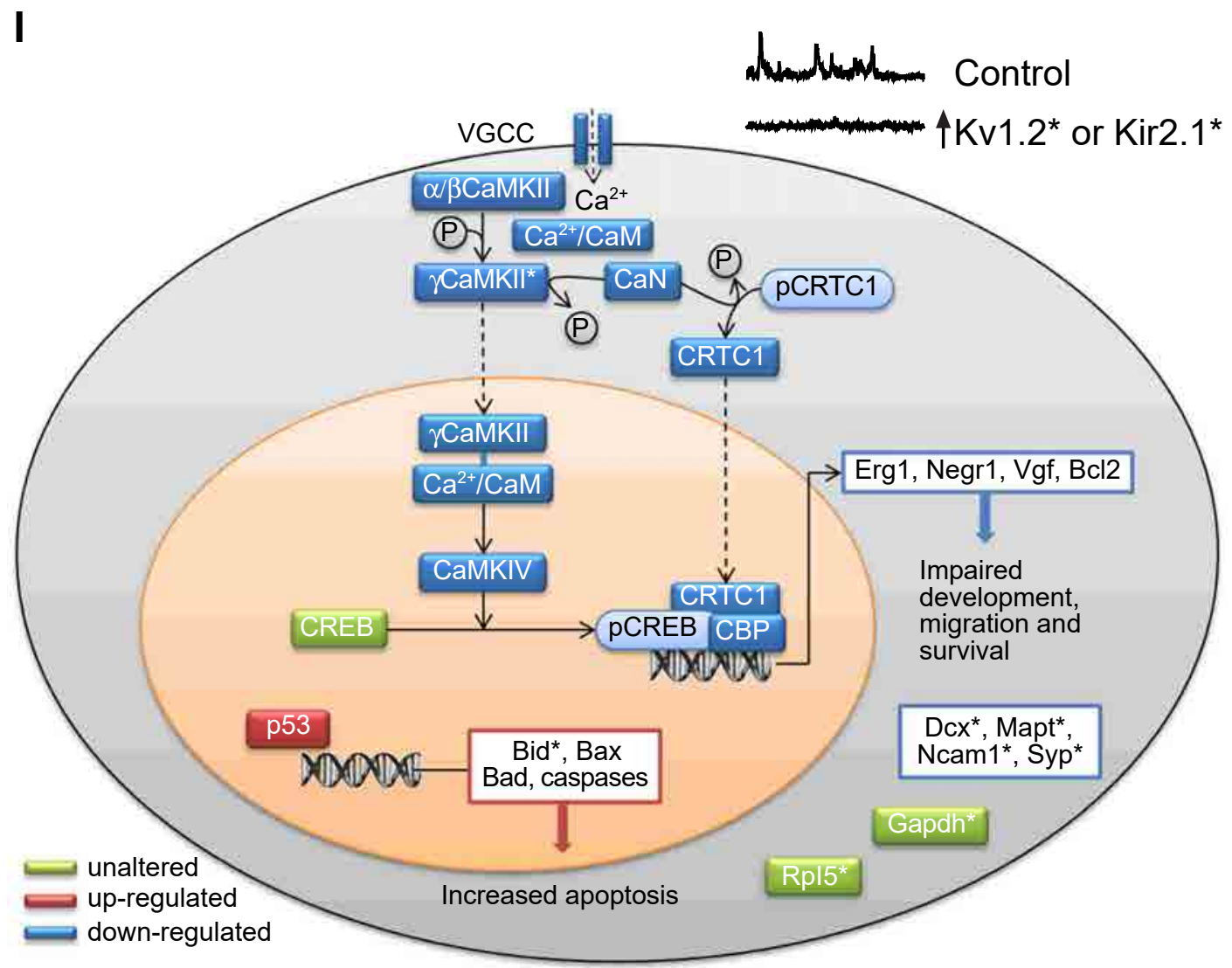


A

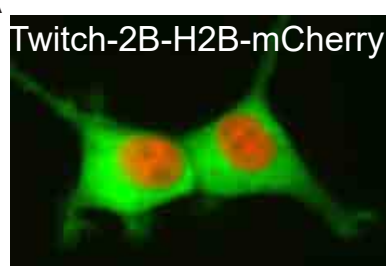

B

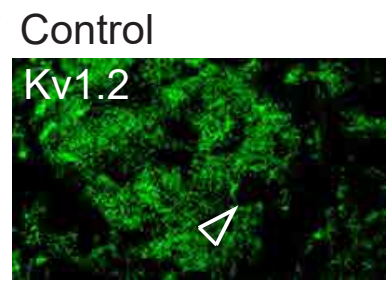

Kv1.2
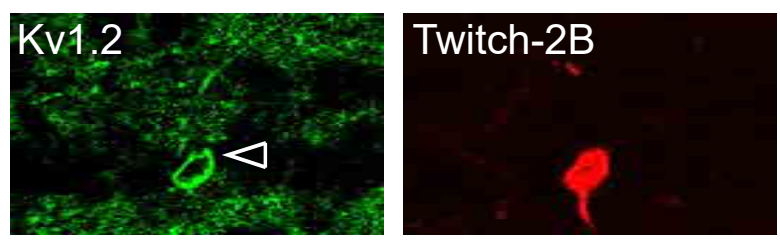
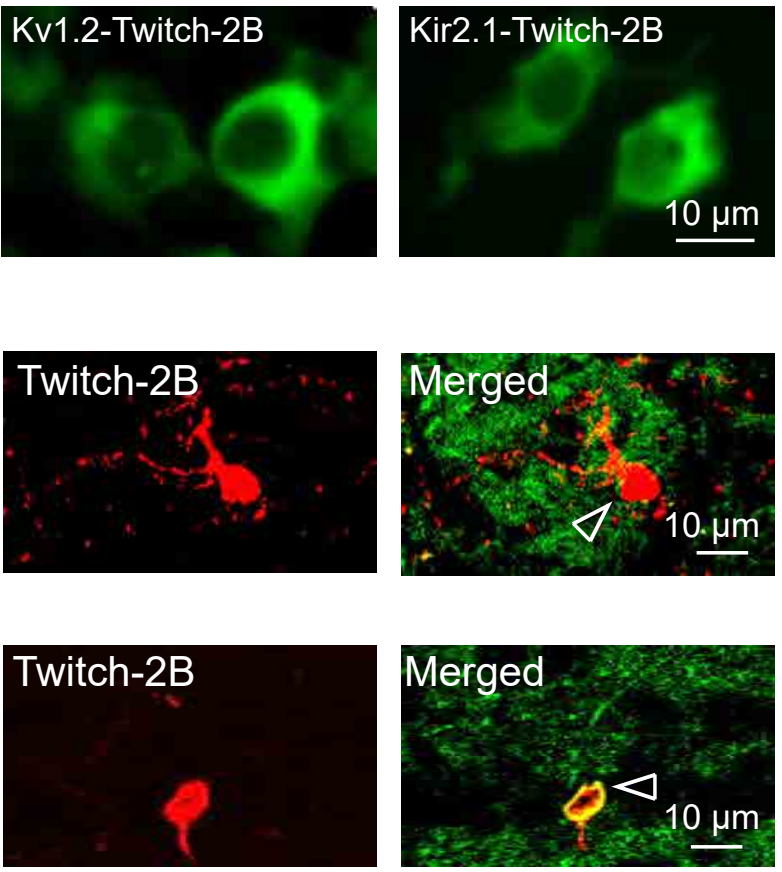

C

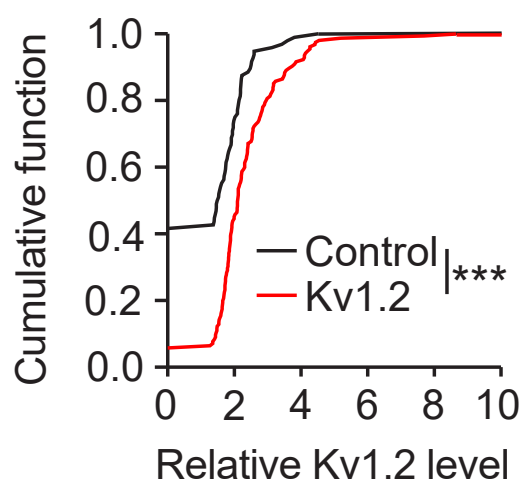

E

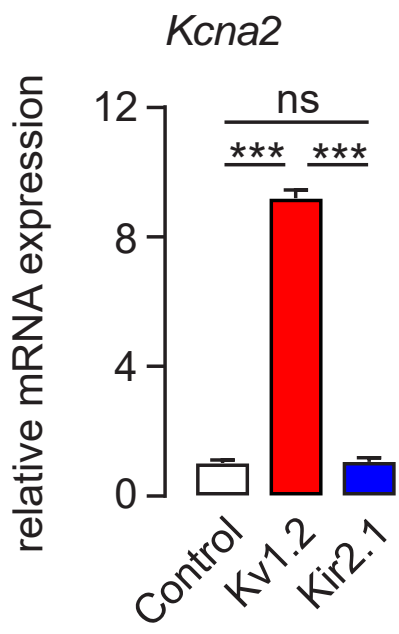

D

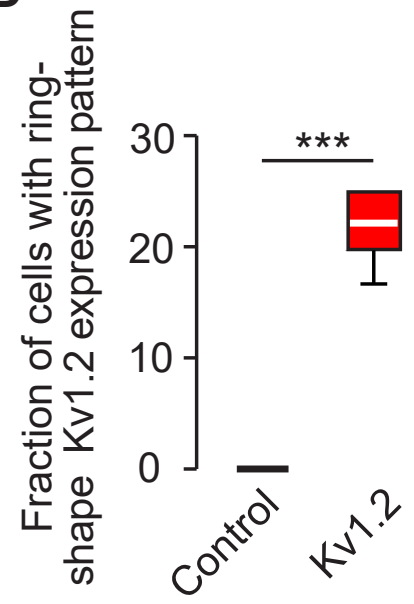

F

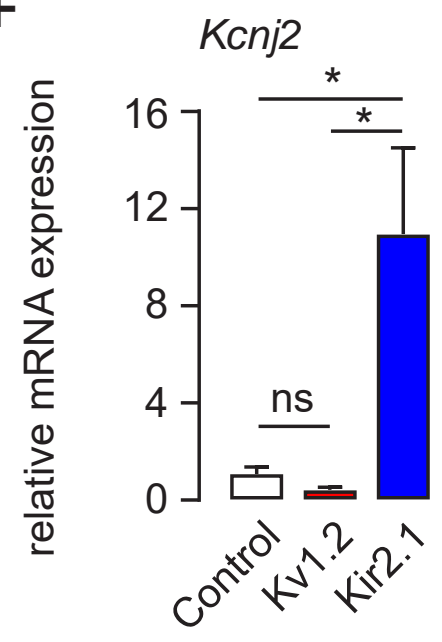


Fig. S2

A

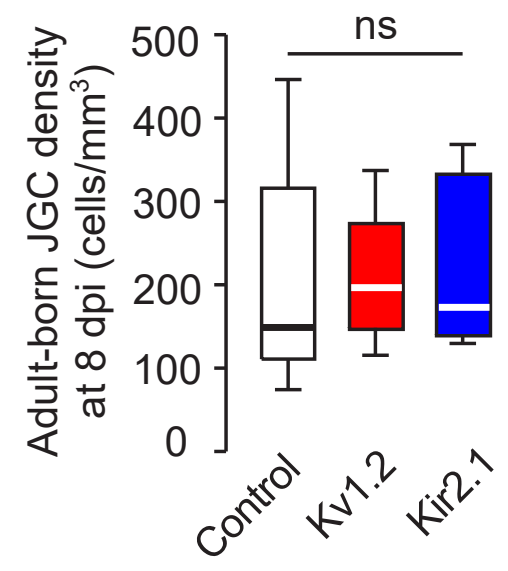

B

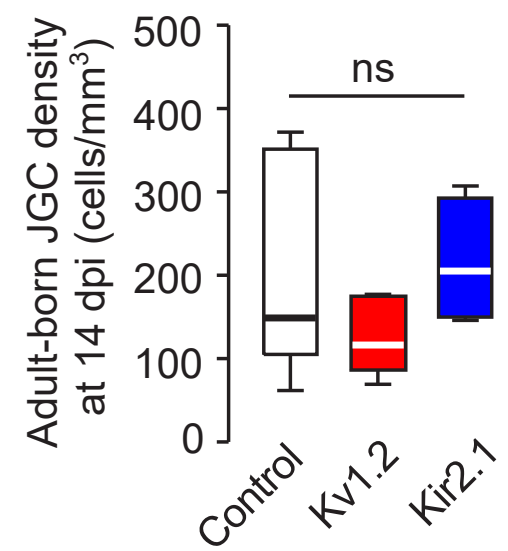


Fijgxiv $\mathbf{S}$ 3print doi: https://doi.org/10.1101/2021.04.21.440775; this version posted April 22, 2021. The copyright holder for this preprint (which was not certified by peer review) is the author/funder. All rights reserved. No reuse allowed without permission.

A

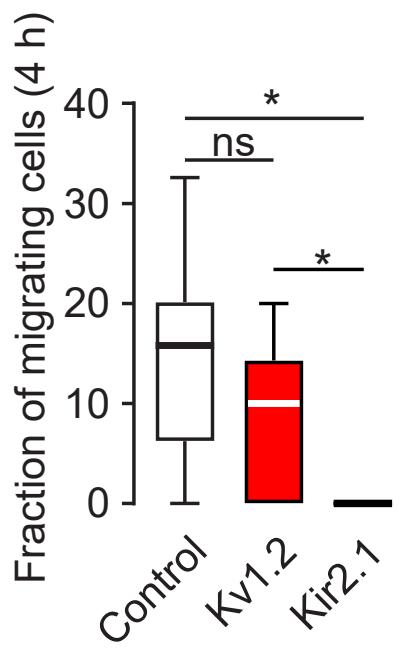

B

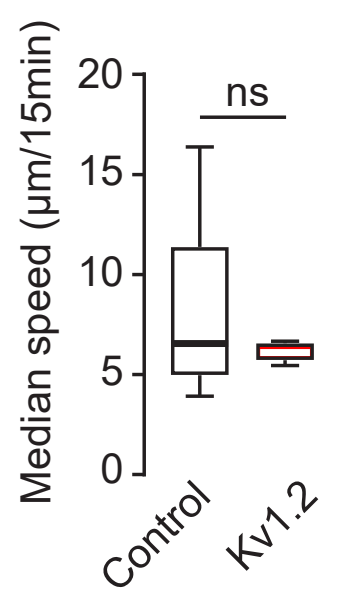

C

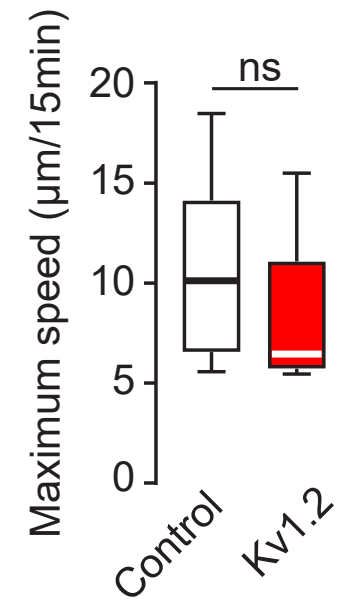

D

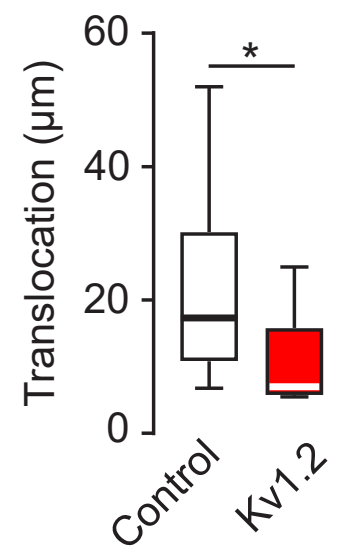


A

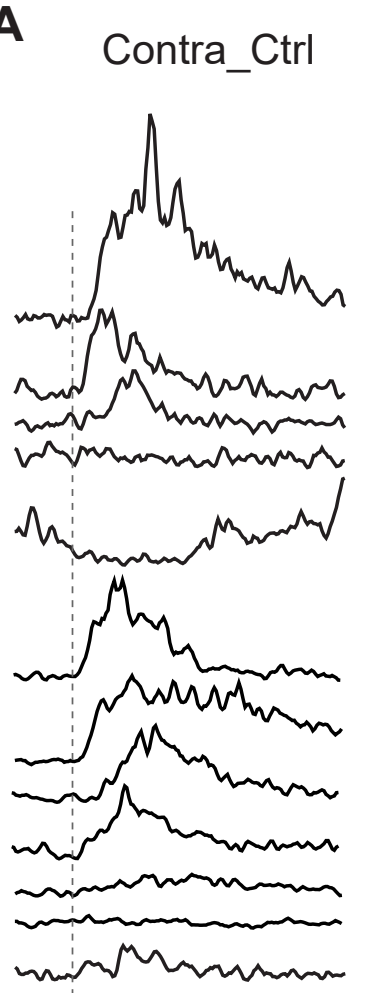

odors
Ipsi_OD

| $0.5 \Delta R / R$

wommunum

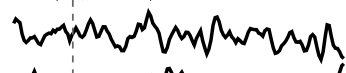
himmonom momennomins rinn inimminnmoms vemmonsumas Mincomman

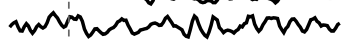
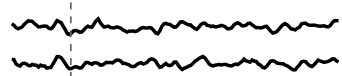

minnNhmonnms

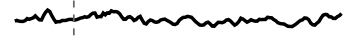

riminnminam

indictranunch

rinmonmonsm

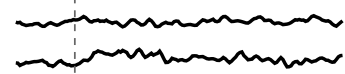

rim

rininviniming

odors

$4 \mathrm{~s}$
B

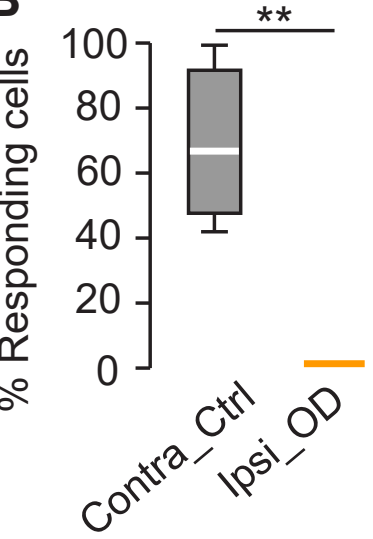

C
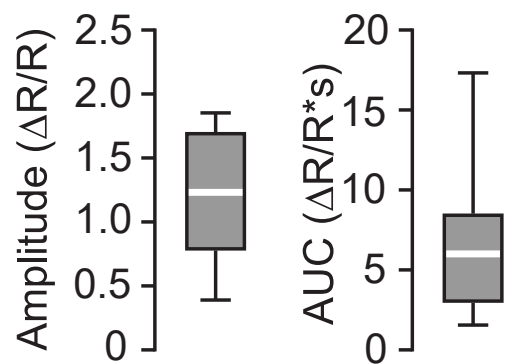<smiles>C=CC=O</smiles> 
A

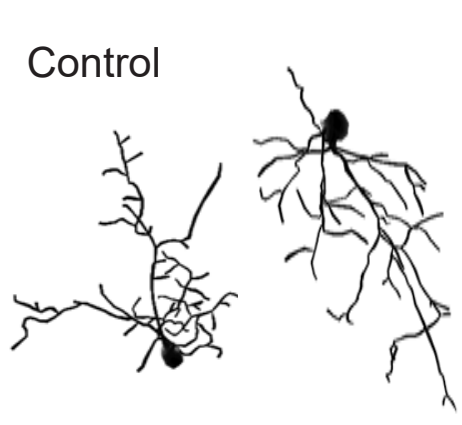

Kv1.2

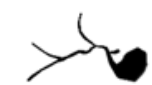

Kir2.1

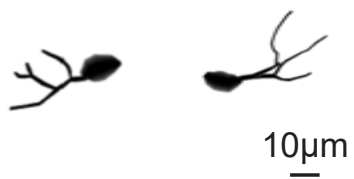

B

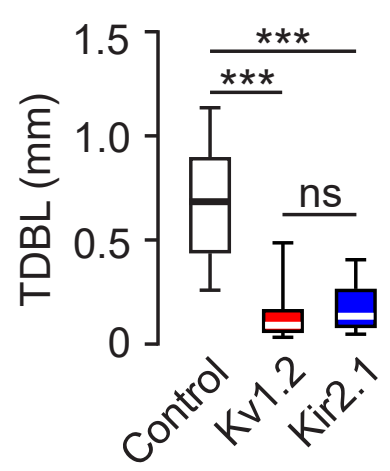

C

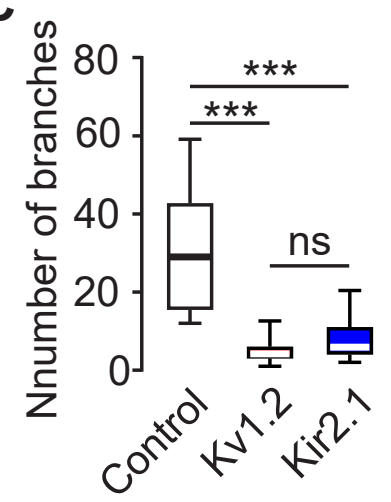

D

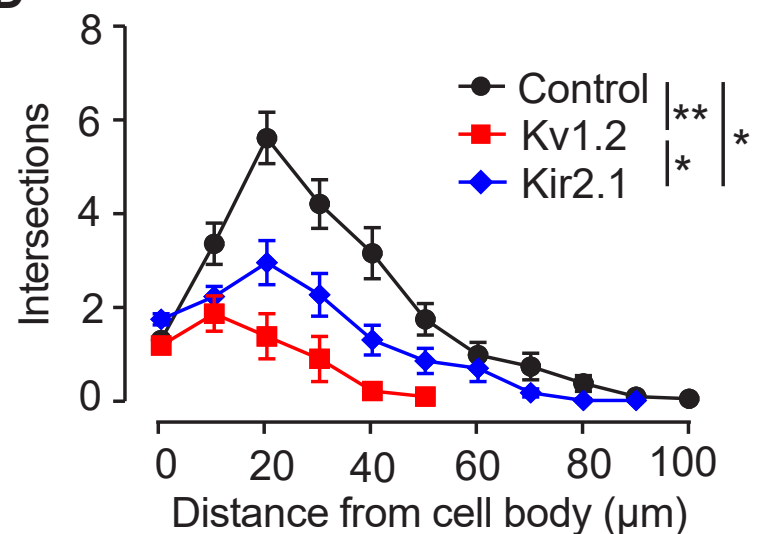


Fig. 56

A
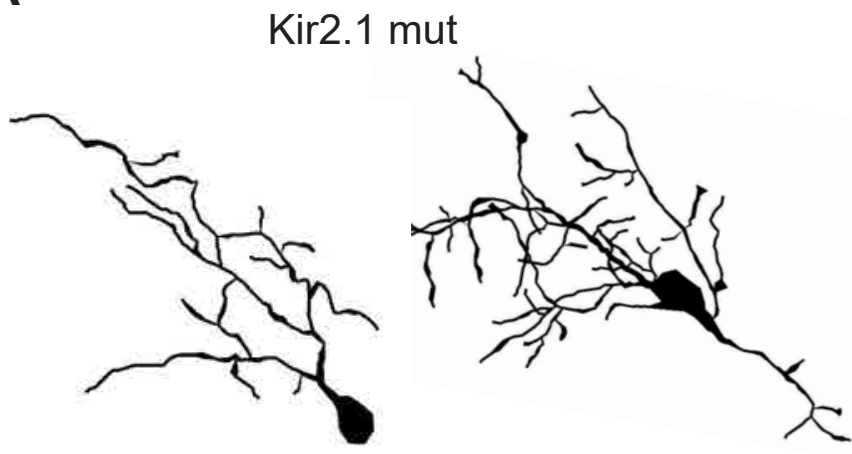

$10 \mu \mathrm{m}$

D

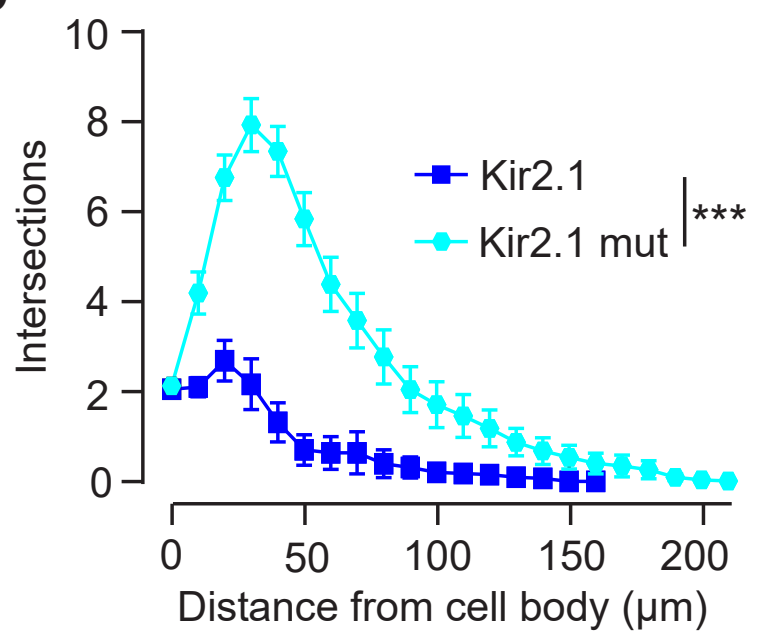

B

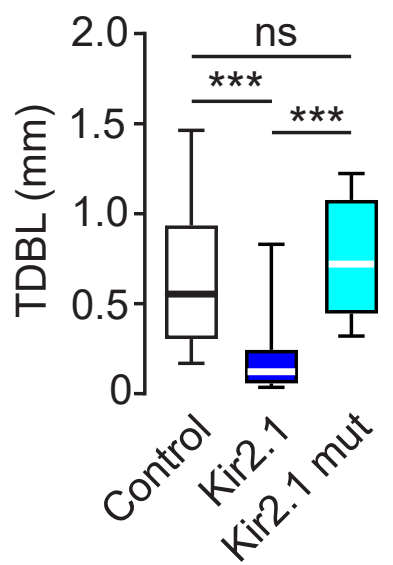

E

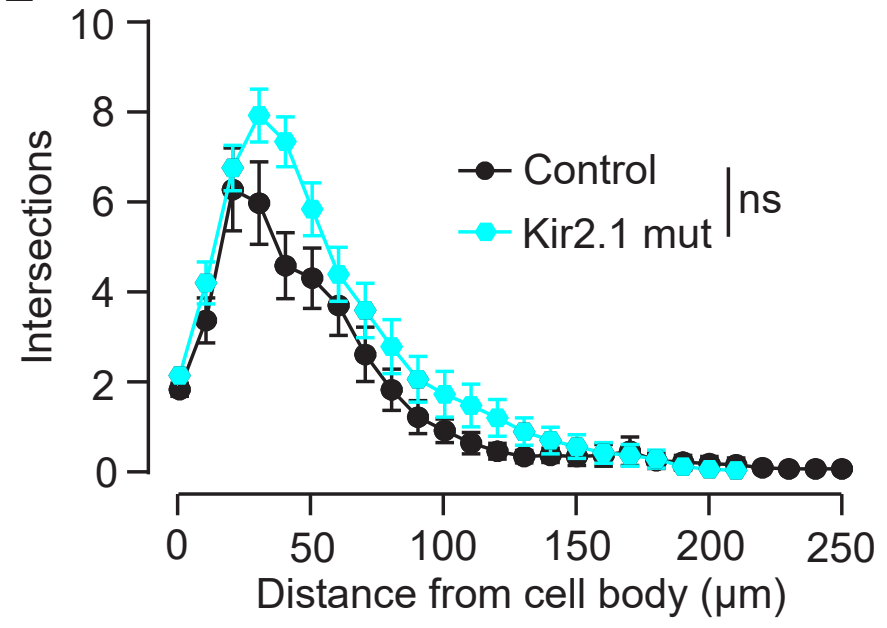

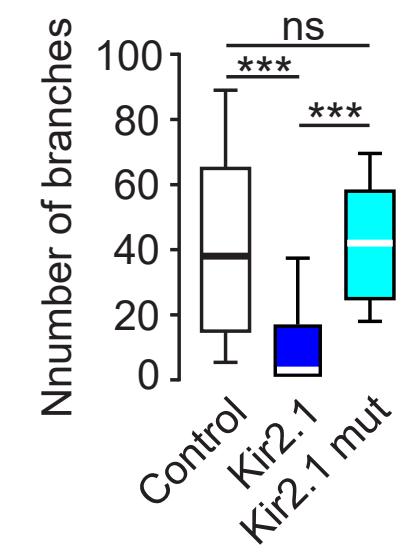

C 
A

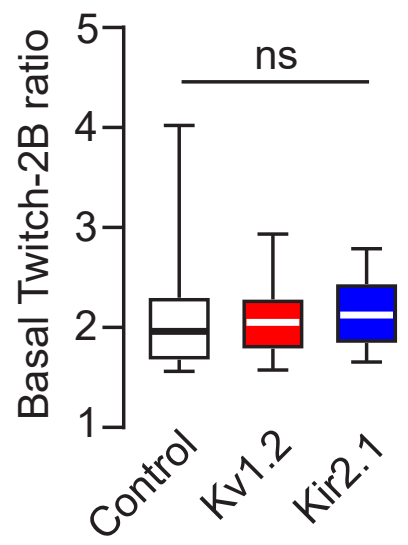

D

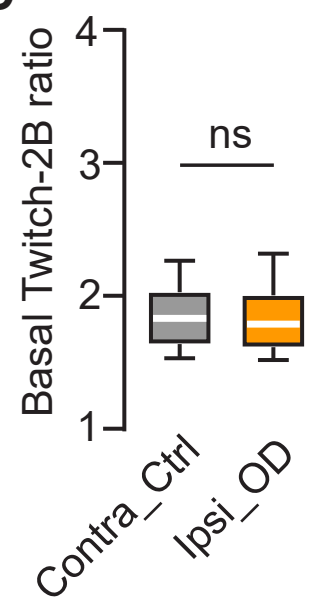

B

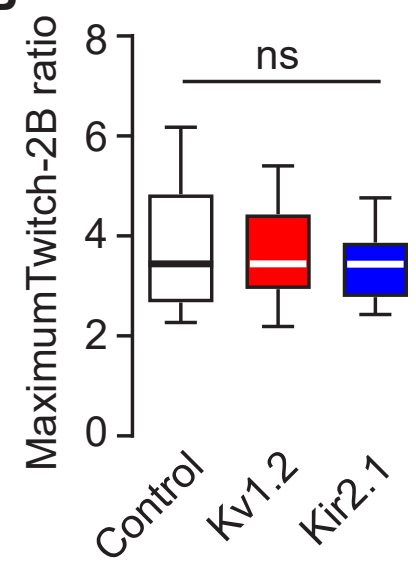

E

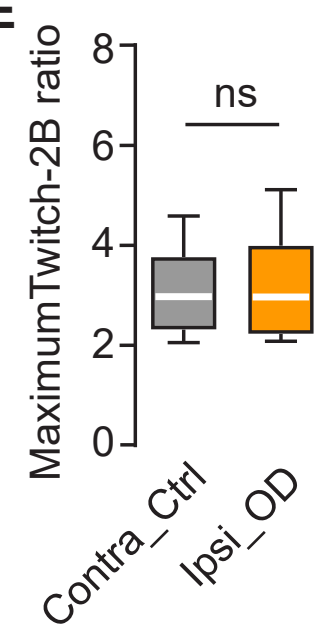

C

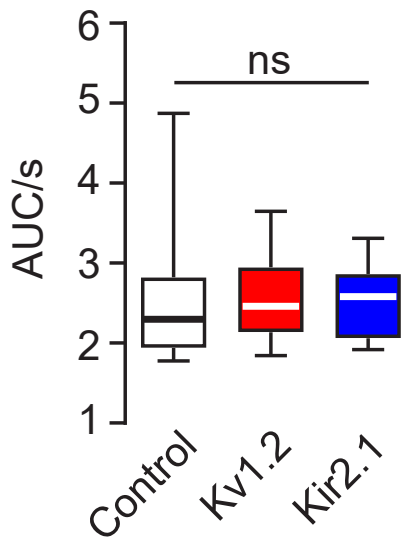

F

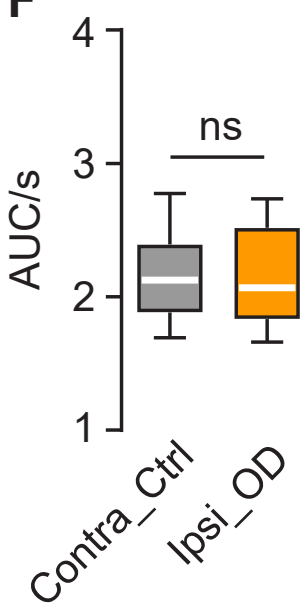


Fig. 58
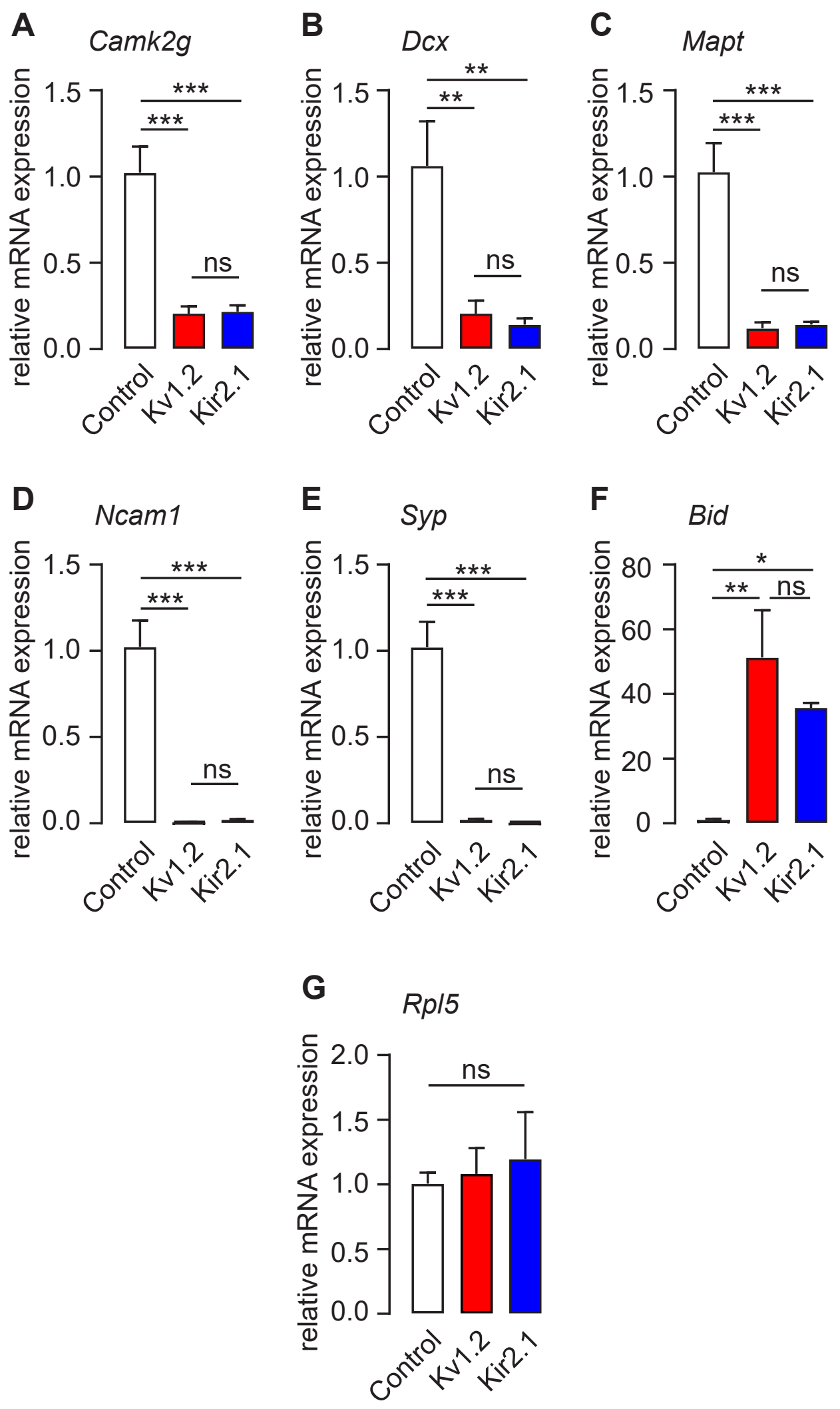


\section{Fig. $\$ 9$}

bioRAv preprint doi: https://doi.org/10.1101/2021.04.21.440775; this version posted April 22, $\mathbb{Z} 21$. The copyright holder for this preprint (which was not certified by peer review) is the author/funder. All riphts reserved. No reuse allowed without permission.
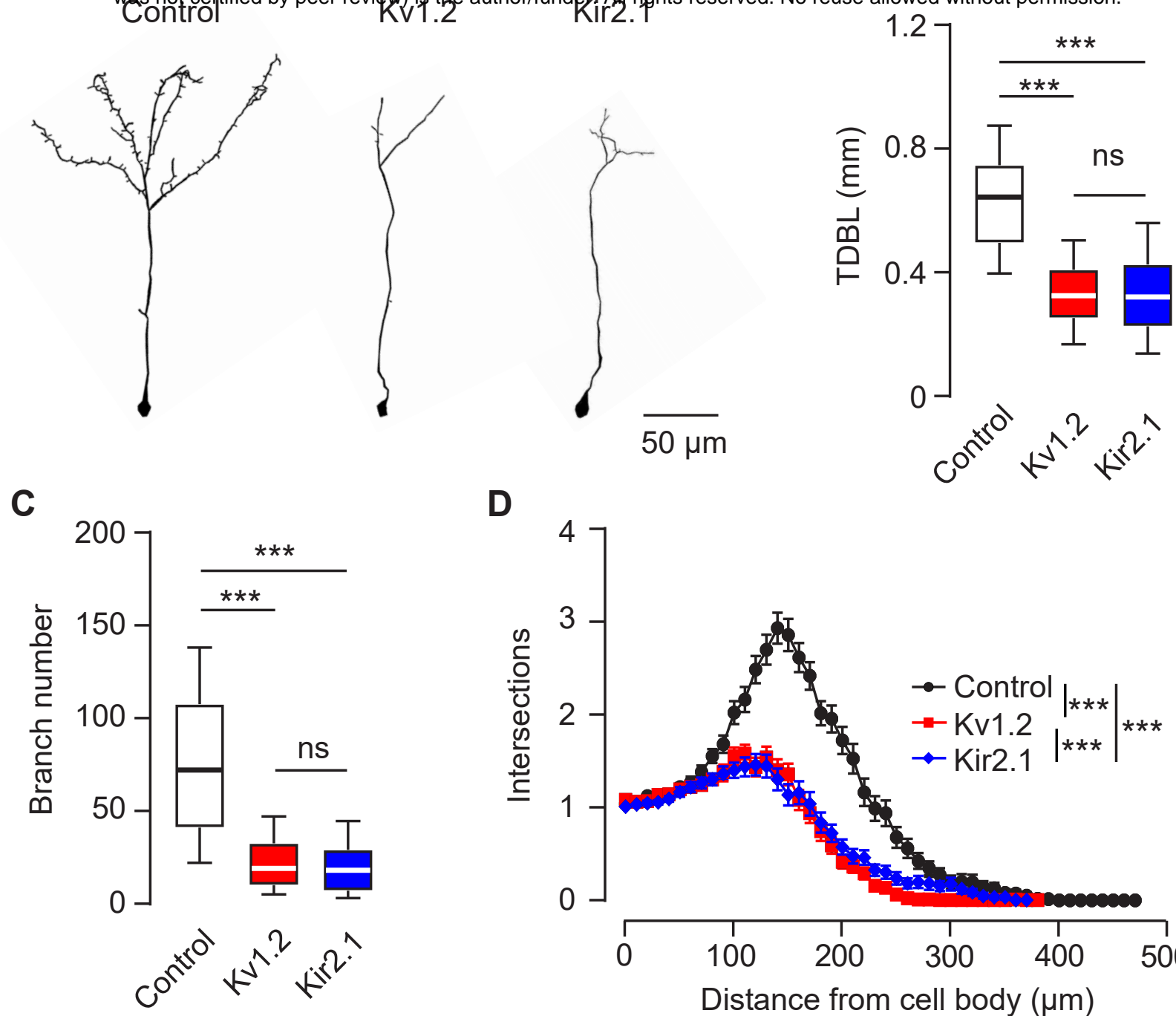

E

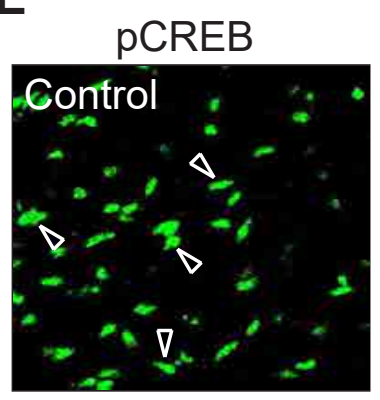

D
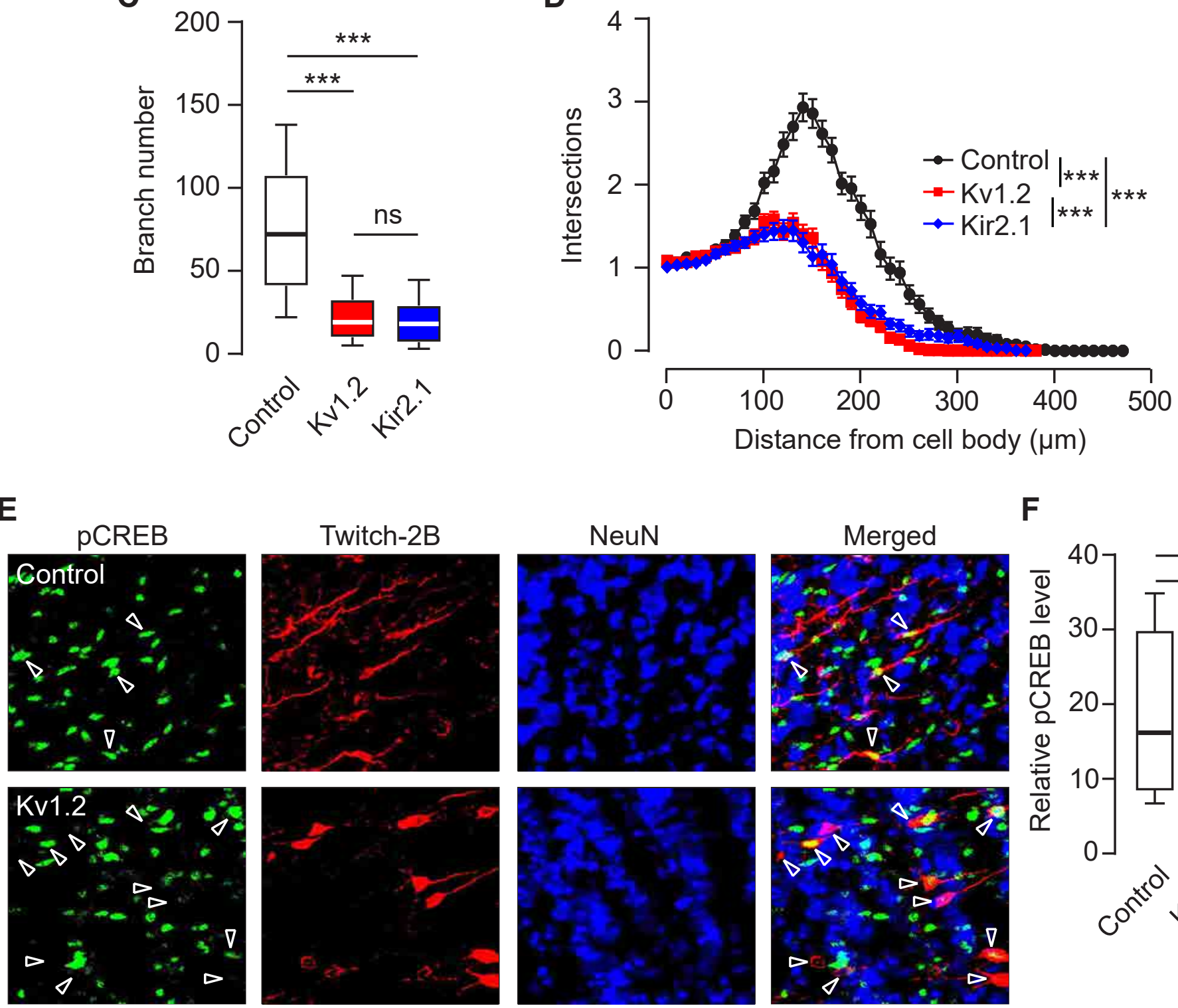

Twitch-2B
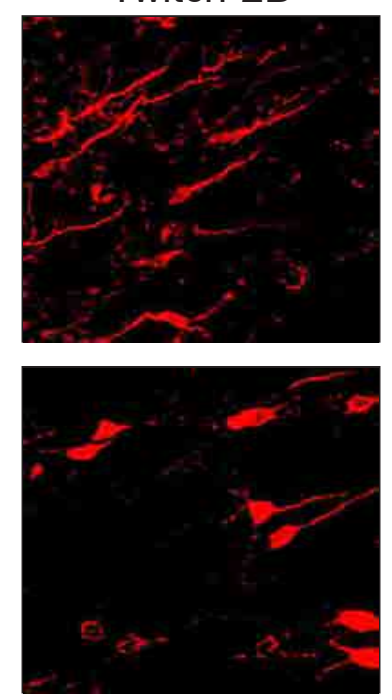

NeuN
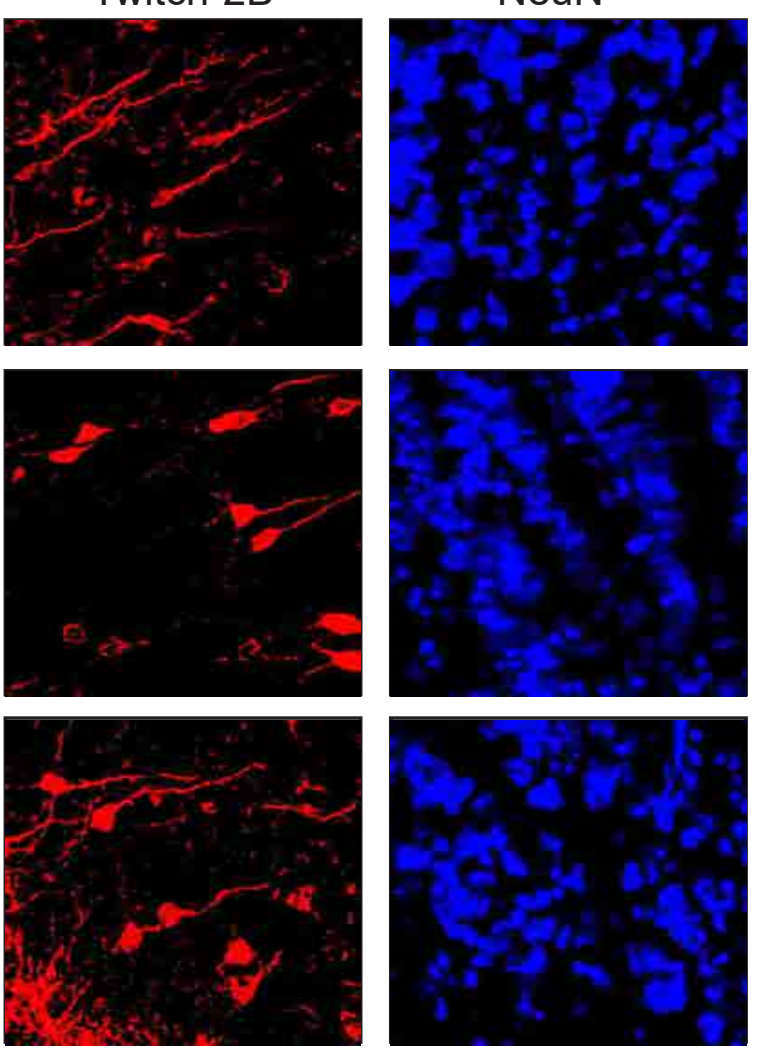

F
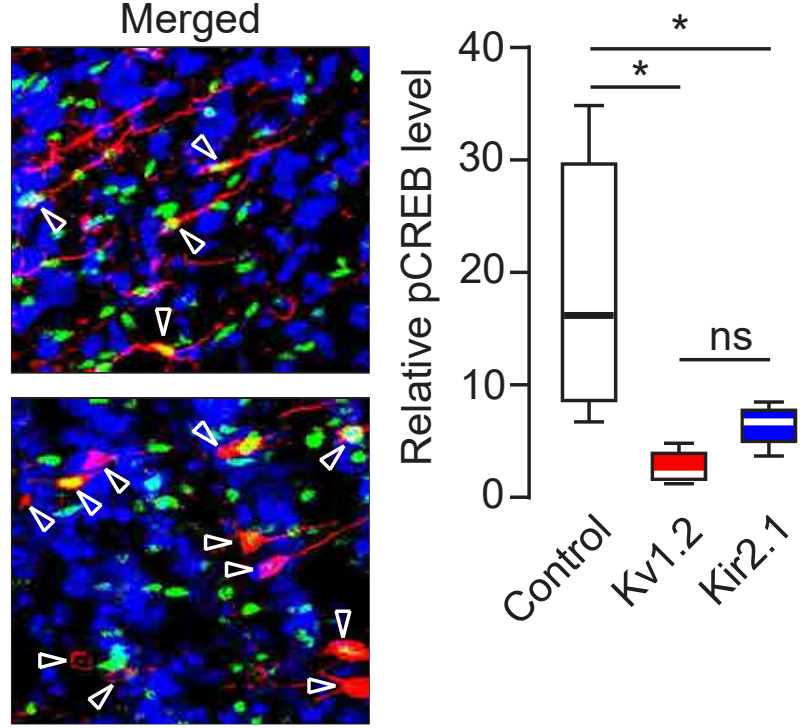
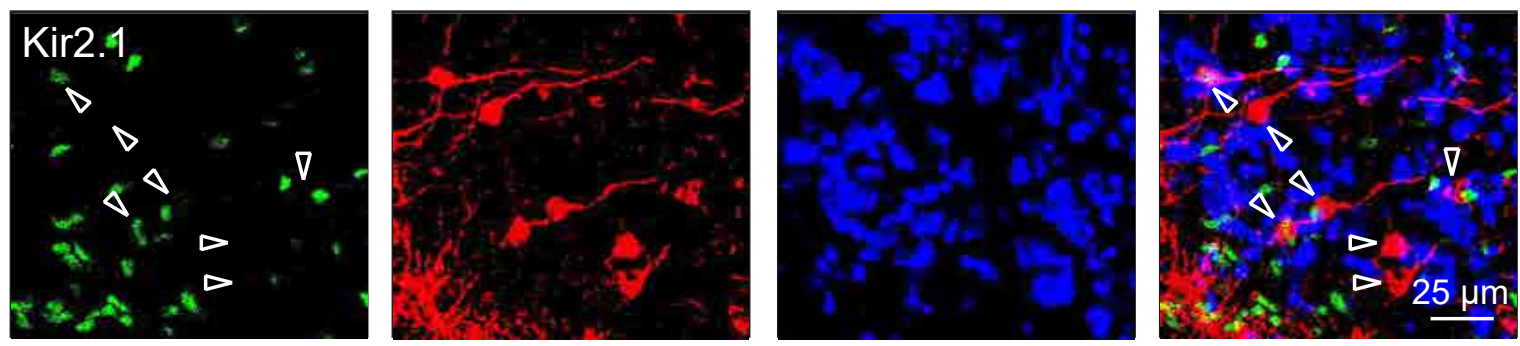
bioRxiv preprint doi: https://doi.org/10.1101/2021.04.21.440775; this version posted April 22, 2021. The copyright holder for this preprint (which was not certified by perreview) is the author/funder. All rights reserved. No reuse allowed without permission.

A

NMDA receptors

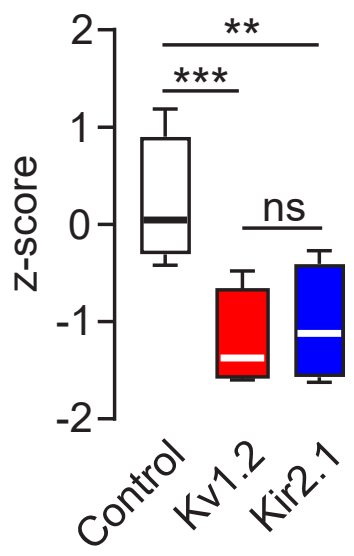

B

\section{MAPK/ERK}

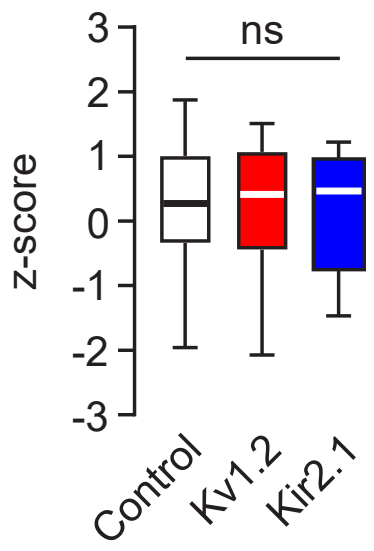

